Florida International University FIU Digital Commons

$11-10-2016$

\title{
Strategic Communications to Prevent HIV Infections among Black and Hispanic Young Adults
}

Elena Sebekos

Florida International University, esebe001@fiu.edu

DOI: $10.25148 /$ etd.FIDC001221

Follow this and additional works at: https://digitalcommons.fiu.edu/etd

Part of the Health Communication Commons, and the Public Health Education and Promotion Commons

\section{Recommended Citation}

Sebekos, Elena, "Strategic Communications to Prevent HIV Infections among Black and Hispanic Young Adults" (2016). FIU Electronic Theses and Dissertations. 3001.

https://digitalcommons.fiu.edu/etd/3001 


\title{
FLORIDA INTERNATIONAL UNIVERSITY
}

Miami, Florida

\section{STRATEGIC COMMUNICATIONS TO PREVENT HIV INFECTIONS AMONG \\ BLACK AND HISPANIC YOUNG ADULTS}

\author{
A dissertation submitted in partial fulfillment of \\ the requirements for the degree of \\ DOCTOR OF PHILOSOPHY \\ in
}

PUBLIC HEALTH

by

Elena Sebekos

2016 
To: Dean Tomás R. Guilarte

Robert Stempel College of Public Health and Social Work

This dissertation, written by Elena Sebekos, and entitled Strategic Communications to Prevent HIV Infections among Black and Hispanic Young Adults, having been approved with respect to style and intellectual content, is referred to you for judgment.

We have read this dissertation and recommend that it be approved.

Hugh Gladwin

H. Virginia McCoy

Mary Shaw

William W. Darrow, Major Professor

Date of Defense: November 10, 2016.

The dissertation of Elena Sebekos is approved.

Dean Tomás R. Guilarte

Robert Stempel College of Public Health and Social Work

Andrés G. Gil

Vice President for Research and Economic Development and Dean of the University Graduate School

Florida International University, 2016 
(C) Copyright 2016 by Elena Sebekos

All rights reserved. 


\section{DEDICATION}

I dedicate this dissertation to my family and Dr. William Darrow. Thank you to my parents and brother for their unconditional love, support, and motivation in completing my $\mathrm{PhD}$. My parents always stressed the importance of education to my brother and me at a young age. Dr. Darrow, thank you for always inspiring me to do my best and for the countless hours you spent helping me conceptualize my study, providing background on the original project, and assisting with the analysis of the data. I love you all very much! 


\section{ACKNOWLEDGMENTS}

First, I would like to thank my mentor and major professor, Dr. William Darrow, and Dr. Hugh Gladwin for encouraging me to use their data sets from Racial and Ethnic Approaches to Community Health (REACH) 2010 in Broward County, Florida, for this study. I am grateful to Dr. Darrow for his support and encouragement throughout my studies and research. Dr. Darrow has made my $\mathrm{MPH}$ and $\mathrm{PhD}$ experience very productive by allowing me to develop my writing and analytical skills and to extend the knowledge I acquired in prior courses.

Second, I would like to thank my committee members for their time and feedback along the way. Thank you to Dr. Shaw for helping me organize my literature review and statement of the problem. Thank you to Dr. H. Virginia McCoy for helping me frame my research questions and statement of the problem. I would like to thank Dr. Gladwin for his availability to answer questions regarding the methodology for evaluating REACH 2010 activities in Broward as well as his help with statistical analyses. I am also grateful to Ann Goraczko, Rita Durst, and Andres Bermeo for meeting with me and describing the REACH 2010 computer-assisted telephone interview data collection procedures.

Finally, I am appreciative to Dr. Elena Bastida and the faculty of the Department of Health Promotion and Disease Prevention for providing me with support and assistance in obtaining funding during my doctoral studies. Thank you to the AHEPA Kendall Chapter No. 476 scholarship committee for selecting me as a recipient for two scholastic awards. I would like to acknowledge the FIU Graduate School for awarding me the Dissertation Year Fellowship. Also, thank you to my PhD classmates, faculty, staff, friends, and family for their support throughout the program. 
ABSTRACT OF THE DISSERTATION

STRATEGIC COMMUNICATIONS TO PREVENT HIV INFECTIONS AMONG

BLACK AND HISPANIC YOUNG ADULTS

\author{
by
}

Elena Sebekos

Florida International University, 2016

Miami, Florida

\title{
Professor William W. Darrow, Major Professor
}

Disparities in HIV disease continue to adversely affect Black and Hispanic populations in the United States. Racial and Ethnic Approaches to Community Health (REACH) 2010 in Broward County, Florida, used strategic communications to alert Black and Hispanic young adults of the serious threat and the choices they could make to prevent HIV infection. This study assessed the channels through which 18-39 year-old African American, Haitian, Afro-Caribbean, and Hispanic residents of 12 high AIDSincidence ZIP-code areas obtained information about HIV/AIDS and which sources they found most helpful. In addition, this study examined how obtaining HIV/AIDS information was associated with histories of HIV testing and perceptions of risk.

A secondary analysis of computer-assisted telephone interview (CATI) data sets was conducted for first-time respondents $(\mathrm{N}=7,843)$ in 2001-2003, 2005, and 2007. All ethnicities identified obtaining HIV/AIDS information most frequently from television public service announcements, talk shows, and programs and considered this source "most helpful." Radio was mentioned second most frequently by Haitian respondents, but African Americans and Caribbean Islanders preferred print media: newspapers and 
magazines. Use of the Internet increased by $22.4 \%$ from 2001 to 2007 , but very few respondents regarded the Internet as "most helpful."

African Americans, Hispanics, and Caribbean Islanders who obtained HIV information from family or friends were more likely to believe that they might become infected with HIV. Caribbean Islanders who obtained information from a church were less likely to believe they were at risk. Among African American, Caribbean, and Hispanic young adults, obtaining information from a doctor or health provider was the best predictor for reporting ever being tested for HIV. African Americans who heard about AIDS on radio stations "HOT 105" and "99 Jamz" were more likely to have been tested for HIV, as were Haitians who saw something about AIDS on a billboard or bus.

Comprehensive HIV-prevention programs should incorporate culturally competent communications components to inform Black and Hispanic young adults of scientific advances in prevention, treatment, and medical care. Further research should examine how diverse ethnic groups in south Florida and elsewhere are accessing and responding to health-related information in the digital age. 


\section{TABLE OF CONTENTS}

CHAPTER

PAGE

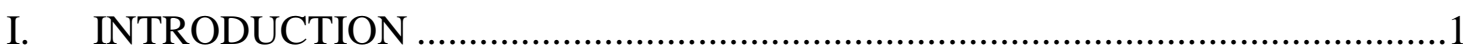

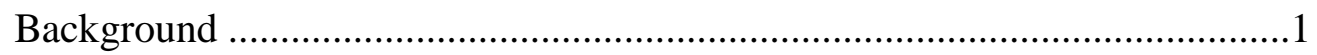

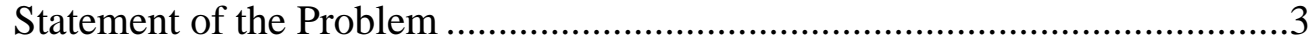

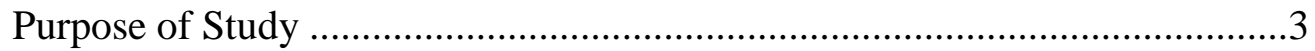

Public Health Significance ..................................................................4

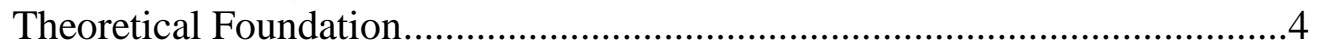

Research Questions .......................................................................... 7

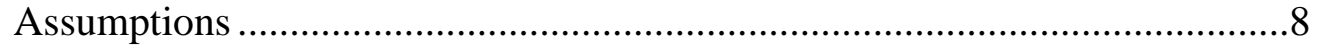

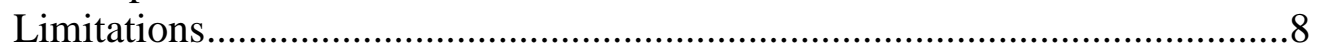

Delimitations ................................................................................. 9

Definitions of Terms .......................................................................... 9

Organization of the Study.................................................................10

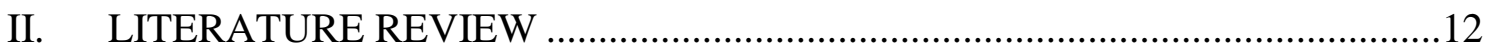

Focus of Literature Review ..............................................................13

Literature Review Methodology ............................................................13

Disparities in HIV/AIDS in the USA and Broward County, Florida .............14

HIV/AIDS Information and Education Efforts in the USA ........................17

About REACH 2010 ............................................................................22

Sources of Health Information Minorities Use and Believe .........................28

Sources of HIV/AIDS Information Minorities Use and Believe ...................34

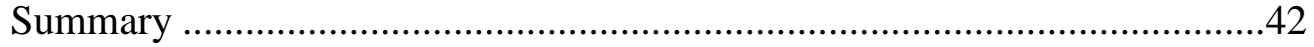

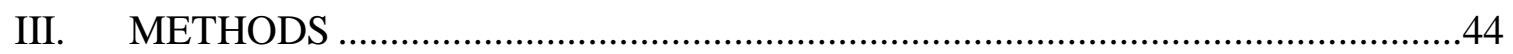

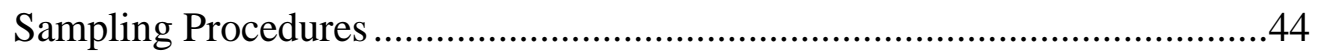

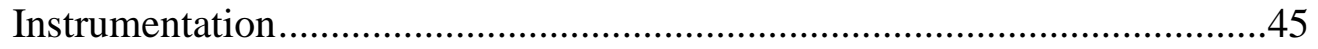

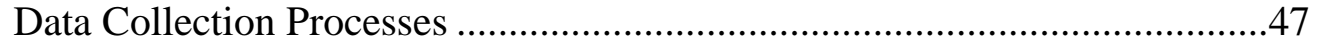

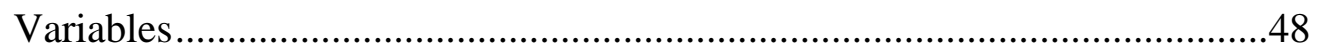

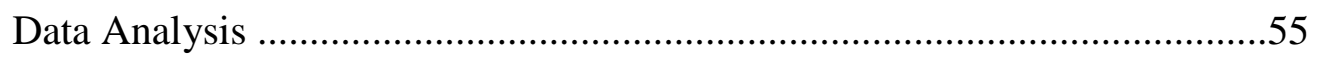

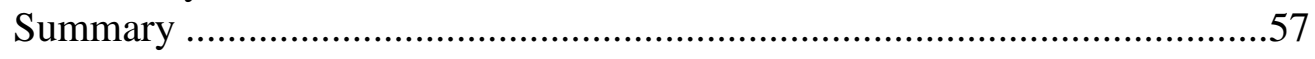

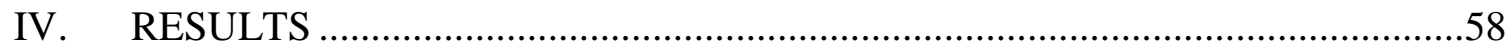

Description of the Sample .............................................................5

Research Question 1 .....................................................................61

Research Question 2 ...................................................................68

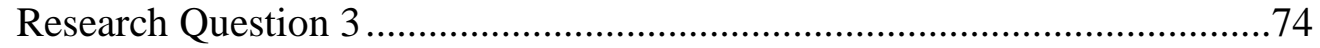

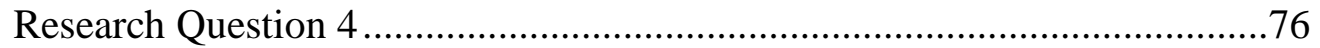

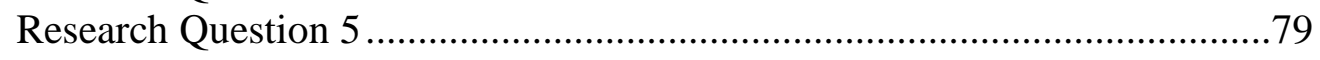

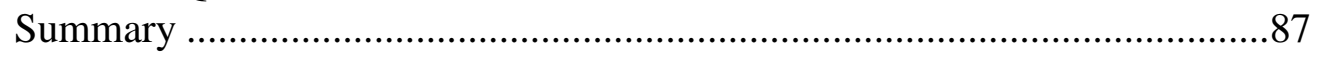




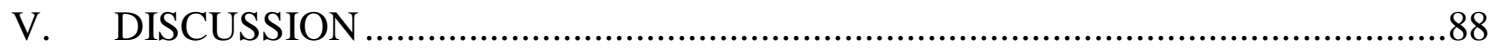

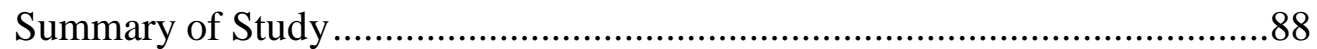

Discussion of Major Findings ....................................................................90

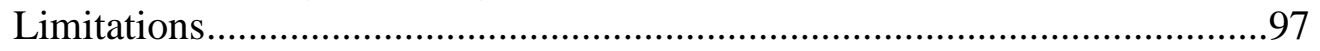

Recommendations for Future Research ..................................................99

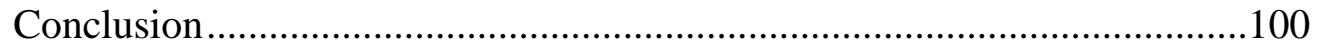

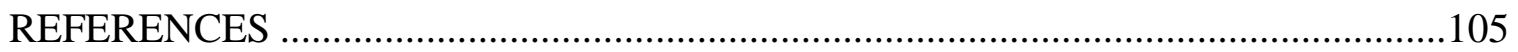

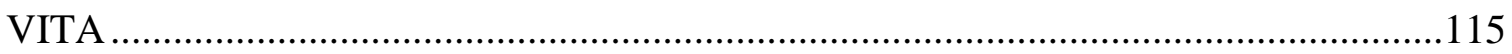




\section{LIST OF TABLES}

TABLE

PAGE

1. Cross-sectional Studies on HIV/AIDS Information Used and Believed by Black and Hispanic Individuals

2. Number of Days Each Month Interviews were Conducted for the Five CATI

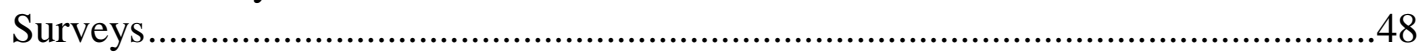

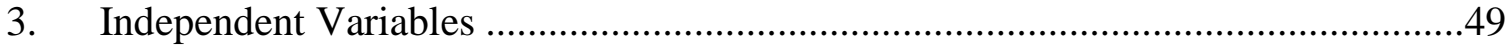

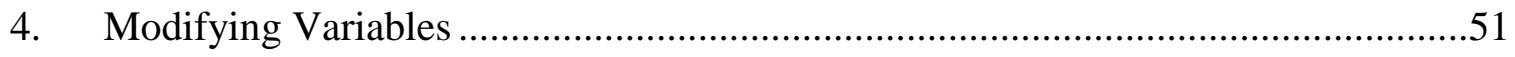

5. Responses for Sources of Information on HIV/AIDS ....................................52

6. Sociodemographic Characteristics of Respondents, 2001-2007 ( $\mathrm{N}=7,843) \ldots \ldots \ldots . .59$

7. Country of Origin of Survey Participants by Gender, 2002-2007 ( $\mathrm{n}=5,816) \ldots \ldots \ldots$...60

8. Sources from which Black Non-Hispanics Reported Obtaining HIV/AIDS

Information by Ethnicity and Country of Origin, 2002-2007 $(n=3,547)$.

9. Sources from which Hispanics Reported Obtaining HIV/AIDS Information by Ethnicity and Country of Origin, 2002-2007 $(n=1,462)$

10. Sources from which Black Non-Hispanics Reported Obtaining the Most Helpful Information about HIV/AIDS by Ethnicity and Country of Origin, 2002-2007 $(\mathrm{n}=3,547)$

11. Sources from which Hispanics Reported Obtaining the Most Helpful Information about HIV/AIDS by Ethnicity and Country of Origin, 2002-2007 $(\mathrm{n}=1,462) \ldots \ldots . .73$

12. Perception of Susceptibility of Respondents, 2001-2007 ( $\mathrm{N}=7,843) \ldots \ldots \ldots \ldots \ldots \ldots . . . .77$

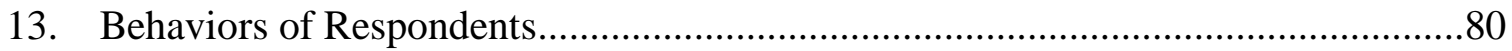

14. Binary Logistic Regression Analyses Predicting Ever Tested for HIV by Ethnicity

15. Binary Logistic Regression Analyses Predicting Condom Usage in the Past Year by Ethnicity 


\section{LIST OF FIGURES}

FIGURE

PAGE

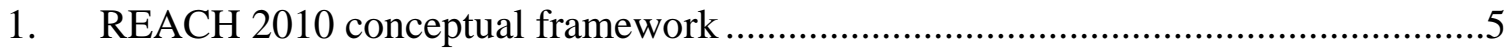

2. Percent of African American, Hispanic, Haitian, and Caribbean young adults who obtained HIV/AIDS information from selected sources, by Education, 2001-2007

3. Percent of respondents who heard something about AIDS in Broward on specific radio stations, by Ethnicity, 2003-2007

4. Percent of respondents who saw something about AIDS in Broward on specific television stations, by Ethnicity, 2003-2005.

5. Trends in obtaining information about HIV/AIDS among racial and ethnic young people in Broward County, 2001-2007 
ABBREVIATIONS AND ACRONYMS

AIDS Coalition to Unleash Power

ACT UP

America Responds to AIDS

ARTA

Center for Community Health Education and Research

CCHER

Centers for Disease Control and Prevention

CDC

Central Coordinating Organization

$\mathrm{CCO}$

Community-based Organization

CBO

Computer-assisted Telephone Interview

CATI

Counseling, Testing, Referral and Partner Notification

CTRPN

Department of Health and Human Services

DHHS

Florida Department of Health

$\mathrm{FDOH}$

Florida International University

FIU

Health Belief Model

HBM

Health Crisis Network

$\mathrm{HCN}$

Hispanic Unity of Florida

HUF

Institute for Public Opinion Research

IPOR

Institutional Review Board

IRB

Men who had Sex with Men

MSM

Metropolitan Statistical Area

MSA

Minority Development and Empowerment, Incorporated

MDEI

National Cancer Institute

NCI

Public Service Announcement

PSA

Racial and Ethnic Approaches to Community Health

$\mathrm{REACH}$ 
Sistas Organizing to Survive

Urban League of Broward County
SOS

ULBC 


\section{CHAPTER I \\ INTRODUCTION}

A major public health priority in the United States is eliminating health disparities among racial and ethnic minority populations (U.S. Department of Health and Human Services [DHHS], 2010). It was one of the two major goals of Healthy People 2010. In order to eliminate health disparities, it is very important to understand the sources of these disparities. Poverty, adverse neighborhood conditions, lack of access to higher education, low literacy, and inadequate access to health services are factors that contribute to health disparities (Steele, Meléndez-Morales, Campoluci, DeLuca, \& Dean, 2007; Thornton et al., 2016). If health professionals do not consider the social determinants of health disparities, interventions may fall short of their goal of achieving health equity.

\section{Background}

HIV disproportionately affects Black or African Americans and Hispanics (Centers for Disease Control and Prevention [CDC], 2016a; CDC, 2015a). According to CDC, there were an estimated 44\% new HIV infections among African Americans (CDC, 2016a) and 23\% among Hispanic Americans (CDC, 2015a) in 2014. African Americans and Hispanics made up 12\% and 17\% of the U.S. population, respectively. In 2014, the estimated number of new HIV infections was highest among individuals aged 20-29 (35.7\%) (CDC, 2016b; CDC, 2015b), followed by individuals aged 30-39 (24.3\%) (CDC, 2016b). For young adults between the ages of 20 to 39, approximately $45.5 \%, 25.1 \%$, and $23.8 \%$ of estimated HIV incidence cases occurred in Blacks, Hispanics or Latinos, and Whites, respectively (CDC, 2016b). In 2014, there were 418 Blacks, 175 Hispanics, 
and 381 Whites diagnosed with HIV in Broward County (Florida Department of Health $[\mathrm{FDOH}]$ in Broward County, n.d.a). Approximately 56.2\% (235) of Blacks, 62.9\% (110) of Hispanics, and 33.3\% (127) of Whites were between the ages of 13-39.

Racial and Ethnic Approaches to Community Health (REACH) 2010 in Broward County, Florida, was conducted from October 2000 through September 2008 to reduce disparities in HIV disease. It targeted African American, Caribbean, Haitian, and Hispanic 18 to 39 year-old residents living in one of twelve ZIP-code areas (Darrow et al., 2004; Obiaja, Darrow, Sanchez-Brana, \& Uribe, 2008; Villanueva et al., 2010). The purpose of REACH 2010 was to reduce rates of HIV infection in Broward County by providing respondents with information that they could utilize to make choices for themselves and their loved ones. Formative research in Broward revealed that residents were not receiving clear messages about HIV and how to prevent HIV infection. In discussion groups, residents stressed that they wanted accurate information. Hence, the project included strategic communications as one of four interventions. Strategic communications involves careful planning that comprises: (1) identifying the audience the intervention or program will target, (2) developing and pretesting messages, and (3) the selection of suitable channels to disseminate the message(s) (CDC, 2011; CDC National Prevention Information Network, 2013; Institute for Dynamic Educational Advancement, 2014).

Moreover, before individuals decide to engage in a behavior (e.g., HIV testing), they go through a series of logical steps. If they are contemplating receiving an HIV test, they might access information from one or more channels. After accessing information on HIV testing, they will decide if they want to obtain specific information (e.g., testing 
locations) and then decide if they are going to use that information. Exposure to the information, the helpfulness of the information, and sensitivity produced by the underlying message(s) are going to determine if the individual can come to a decision about whether he or she is going to engage in the behavior or not (Rice \& Atkin, 2013).

\section{Statement of the Problem}

This proposal addresses a gap in the existing literature regarding the limited knowledge on HIV/AIDS sources of information accessed and used by racial and ethnic minority populations (Cline \& Engel, 1991; Cunningham, Davidson, Nakazono, \& Andersen, 1999; Hu, Keller, \& Fleming, 1989). Moreover, less is known about which HIV/AIDS sources Black and Hispanic populations find helpful (Rich, Holmes, \& Hodges, 1996), obtain HIV/AIDS information from (Essien, Ross, Linares, \& Osemene, 2000), and depend on to make informed decisions. Additionally, there is even less known about the relationship between HIV/AIDS information obtained, HIV testing behaviors, and perceptions of contracting HIV/AIDS among Black and Hispanic young adults.

\section{Purpose of Study}

The purpose of this study is four-fold: (a) determine the channels through which racial and ethnic minorities, specifically African Americans, Haitians, Caribbean Islanders, and Hispanics, obtained information about HIV/AIDS using the entire series of REACH 2010 computer-assisted telephone interview (CATI) surveys (2001, 2002, 2003, 2005, 2007) as a source of data; (b) investigate which channels provided the most helpful information about HIV/AIDS; (c) assess changes over time for obtaining information about HIV/AIDS; and finally (d) examine the relationship between obtaining HIV/AIDS 
information and being tested for HIV in the past twelve months and perceptions of contracting HIV/AIDS.

\section{Public Health Significance}

Results of this study will provide public health agencies and health educators with detailed information about how various Black and Hispanic young adult populations obtain HIV-related information to guide their decisions regarding prevention, testing, and personal health status. Because data were collected before and during the period of social media adoption, the increasing use of Internet by racial and ethnic minority populations can be assessed. Findings should be useful in improving communications by public health officials to various communities at increased risk for HIV/AIDS.

\section{Theoretical Foundation}

The Broward Coalition utilized the PRECEDE/PROCEED health promotion planning model and principles of community organization to develop interventions for REACH 2010 in Broward County, Florida (Darrow et al., 2004). The PRECEDE model helped guide the needs assessment process as well as the development of suitable interventions for residents in Broward (Green \& Kreuter, 1992). The PROCEED model facilitated the implementation of interventions and their evaluation. The community organization model helped generate knowledge about eliminating health disparities in

HIV disease through the use of the concepts "critical consciousness," "empowerment," “community capacity building," and "community ownership" (National Cancer Institute [NCI], 2005).

The formative evaluation phase revealed that residents did not know what to believe about HIV/AIDS because they had heard so many different things from so many 
different sources. After speaking with residents, stakeholders, and influential community leaders, coalition members decided that they had to create and deliver consistent, accurate, nonjudgmental, and unambiguous messages through community outreach, the media, and advocacy. The Broward Coalition placed messages on different media (e.g., bus signs, television, radio, palm cards) that emphasized sexually active young people could choose from different options, such as mutual monogamy and receiving an HIV test, to reduce HIV infection. Local spoken-word poets were recruited to craft messages and participate in poetry slams in Broward to raise awareness and convey culturally relevant messages on how to prevent HIV transmission. Many community members acknowledged the importance of active participation, community ownership, and collaboration in reducing the HIV/AIDS problem in their communities.

Figure 1 illustrates the conceptual framework used to guide this study. The concepts in the REACH 2010 conceptual framework were derived from McGuire's classic Communication-Persuasion Matrix and the Health Belief Model (HBM). The three concepts in the middle of Figure 1 represent variables that might modify behaviors.

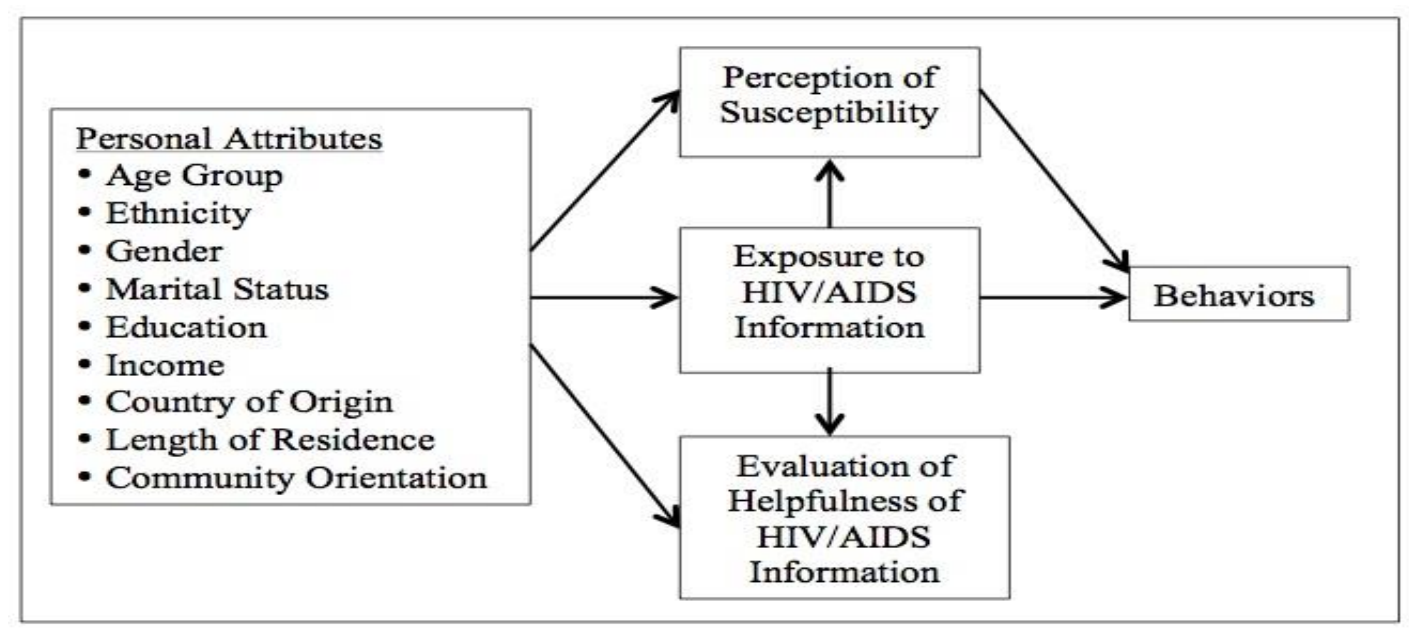

Figure 1. REACH 2010 conceptual framework. 
The concept "perception of susceptibility" is derived from HBM. It is defined as the belief that a condition (e.g., health threat or natural disaster) is real and that there is a possibility of being exposed to it (NCI, 2005; Simons-Morton, McLeroy, \& Wendel, 2012). "Perception of susceptibility" explored a perceived risk (e.g., chance of getting HIV, level of HIV/AIDS in Broward, and meant to use a condom but did not) among Black and Hispanic young adults living in Broward County. CATI survey respondents who reported an increased level of risk of HIV infection were presumed to be more likely to have been exposed to HIV/AIDS information and/or have obtained information about HIV from different media.

The concept "exposure to HIV/AIDS information" is derived from McGuire's classic Communication-Persuasion Matrix (Rice \& Atkin, 2013). Channel or media, where a message is placed, is one of the input variables in this matrix. Researchers should be familiar with their intended audience's cultural attitudes, beliefs, and preferences, among other factors, when selecting communication channels to reach their audience of interest (NCI, 2004). Knowing which channels the "at risk" population prefers and finds credible allows public health practitioners to communicate effectively with them. "Exposure to HIV/AIDS information" explored whether the intended audience heard or saw anything about AIDS on specific radio and television stations (verbal messages and images) and included channels from which individuals reported obtaining HIV/AIDS information.

The concept "evaluation of helpfulness of HIV/AIDS information" was used to examine which channels the target audience found most helpful. In addition, "perception of susceptibility" and "exposure to HIV/AIDS information" explored whether there was a 
change in behavior(s) (response to risk). Behaviors examined in this study included: (1) whether individuals were tested for HIV in the past 12 months, (2) if they received results of a HIV test in the past 12 months, (3) if they have ever been tested for HIV, (4) if they have ever received HIV results, and (5) if they used a condom in the past year.

\section{Research Questions}

The following five research questions guided this study.

\section{Research Question 1}

What are the similarities and differences in obtaining information about HIV prevention from various channels (media) between Black (e.g., Haitians, Caribbean Islanders, African Americans) and Hispanic (e.g., Peruvians, Puerto Ricans, Colombians) young adults living in Broward County?

\section{Research Question 2}

Which media sources provided the most helpful information about HIV prevention for Black and Hispanic young adults, 18 to 39 years old, living in Broward County?

\section{Research Question 3}

How did obtaining information about HIV prevention from media sources change during 2001-2007 between Black and Hispanic young adults living in Broward County?

\section{Research Question 4}

What is the relationship between obtaining information about HIV/AIDS from media sources and perceived susceptibility of HIV during 2001-2007 among Black and Hispanic residents of Broward County? 


\section{Research Question 5}

What is the relationship between obtaining information about HIV/AIDS from media and engaging in different behaviors (e.g., being tested for HIV in the past 12 months, receiving results of HIV test in the past year) among Black and Hispanic residents of Broward County?

\section{Assumptions}

The study made the following assumptions:

1. Participants comprehended the questions they were asked.

2. Participants responded accurately and honestly to the CATI survey.

3. Respondents reported their correct age and ethnicity.

4. Individuals who met the inclusion criteria had a landline telephone.

5. The responses obtained from the five CATI surveys are representative of trends in access and use of strategic communications sources in Broward County.

6. The Institute for Public Opinion Research (IPOR) interviewers administered the survey as designed and recorded the responses of participants accurately.

\section{Limitations}

The study was limited by the following:

1. The sample was drawn from a listing of residential landline telephones.

2. Respondents who answered the telephone call had to meet the inclusion criteria and be home when IPOR called to conduct the survey.

3. Data were self-reported and not verified by the IPOR research team; some responses may reflect a social desirability bias. 
4. Since the study consisted of five cross-sectional surveys, causality cannot be inferred.

5. Generalizability is limited to young Black and Hispanic residents of Broward County.

6. REACH staff did not anticipate the widescale adoption of cellular telephones or the Internet increasing in use when the CATI survey was designed in fall 2000.

\section{Delimitations}

The study was delimited by the following factors:

1. Participants were mainly selected from the 12 ZIP-codes with highest AIDS incidence during 1994-1999.

2. Respondents had to have a landline telephone to be selected as participants for CATI surveys.

3. Each phone call was scheduled to last 10 to 15 minutes.

\section{Definitions of Terms}

1. Black - Individuals who identify as African American, Caribbean or Caribbean American, or Haitian or Haitian American.

2. Broward Coalition - The collaboration between Florida International University (FIU) and three community-based organizations, Urban League of Broward County (ULBC), Hispanic Unity of Florida (HUF), Minority Development and Empowerment, Incorporated (MDEI), to reduce HIV infections in Broward County, Florida. 
3. Caribbean Islanders - For the purpose of this study, this ethnic group refers to people who identify as Caribbean, born in a Caribbean country, or Caribbean American.

4. Exposure to HIV/AIDS information - Respondents who are not actively seeking HIV/AIDS information, but see or hear something about HIV/AIDS on specific television or radio stations or other media.

5. Haitian - Individuals who identify as Haitian or Haitian American. When discussing ethnicity and country of origin in the results section, Haitian Americans are distinguished from Haitians, who migrated from Haiti.

6. Hispanic - Individuals who identify as Hispanic or Hispanic American.

7. Obtaining information about HIV/AIDS - Participants who are actively seeking HIV/AIDS information, such as statistics, risk of acquiring HIV, symptoms of HIV, testing locations, from a particular channel.

8. Perceptions of contracting HIV/AIDS - Perceptions of becoming infected with HIV, the virus that causes AIDS.

9. Strategic communications - Planned, purposeful, and specific use of mass and small media to communicate HIV-prevention messages with members of priority communities.

10. Young adults - Participants who were 18 to 39 years of age when first enrolled and interviewed by an IPOR staff member for one of the five CATI surveys.

\section{Organization of the Study}

The chapters that follow will present the following topics. Chapter 2 presents a review of the literature. Chapter 3 describes the instrumentation, variables of interest, 
and the analysis plan. Chapter 4 presents the results of secondary analyses performed on the REACH 2010 CATI data sets. Chapter 5 concludes with the discussion of major findings, conclusions, and recommendations for interventions and future research. 


\section{CHAPTER II}

\section{LITERATURE REVIEW}

Racial and ethnic minorities, in particular African Americans and Hispanics, are affected to a greater extent than the predominantly White population by HIV/AIDS (CDC, 2015c; CDC, 2016d). In 2014, the estimated rate of new HIV infections for Black adult and adolescent men in the U.S. was 94.0 per 100,000, for Hispanic men 41.5 per 100,000, and for White men 12.6 per 100,000 population (CDC, 2015b). For adult and adolescent women, the estimated rate of new HIV infections for Blacks was 30.0 per 100,000, for Hispanics 6.5 per 100,000, and for Whites 1.7 per 100,000 population. According to CDC, African-American men and women between the ages of 13 to 24 account for 34\% of new HIV infections that occur among all African Americans annually (CDC, 2014).

To eliminate health disparities among minority populations, CDC offered competitive cooperative agreements to fund REACH in 1999 (CDC, n.d.). REACH 2010, funded from 1999 to 2006, focused on six priority diseases, one being HIV/AIDS. In 1999, the REACH 2010 Broward Coalition in Broward County received funding from CDC to reduce disparities in HIV disease in Broward County, Florida. After formative research revealed an absence of clear and appropriate messages to prevent HIV transmission among vulnerable Black and Hispanic residents, coalition members decided to adopt strategic communications as one of four major interventions (Darrow et al., 2004). LaCroix and colleagues (2014) conducted a meta-analysis to synthesize evaluations of mass media-delivered HIV prevention interventions, 1986-2013, and found only six relevant studies in the U.S. Two of these studies evaluated the 1987-1988 
"America Responds to AIDS" (ARTA) campaign and the other four assessed local community communication efforts targeting sexually active adolescents, bisexual Latino men, low-income women, and high-sensation seeking and impulsive-decision making young adults (LaCroix, Snyder, Huedo-Medina, \& Johnson, 2014; Zimmerman et al., 2007).

\section{Focus of Literature Review}

This chapter reviews the literature published between January 1989 and March 2016 on sources of HIV/AIDS information used and believed by Black (African American, Haitian, and other West Indian/Caribbean) and Hispanic populations. The literature review is organized around the following five topics: (1) disparities in reports of AIDS and HIV infection in the United States, the American South, Florida, and Broward County, Florida, (2) HIV/AIDS information and education efforts in major metropolitan areas and the United States, (3) REACH 2010, (4) sources of health information utilized and trusted by racial and ethnic minorities, and (5) sources of HIV/AIDS information that racial and ethnic minorities use and find credible.

\section{Literature Review Methodology}

Various techniques were utilized to obtain pertinent research regarding the consumption, credibility, and preference of sources of HIV/AIDS information and health information for young adults between the ages of 18 to 39 . The electronic databases, PubMed, CINAHL, Social Services Abstracts, and Applied Social Sciences Index and Abstracts (ASSIA) were used to search for research articles. To obtain pertinent publications, combinations of various keywords were utilized. They included: (1) health communication, communication, sources of information, strategic communication, health 
information, media preference, mass media, and credibility of HIV information, (2) HIV, AIDS, HIV infections, and HIV prevention, (3) racial and ethnic minorities, Black, African American, Haitian, Afro Caribbean, and Hispanic, (4) national HIV/AIDS efforts, STOP AIDS project, and America Responds to AIDS, and (5) United States, Florida, Broward County, and Fort Lauderdale.

Google Scholar, specific journals containing public health research studies (e.g., AIDS Education and Prevention, Journal of Ethnicity and Disease, and American Journal of Public Health), as well as the Journal of Health Communications were searched for scholarly articles. Additionally, articles were cross-referenced from publications obtained.

Furthermore, numerous articles were obtained when employing various keywords; however, they were drastically reduced because many did not meet the criteria to be included. Inclusion criteria for publications included: (1) published between January 1, 1989 and March 26, 2016, (2) research study had to be written in English and be able to be retrieved, (2) studies conducted in the United States that included individuals 18 to 39 years old, and (3) racial and ethnic minorities (African American, Haitian, Jamaican, and other Caribbean individuals and Hispanics).

\section{Disparities in HIV/AIDS in the USA and Broward County, Florida}

HIV infection in the United States. In 2010, among individuals 13 to 24 years old, Blacks accounted for 57\% of new HIV cases (The Henry J. Kaiser Family Foundation, 2014a). Among that same age group, Latinos accounted for $20 \%$ of new HIV cases (The Henry J. Kaiser Family Foundation, 2014b). Despite representing a small percentage of the U.S. population (12\% and 17\%, respectively), these two 
subpopulations represented the largest numbers of estimated new cases of HIV (CDC, 2016d; CDC, 2014). In 2014, the estimated rate of new HIV infections for Black men was 94.0 per 100,000, for Hispanic men 41.5 per 100,000, and for White men 12.6 per 100,000 population (CDC, 2015b). For women, the estimated rate of new HIV infections for Blacks was 30.0 per 100,000, for Hispanics 6.5 per 100,000, and for Whites 1.7 per 100,000 population. Black and Hispanic men and women are greatly burdened with HIV. Reasons for higher reported rates in Black and Hispanic populations included poverty, prevalence of STDs in the community, discrimination, and failures to seek or be tested for HIV and other STDs. Insufficient information also contributed to disparities among Hispanics (Cristancho, Peters, \& Garces, 2014).

According to CDC, southern states, including Louisiana, Mississippi, and Florida, contained the highest rate of new HIV cases in 2014 (18.5 per 100,000), followed by the Northeast (14.2 per 100,000) and West (11.2 per 100,000) regions (CDC, 2016d). In 2014, Baton Rouge, Louisiana, was the number one metropolitan statistical area (MSA) with the highest rate of diagnosed cases of HIV infection among adults and youth, followed by Miami-Fort Lauderdale-West Palm Beach, Florida, New Orleans-Metairie, Louisiana, Jackson, Mississippi, and Orlando-Kissimmee-Sanford, Florida (CDC, 2016c). In 2013, the Miami-Fort Lauderdale-West Palm Beach MSA had the highest prevalence rate of HIV among adult and adolescent men and women.

HIV infection in Broward County. Broward County has an ethnically diverse, heterogeneous population (FDOH in Broward County, n.d.). Various Hispanic nationalities (Mexicans, Colombians, Cubans, Peruvians, Puerto Ricans) and Black (African Americans, Haitians, Jamaicans, and other Caribbean Islanders) inhabitants 
reside in the county (Uribe et al., 2009; Villanueva et al., 2010). During 1999, the number of new HIV infections for Blacks was 193 per 100,000, for Hispanics 23.7 per 100,000, and for Whites 20.8 per 100,000 (Darrow et al., 2010). The incidence of HIV was 9.3 times higher among Blacks than Whites. The REACH 2010 project in Broward County took on the responsibility of trying to eliminate this disparity in HIV incidence over the next ten years.

In 2010, Fort Lauderdale, Florida, had the second highest incidence of HIV in the U.S. (FDOH in Broward County, n.d.). The Broward County population was primarily White (43\%), followed by Black (26\%), Hispanic (25\%), and other ethnic groups (6\%). Blacks accounted for $51 \%$ of individuals living with HIV/AIDS in this area, while representing only one quarter of the population. Additionally, Hispanics accounted for $14 \%$ of individuals living with HIV/AIDS in this area, while their White counterparts accounted for $35 \%$ of people living with HIV/AIDS. According to FDOH in Broward County in 2010, one in 43 Blacks, one in 127 Whites, and one in 168 Hispanics was living with HIV. With regard to gender, one in 62 men and one in 159 women had been diagnosed with HIV.

The majority of Black adults and youth residing in Fort Lauderdale in 2014, reported acquiring HIV through heterosexual contact $(n=211)$, followed by male-tomale sexual contact $(n=121)(C D C, 2016 c)$. Hispanics reported male-to-male sexual contact $(\mathrm{n}=122)$ most frequently for getting HIV followed by heterosexual contact $(\mathrm{n}=$ 22). In addition, in 2011, nearly one third (31\%) of new HIV cases were among residents of Broward between the ages of 30 to 39 (FDOH in Broward County, n.d.). Among men 
between the ages of 25-34, Miami and Fort Lauderdale were ranked as having the highest rate in diagnoses of HIV infections in 2014 (CDC, 2016c).

Miami ranked number two in diagnoses of HIV infection among adults and adolescents in 2014 with a rate of 50.0 per 100,000 population (CDC, 2016c). Miami had the highest rate of new HIV infections $(58.4$ per 100,000) followed by Fort Lauderdale (52.8 per 100,000) and West Palm Beach (30.7 per 100,000). In Fort Lauderdale, the rate of new HIV infections for adult and adolescent Black men was 143.1 per 100,000, for Hispanic men 71.2 per 100,000, and for White men 71.3 per 100,000. The rates per 100,000 of new HIV infections among women were lower (e.g., Black women 59.3, Hispanic women 6.7, White women 7.3). These numbers are alarming and illustrate that the continuing spread of HIV among minority populations remains an urgent problem that needs to be addressed.

\section{HIV/AIDS Information and Education Efforts in the USA}

HIV infection, which can lead to AIDS, is a serious problem that has led to approximately 34 million deaths worldwide (World Health Organization, 2016) and 36.7 million individuals living with HIV in 2015 (Joint United Nations Programme on HIV/AIDS, 2016). With its emergence in the 1980s, public health officials throughout the United States and elsewhere worked diligently to identify the parameters of the problem (Keiser, 1991; Ratzan, Payne, \& Massett, 1994). When they discovered the route of transmission of HIV/AIDS, public health officials tried to inform the public about this deadly virus and how it was spread. Education efforts included the STOP AIDS Project, a local community-mobilization project in San Francisco, and later on a national effort, ARTA. Despite earlier successful HIV prevention efforts (e.g., the 
project in San Francisco and How to Have Sex in an Epidemic), the number of new AIDS cases remains a serious problem in the United States (Stewart \& Rappaport, 2009). Projects in the early 1980s emphasized prevention through community mobilization. More recently, prevention efforts have stalled because there has been a shift from community-based education to patient-centered counseling and case-management of persons infected with HIV (Darrow, 2013).

California. In 1984, the STOP AIDS Project in the San Francisco Bay area of California emerged out of focus groups conducted to identify interventions to encourage safer sexual practices (Stanford University Libraries, 2012; Wohlfieler, 1997). This local effort targeted gay and bisexual men, especially those engaging in unprotected sexual intercourse. The purpose of this campaign was to reduce the transmission of HIV. Men who had sex with men (MSM) created this project, which emphasized community mobilization. Members held small workshops in their living rooms, where they gathered and discussed what they knew about HIV/AIDS and risky sexual behaviors that can lead to infection (Puckett \& Bye, 1987; Stanford University Libraries, 2012; Wohlfieler, 1997). Workshops included informal discussions on sexual negotiation and skill building (e.g., condom demonstrations) (Darrow, 2013). Additionally, community members conducted outreach in various neighborhoods. Themes and images of the campaign included the promotion of safer sex practices by members of the community such as the Sisters of Perpetual Indulgence through the publication of the pamphlet, Play Fair. Messages were explicit and nonjudgmental recommending MSM to "play safe." Sources of HIV/AIDS information for the San Francisco community included predominantly interpersonal sources (e.g., workshops and street outreach) as well as pamphlets. 
New York. Similarly, various community organization efforts were taking place in New York. In 1982, a group of male homosexuals created the Gay Men's Health Crisis (Darrow, 2013; Feldman \& Miller, 1998) to provide their community with support services for the HIV epidemic. Services included counseling, prevention workshops, an AIDS hotline, an AIDS-related newsletter, and a buddy program (Feldman \& Miller, 1998). The latter paired "a volunteer with a person living with AIDS; the volunteer helps the client with household chores, medical appointments, and emotional support" (p. 163). Additionally, gay men in the City of New York who had AIDS published, How to Have Sex in an Epidemic: One Approach, safer sex guidelines in 1983, before the identification of the etiologic agent of AIDS (Stewart \& Rappaport, 2009). Earlier efforts, such as these, focused on two-way communication with their communities. HIV/AIDS was viewed as a community problem and not an individual problem. As a result, there was a decline in the number of new AIDS cases in San Francisco from 1982 to $1987,18.4 \%$ to $1 \%$, respectively. With the introduction of HIV-antibody testing in the mid 1980s, this decline did not last long. HIV testing replaced prevention efforts. Many have questioned whether Counseling, Testing, Referral and Partner Notification (CTRPN) programs promote prevention, since they focus on the individual and ignore the collective response of the community (Darrow, 2013).

Like the STOP AIDS Project and the individuals responsible for the safer sex guide, How to Have Sex in an Epidemic, the AIDS Coalition to Unleash Power (ACT UP) stressed prevention through community involvement (Stewart \& Rappaport, 2009). Members of the gay community formed ACT UP, a coalition in 1987 in response to the government's failure to fund AIDS research and come up with effective treatments and a 
vaccine. They held public demonstrations (e.g., placing a condom over Senator Helms' home) and die-ins to change things, especially the Helms Amendment, which restricted the discussion of sexuality and drug use from 1987 to 1992 . ACT UP emphasized to the government that individuals who have AIDS should be involved in policy-making since they are the ones most affected. The government should view them as experts, not victims.

United States. The national HIV/AIDS campaign, ARTA, differed considerably from the local project in San Francisco and those in New York. Before CDC launched the campaign in 1987, there was an absence of clear messages about HIV/AIDS in the media (Keiser, 1991; Ratzan, Payne, \& Massett, 1994). Consequently, ARTA aimed to raise awareness of a threat and inform the public through public service announcements (PSAs), satellite interviews, and news conferences featuring important individuals, such as U.S. Surgeon General C. Everett Koop (Keiser, 1991; Ratzan, Payne, \& Massett, 1994; Siska, Jason, Murdoch, Yang, \& Donovan, 1992; Swanson, 1993; Woods, Davis, \& Westover, 1991). It targeted everyone living in the U.S., with specific projects aimed at women, teens and parents, and high-risk groups (e.g., persons with multiple sex partners). However, ARTA ignored specific messages for homosexuals and injecting drug users, two of the groups with the highest risk of contracting HIV/AIDS (Ratzan, Payne, \& Massett, 1994; Swanson, 1993).

Furthermore, themes and images included "be careful, this can be you" with pictures depicting healthy individuals. None showed seriously ill people. The tone was serious for ARTA with messages at times lacking clarity (e.g., PSA with man placing socks on his feet), which is in contrast to the humorous, sex positive, and explicit 
messages from the community-based STOP AIDS Project. The local campaign encouraged the involvement of everyone affected by the epidemic unlike the national campaign where high officials in the Reagan administration had the final word. Additionally, broadcast and print media were utilized frequently by the U.S. Public Health Service to communicate messages about HIV/AIDS (DeJong, Wolf, \& Austin, 2001). CDC developed more than 22 television and radio PSAs for ARTA (DeJong, Wolf, \& Austin, 2001; Swanson, 1993). DeJong, Wolf, and Austin (2001) wrote that in 1991, "television advertising was the primary source of recent HIV/AIDS information for $72 \%$ of Americans" and in 1989, "48\% of injection drug users in Baltimore first learned about HIV/AIDS from television sources" (p. 250).

The STOP AIDS Project targeted specific populations, gay men and injecting drug users, while ARTA targeted the general population. During the late 1980s, when ARTA was getting ready to launch phase three of the campaign, the media focused on the high AIDS rates that disproportionately affected Blacks and Hispanics (Keiser, 1991). As the problem became more severe in racial and ethnic minority populations, various campaigns and organizations attempted to reach "at risk" populations in Florida (e.g., Health Crisis Network [HCN]) and elsewhere.

Florida. In 1983, a group of gay men founded HCN in Miami, Florida, to help people with HIV/AIDS (Feldman \& Miller, 1998). This organization offered AIDS patients and their loved ones information about the disease, counseling, transportation, and housing assistance among other services. Additionally, HCN helped and trained other organizations dealing with HIV disease. They had a hotline with trained volunteers and other individuals to provide callers with support and information on HIV. In 1999, 
FDOH launched the "We Make the Change" campaign, which informed Florida's minority populations about HIV prevention programs (FDOH, 2012). This campaign is now called "Stop the Spread" (FDOH, 2016). It consists of several initiatives, including Man Up, Faces of HIV, and Sistas Organizing to Survive (SOS). Many of the initiatives emphasize receiving an HIV test and knowing your status. Another effort that began in Broward County, Florida, in 1999 was REACH 2010. REACH 2010 sought to complement and not duplicate projects and campaigns dealing with HIV/AIDS in South Florida, such as "We Make the Change" and HIV testing efforts supported by FDOH, FDOH in Broward County, and other funding agencies.

\section{About REACH 2010}

The President's Initiative on Race. In 1997, President Clinton announced his plan, "One America in the $21^{\text {st }}$ Century: The President's Initiative on Race" (White House, n.d.). He acknowledged that health disparities were adversely affecting racial and ethnic populations in the U.S. and researchers needed to identify the underlying causes. The following year the president announced the allocation of $\$ 400$ million to REACH 2010 projects (Brooks, 1998). REACH 2010, funded from 1999 to 2006, focused on six diseases (i.e., HIV/AIDS, infant mortality, immunizations, diabetes, cardiovascular diseases, and breast and cervical cancer) in six minority populations (CDC, n.d.; DHHS, 1999). The target populations included Alaska Natives, Asian Americans, African Americans, Hispanics, Native Americans, and Pacific Islanders. The project consisted of two phases: Phase I, developing a community action plan and baseline measures in collaboration with three or more partnering organizations and Phase II, implementation and evaluation of interventions (DHHS, 1999; Giles et al., 2004). Phase I started in 
October 1999 and lasted for 12 months (DHHS, 1999). Applicants awarded funding for Phase I were eligible to apply for continuation funds for Phase II. The CDC funded 40 projects (CDC, n.d.), three of which addressed HIV/AIDS (Giles et al., 2004). The central coordinating organizations (CCOs) focusing on HIV/AIDS were: (1) Association of American Indian Physicians, (2) Center for Community Health Education and Research (CCHER), and (3) FIU. The former received funding for core capacity building with American Indians and Alaska Natives in Oklahoma, while the two latter organizations received funding for program planning, implementation, and evaluation (Giles et al., 2004). Funded projects emphasized community-based approaches in that CCOs had to involve the community they selected to work with in the identification, development, and dissemination of "effective strategies" to eliminate health disparities (CDC, n.d.). CDC stressed community mobilization to develop and implement sustainable programs.

CCHER is located in Dorchester, Massachusetts. The funded project focused on Haitians living in the Boston area (Metayer, Jean-Louis, \& Madison, 2004). Many Haitians residing in Boston were recent immigrants and there was a lack of culturally appropriate HIV services for this ethnic group. CCHER formed a coalition and focused on capacity building. Through their working group, they developed HIV prevention curricula that were "culturally and linguistically" suitable to their target population.

REACH 2010 in Broward County, Florida. FIU, a Hispanic-serving institution, operated as CCO for the CDC-funded project. REACH 2010 in Broward targeted Black (e.g., African-, Caribbean-, and Haitian-American) and Hispanic 18 to 39 year-old residents living in one of 12 ZIP-code areas with a high incidence of AIDS 
(Darrow, 2013; Darrow et al., 2004; Hlaing \& Darrow, 2006; Sanchez-Brana, 2011).

Geographic information system software was one method used to "help identify communities and locate neighborhoods with elevated levels of HIV disease" (Darrow et al., 2004). Secondary data obtained during the planning phase (1999-2000) revealed that approximately $73.3 \%$ of AIDS cases reported from 1994 to 1999 were among minority populations between the ages of 18 to 39 . These cases were predominantly concentrated in 12 ZIP-code areas with Interstate highway 95 (I-95) in close proximity. Four ZIPcodes were located in the north of Broward County, four were in the south, and four were in the middle. About two thirds of the "county's impoverished population lived in these areas" (p. S110). REACH 2010 in Broward was the first comprehensive, culturally competent, community-based effort to address racial and ethnic disparities in HIV disease (Darrow et al., 2010).

The overarching goal of REACH 2010 in Broward County was to eliminate racial and ethnic disparities in HIV disease. The CDC-funded project sought to reduce rates of HIV infection in Broward; hence, it focused predominantly on primary prevention. Efforts conducted by the REACH 2010 Broward Coalition were designed to complement health department initiatives to increase rates of HIV and STD testing. The coalition could not duplicate services offered by FDOH in Broward County and other AIDS organizations or groups in Broward County, Florida. REACH 2010 added urine testing on a limited basis, since that was not one of the services provided by the health department.

To be successful in promoting health and preventing disease, investigators must collaborate with communities (Ruffin, 2010). They have to know what resources are 
present and what limitations communities must overcome to deal effectively with public health problems (Wendel et al., 2009). REACH 2010 in Broward avoided utilizing a topdown approach; it required community involvement and insisted on community ownership from the very outset (Darrow et al., 2004). Everyone in the community had something to contribute, not just those who engaged in risky behaviors and might be exposed to HIV. Projects had to be developed and implemented at the community-level. The majority of the 12 members on the community advisory board for REACH 2010 had to be members of minority communities. Dr. William Darrow served as the principal investigator and project leader for the Broward County project and collaborated with four community-based organizations (CBOs). Think Life and ULBC represented the AfricanAmerican community. Think Life went out of business shortly after FIU received the grant from CDC and ULBC was selected to replace them. HUF represented the Hispanic community. Finally, MDEI represented the Haitian and Afro-Caribbean communities. Together these three CBOs along with FIU were responsible for carrying out the project through the Broward Coalition. The coalition sought and used community input throughout the duration of the project. Community members did not want anyone to talk down to them, so unlike ARTA, no images of doctors in white coats or other authority figures were used. Moreover, multiple channels of communication and levels of influence were adopted to the extent that resources allowed. Community capacity building is essential for sustaining programs when project-specific funding ends (Wendel et al., 2009), so FIU offered training and other support to collaborating CBOs in Broward County. 
When designing REACH 2010, coalition members sought to learn from Florida's successful "truth" campaign to deter tobacco use among teenagers and young adults (Citizen's Commission to Protect the Truth, 2007; Hicks, 2001; Niederdeppe, Farrelly, \& Haviland, 2004) as well as from previously conducted HIV campaigns, such as the STOP AIDS Project and ARTA, described earlier. The "truth" campaign was well funded and able to conduct formative research to guide program development and implementation of interventions (Hicks, 2001), leading to a decrease in smoking among youth (Farrelly, Davis, Haviland, Messeri, \& Healton, 2005). REACH 2010 in Broward consisted of two phases: Phase I, formative research, lasted from October 1999 to September 2000 and Phase II, the implementation and evaluation of interventions that were grounded in community-based research to reduce disparities, lasted from October 2000 to September 2008 (Darrow et al., 2004). Coalition members wanted to determine how to better communicate with Black and Hispanic adults residing in areas of Broward County with a high incidence of HIV and AIDS about achieving better health outcomes and improvements in the quality of life.

In order to prevent the spread of HIV, the Broward Coalition decided to implement four interventions: horizontal educational outreach, vertical educational outreach, capacity building with infrastructure development, and strategic communications (Darrow, 2013; Obiaja et al., 2008; Sanchez-Brana, 2011). Horizontal educational outreach involved continuous interpersonal contact between community health outreach workers and residents at risk of acquiring HIV to provide clear, accurate, consistent, and unambiguous messages to encourage and reinforce health-promoting behaviors. Vertical educational outreach involved continuous interpersonal contact 
between outreach workers and gatekeepers, shopkeepers, business leaders, and political leaders. Infrastructure development required capacity building in the cooperating CBOs and local health department. Representatives of FIU and the CBOs participated in REACH 2010 meetings at CDC and in site visits made by CDC staff to Broward County. Additionally, staff members from FIU offered training sessions to members from the CBOs and community residents about recent developments in HIV and HIV prevention (REACH 2010 at FIU, 2007). Participants from the community and members from the three CBOs engaged in role-playing and condom negotiation and demonstrations. Finally, strategic communications consisted of planned, purposeful, and specific utilization of television, radio, newspapers, magazines, pamphlets, bus signs, and palm cards to provide at-risk residents in Broward County with choices to engage in healthseeking behaviors.

"Mass media, community-based, and interpersonal channels are being used strategically to reinforce one another and maximize impact" (O'Sullivan, Yonkler, Morgan, \& Merritt, 2003, p. 5). FDOH was unable to use local media to the maximum extent possible due to their funding priorities and limited resources. Their primary focus was on HIV testing for secondary prevention, not on behavior change for primary prevention. Therefore, the Broward Coalition decided to make up for this deficiency by collaborating closely with local radio stations, local television stations, Broward New Times, Sun Sentinel, Westside Gazette, and other periodicals that could reach residents of the hardest hit communities through strategic communications.

The tone and messages of the REACH 2010 project stressed cultural competency and choices. REACH 2010 developed and delivered PSAs on television and the radio, 
bus signs, and other promotional messages in English, Spanish, and Haitian Creole. Messages encouraged young adults to consider their choices: (1) abstain from sex and drugs, (2) be faithful to one sexual partner, (3) use a latex condom, and (4) take the HIVantibody test. Messages were crafted and presented by a variety of sources, including local spoken-word poets, and focused on increasing the target population's awareness of contracting HIV, reducing the incidence of HIV in Broward County, and promoting primary prevention (Darrow et al., 2010). Spoken-word poets and others appearing in television PSAs and other promotional items lived in communities in south Florida and were representative of the target population.

\section{Sources of Health Information Minorities Use and Believe}

Over the years, the amount of channels that convey health information have increased to not only include interpersonal sources (e.g., friends, family, and doctors), small and mass media, but also social media platforms such as Facebook, Instagram, and Twitter (Clayman, Manganello, Viswanath, Hesse, \& Arora, 2010). Knowing which media Hispanic (Clayman et al., 2010) and other minority populations utilize and trust permits public health professionals to design, develop, and implement suitable interventions and programs and to disseminate messages about health more effectively (Brodie, Kjellson, Hoff, \& Parker, 1999; Cristancho et al., 2014; Dutta-Bergman, 2004; Kreuter \& Wray, 2003; O’Malley, Kerner, \& Johnson, 1999; Richardson, Allen, Xiao, \& Vallone, 2012). Additionally, identifying which health information sources various Black and Hispanic subgroups consume permits investigators to determine whether they can utilize a one-size-fits-all intervention(s) for all subgroups or whether they need to create different interventions for each subgroup. 


\section{Sources of health information used by Black and Hispanic populations.}

Dutta-Bergman (2004) utilized data obtained from three nationally conducted mail surveys to obtain information on four indicators of health orientation (health consciousness, health information orientation, health-oriented beliefs, and healthy activities). Participants had a mean age of 44.9 and the majority were White. Primary sources of health information included: television (82.9\%), family and friends (71.1\%), and newspapers and magazines (77.6\%). Individuals reporting family and friends and newspapers and magazines as primary sources of health information were more likely to be health conscious, health information oriented, hold strong health beliefs, and engage in healthy activities. Likewise, participants who reported obtaining health information from the Internet held strong health beliefs and engaged in healthy activities. Participants reporting television and radio as primary sources of health information were less likely to be health conscious and held weaker health beliefs. For individuals who passively seek out information, television and radio would be appropriate channels to disseminate health messages to them (Dutta-Bergman, 2004). For those actively seeking health information, the Internet and other print media would be suitable to distribute prevention information.

Several other researchers confirmed that Hispanics used (Clayman et al., 2010; Geana, Kimminau, \& Greiner, 2011) and obtained health information from television frequently (Brodie et al., 1999; Livingston, Minushkin, \& Cohn, 2008; O'Malley et al., 1999). Additionally, Brodie and colleagues (1999) identified television as the health information source from which African Americans and Whites most frequently received health information in the past 12 months and the one that all three groups most preferred. Researchers obtained the data from three different random telephone surveys conducted 
in the U.S. in the spring of 1998. Whites reported receiving health information from family and friends the second most frequently, whereas Latinos mentioned doctors and other health providers and African Americans reported family and friends and doctors and other health providers (Brodie et al., 1999). Although all three ethnic groups identified television and doctors/health providers as the two sources that provided the most health information, many African Americans and Latinos stated they were not obtaining sufficient health information from the media. African Americans preferred receiving health information from general market media than Black media even though they viewed the latter as more credible. Similarly, the majority of Latinos (40\%) preferred obtaining health information from the general media. Latinos who spoke mostly Spanish preferred Latino-oriented media while those who spoke mostly English or were bilingual preferred obtaining health information from the general media. Brodie and colleagues (1999) observed, "The media must recognize their potent role in communicating health information to the public and should strive to offer more coverage of minority health concerns" (p. 164).

Cristancho and colleagues (2014) noted that "in spite of increasing cultural diversification in the U.S., most health information available is based on the assumption of cultural homogeneity" (p. 41). The authors conducted a study to examine the preferences of health information among Hispanic immigrants living in rural Illinois. The majority of respondents were from Mexico (80.7\%), resided in Illinois for five years or less (39.5\%), and were between the ages of 27 and 36 (36.5\%) (Cristancho et al., 2014). Preferred media to receive health information included workshops conducted in Spanish (55.1\%), Spanish television and radio stations (33.3\%), and information through 
the mail (30.8\%). Latino respondents preferred home visits the least. Additionally, Hispanic immigrants reported workshops in Spanish the most frequently as a preferred source, whereas second generation Hispanics reported the mail more frequently. Individuals who were older than 36 , had a high school education, and resided in the U.S. for six to 10 years preferred "in-person" sources (e.g., workshops, home visits), while participants who were born in the U.S. and college educated preferred "impersonal" health information sources (e.g., television, radio, mail).

Doctors and other medical professionals as well as family and friends were popular sources of health information for many Hispanic respondents in various surveys. In a nationally representative CATI survey conducted by the Pew Hispanic Center among Hispanics, Hispanics mentioned getting health information from doctors and other medical professionals, television, and family or friends the most frequently in the past year (Livingston et al., 2008). Similarly, Latinos and non-Latinos residing in an urban, underserved, multiethnic community in Wyandotte County, Kansas, identified pharmacists (52.0\% versus $49.2 \%)$ and family members (36.9\% versus $37.9 \%)$ as sources of health information used frequently (Geana et al., 2011). Latinos under the age of 45 reported using friends as a source of health information more frequently compared with older Latinos. In the study conducted by O’Malley et al. (1999), the researchers found that Hispanic (Colombian, Dominican, Ecuadorian, and Puerto Rican) and Black (Caribbean, Haitian, and U.S.-born Black) subgroups mentioned obtaining health information the most frequently from doctors and other health professionals. Women were more likely to report obtaining health information from health care professionals than men (O’Malley et al., 1999). Richardson and colleagues (2012) found that Hispanic 
as well as Black and White respondents, 18 years of age and older, reported accessing health information from health providers and the Internet most frequently. Moreover, in a survey conducted by Dobransky and Hargittai (2012) in 2009, college students at the University of Illinois between the ages of 18 to 29 mentioned friends or family as the second most frequent source from which they obtained health information for illnesses and health lifestyles in the past year. Participants cited the Internet, specifically websites, the most frequently for obtaining both treatment and preventive health content. Individuals who used the Internet for a greater number of years, spent more hours online weekly, had more access locations, and who were better skilled were more likely to report obtaining health information from websites (Dobransky \& Hargittai, 2012).

Credibility and usefulness of health information sources. If respondents find the channels selected to convey health information helpful, they are more likely to attend to the message(s) (Geana et al., 2011). Hence, it is important to consider the sources of health information individuals' use and whether they find those sources useful. Latinos perceived the Internet, pharmacists, newspapers, and magazines as the most useful whereas non-Latinos mentioned religious leaders, pharmacists, friends, and family as the most useful. Likewise, Latinos and non-Latinos used the Internet as a source of health information (35.2\% versus $44.3 \%)$ and found it highly useful (95.2\% versus $94.4 \%)$.

Brodie and colleagues (1999) explored the credibility of various sources of health information. African Americans identified health care providers, followed by Black media, and churches and religious organizations as the most credible health information sources (Brodie et al., 1999). Richardson and colleagues (2012) found that Blacks as well as Hispanics and Whites mentioned trusting a health professional most frequently to 
obtain health information followed by government health agencies and the Internet. Blacks were statistically significant more likely than Whites to report they trusted government health agencies, religious organizations and leaders, the Internet, charitable organizations, television, and newspapers or magazines. Nevertheless, in the study by Brodie and colleagues, Whites and African Americans identified government agencies as the least trustworthy for providing health information.

Furthermore, familiarity and comfort with the English language can play a role in the media individuals utilize and trust to obtain information on various health topics. Clayman and colleagues (2010) utilized data from the 2005 Health Information National Trends Survey administered to a random sample of the general adult population in the U.S. to determine if Hispanics who were comfortable speaking English differed from Hispanics who were less comfortable speaking English in terms of media use and sources of health information they trusted. Hispanics who were less comfortable speaking English were more likely to report having less than a high-school education and a lower income than Hispanics who were more comfortable speaking English and non-Hispanic Whites. Hispanics who were comfortable speaking English mentioned doctors, Internet, and television more frequently as trusted sources for obtaining health information while Hispanics who were not comfortable speaking English mentioned doctors, family and friends, and television more frequently (Clayman et al., 2010). Hispanics who were comfortable speaking English perceived health information from the Internet, newspapers, and magazines as significantly more trustworthy than other sources. Print media and the Internet may not be the best channels to deliver health information to those with less education and low income; instead, mass media, doctors, and family and friends 
might be more appropriate media to disseminate health information to Hispanic individuals who are less comfortable speaking English.

\section{Sources of HIV/AIDS Information Minorities Use and Believe}

Few studies exist on the HIV/AIDS sources of information racial and ethnic minorities' use (Cline \& Engel, 1991; Cunningham et al., 1999; Hu et al., 1989), believe (Cline \& Engel, 1991; Marin \& Marin, 1990; Rich et al., 1996), and trust (Rich et al., 1996), especially among Haitians, Jamaicans and other Caribbean Islanders and Hispanic nationalities living in the United States (Table 1). Moreover, less is known about which HIV/AIDS sources Black and Hispanic populations find reliable (Essien et al., 2000) and helpful (Rich et al., 1996) and from which ones they obtain HIV/AIDS information. Exposure to HIV/AIDS information (Wolitski et al., 1996) is another variable for which there is a scarcity of published literature.

Black individuals in the HIV literature are frequently combined into a single category, Black or African American (Agyemang, Bhopal, \& Bruijnzeels, 2005; Brodie et al., 1999; Cunningham et al., 1999; Essien et al., 2000; Wolitski et al., 1996), and then compared with the predominantly White population. However, the culture of African Americans who have lived in the U.S. for generations is different from that of Caribbean Islanders, Haitian Americans, and other groups who have more recently immigrated to the U.S. (Villanueva et al., 2010). Haitians and other Caribbean individuals speak different languages and have different normative values and belief systems. Cultural identity shapes our relationships and expectations. According to Davis and colleagues (2010), "African Americans are heterogeneous in their attitudes, behaviors, and beliefs" (p. 532). Hence, different cultures might have different attitudes and perceptions about 
Table 1

Cross-sectional Studies on HIV/AIDS Information Used and Believed by Black and Hispanic Individuals

\begin{tabular}{|c|c|c|c|c|c|c|c|}
\hline Authors & $\begin{array}{l}\text { Study } \\
\text { Year }\end{array}$ & Location & $\begin{array}{l}\text { Selection of } \\
\text { Participants }\end{array}$ & $\begin{array}{l}\text { Characteristics } \\
\text { of Participants }\end{array}$ & Instrument & $\begin{array}{c}\text { Response } \\
\text { Rate }\end{array}$ & Questions \\
\hline $\begin{array}{l}\text { Marin \& } \\
\text { Marin } \\
\text { (1990) }\end{array}$ & n.d. & San Francisco & $\begin{array}{l}\text { Random digit } \\
\text { dialing, sampled } 27 \\
\text { census tracts where } \\
\text { at least } 10 \% \text { of } \\
\text { residents were } \\
\text { Hispanic }\end{array}$ & $\begin{array}{l}460 \text { Hispanic } \\
18-63 \text { years old } \\
184 \text { men, } \\
276 \text { women }\end{array}$ & $\begin{array}{l}\text { Telephone } \\
\text { interviews } \\
\text { (Spanish \& } \\
\text { English) }\end{array}$ & $71.5 \%$ & $\begin{array}{l}\text { Asked to rate } \\
\text { believability of } \\
\text { information about AIDS } \\
\text { from specific channels } \\
\text { \& sources }\end{array}$ \\
\hline $\begin{array}{l}\text { Cline \& } \\
\text { Engel (1991) }\end{array}$ & n.d. & $\begin{array}{l}\text { Major } \\
\text { university in } \\
\text { the southeast } \\
\text { U.S. }\end{array}$ & $\begin{array}{l}\text { Questionnaires } \\
\text { were mailed to } \\
\text { randomly selected } \\
\text { undergraduate } \\
\text { students ( } 1250 \\
\text { were selected to } \\
\text { stratify by gender, } \\
\text { ethnicity, \& year in } \\
\text { school; } 50 \text { were } \\
\text { selected to } \\
\text { oversample } \\
\text { minority students) }\end{array}$ & 588 students & Questionnaire & $46 \%$ & $\begin{array}{l}\text { Believability of source } \\
\text { for AIDS information } \\
\text { Likelihood that, if you } \\
\text { want to know more } \\
\text { about AIDS, you would } \\
\text { seek information from } \\
\text { this source = likelihood } \\
\text { of use } \\
\text { Identify "the five } \\
\text { sources [above] that } \\
\text { have provided you } \\
\text { personally with the } \\
\text { most information about } \\
\text { AIDS" }\end{array}$ \\
\hline
\end{tabular}


Table 1. Continued

\begin{tabular}{|c|c|c|c|c|c|c|c|}
\hline Authors & $\begin{array}{l}\text { Study } \\
\text { Year }\end{array}$ & Location & $\begin{array}{l}\text { Selection of } \\
\text { Participants }\end{array}$ & $\begin{array}{l}\text { Characteristics } \\
\text { of Participants }\end{array}$ & Instrument & $\begin{array}{c}\text { Response } \\
\text { Rate }\end{array}$ & Questions \\
\hline $\begin{array}{l}\text { Hu et al. } \\
\text { (1989) }\end{array}$ & $\begin{array}{l}\text { January } \\
1988\end{array}$ & $\begin{array}{l}3 \text { outpatient } \\
\text { clinics in } 3 \\
\text { counties in } \\
\text { North-Western } \\
\text { Oregon } \\
\text { (serving large } \\
\text { percentages of } \\
\text { Hispanics) }\end{array}$ & $\begin{array}{l}\text { Convenience } \\
\text { sample }\end{array}$ & $\begin{array}{l}216 \text { Hispanic } \\
15-73 \text { years old } \\
92 \text { men, } \\
124 \text { women }\end{array}$ & $\begin{array}{l}\text { Face-to-face } \\
\text { interviews \& } \\
\text { questionnaire } \\
\text { (both in English } \\
\text { \& Spanish) }\end{array}$ & $76.9 \%$ & $\begin{array}{l}\text { Frequency of media } \\
\text { usage, importance of } \\
\text { media, have you } \\
\text { received AIDS } \\
\text { information before }\end{array}$ \\
\hline $\begin{array}{l}\text { Rich et al. } \\
\text { (1996) }\end{array}$ & $\begin{array}{l}\text { Sep. } \\
1989- \\
\text { June } \\
1990\end{array}$ & $\begin{array}{l}\text { Inner-city } \\
\text { community } \\
\text { college in the } \\
\text { Boston } \\
\text { metropolitan } \\
\text { area }\end{array}$ & $\begin{array}{l}\text { Convenience } \\
\text { sample of students } \\
\text { enrolled in the } \\
\text { health sciences \& } \\
\text { general studies } \\
\text { programs }\end{array}$ & $\begin{array}{l}102 \text { students } \\
\text { Mean age }=27 \\
64 \% \text { female } \\
25 \% \text { Black, } \\
8 \% \text { Latino }\end{array}$ & $\begin{array}{l}\text { Questionnaire } \\
\text { (58 items) }\end{array}$ & $100 \%$ & $\begin{array}{l}\text { Trusted sources of } \\
\text { information about AIDS } \\
\text { From whom would you } \\
\text { most likely believe } \\
\text { information about AIDS } \\
\text { "How helpful have the } \\
\text { following sources of } \\
\text { information on AIDS } \\
\text { been to you?" }\end{array}$ \\
\hline $\begin{array}{l}\text { Cunningham } \\
\text { et al. (1999) }\end{array}$ & $\begin{array}{l}\text { June } \\
1990- \\
\text { March } \\
1991\end{array}$ & $\begin{array}{l}\text { Baltimore, MA } \\
\text { (urban setting) }\end{array}$ & $\begin{array}{l}\text { Multistage area } \\
\text { probability } \\
\text { techniques }\end{array}$ & $\begin{array}{l}948 \text { adults ( } 35- \\
44 \text { years old) } \\
\text { - } 733 \text { White } \\
\text { - } 215 \text { Black } \\
\\
821 \text { older adults } \\
\text { (65-74 yrs.) }\end{array}$ & $\begin{array}{l}\text { Household } \\
\text { interviews \& } \\
\text { AIDS-specific } \\
\text { instrument based } \\
\text { on the National } \\
\text { Health Interview } \\
\text { Survey }\end{array}$ & $\begin{array}{l}74 \% \text { (35- } \\
44 \text { yrs. old) } \\
72 \% \text { (65- } \\
74 \text { yrs. old) }\end{array}$ & $\begin{array}{l}\text { Nine items on "how } \\
\text { much they have learned } \\
\text { about AIDS" = sources } \\
\text { used }\end{array}$ \\
\hline
\end{tabular}


Table 1. Continued

\begin{tabular}{|c|c|c|c|c|c|c|c|}
\hline Authors & $\begin{array}{l}\text { Study } \\
\text { Year }\end{array}$ & Location & $\begin{array}{l}\text { Selection of } \\
\text { Participants }\end{array}$ & $\begin{array}{l}\text { Characteristics } \\
\text { of Participants }\end{array}$ & Instrument & $\begin{array}{l}\text { Response } \\
\text { Rate }\end{array}$ & Questions \\
\hline $\begin{array}{l}\text { Wolitski et } \\
\text { al. (1996) }\end{array}$ & $\begin{array}{l}\text { Feb. } \\
1991- \\
\text { July } \\
1991\end{array}$ & $\begin{array}{l}5 \text { inner city } \\
\text { neighborhoods } \\
\text { in the U.S.: } \\
\text { Dallas, TX; } \\
\text { Denver, CO; } \\
\text { New York } \\
\text { City, NY; } \\
\text { Seattle, WA; } \\
\text { \& Long } \\
\text { Beach, CA }\end{array}$ & $\begin{array}{l}\text { Random subsample } \\
\text { from full dataset, } \\
\text { selected } \\
\text { neighborhoods } \\
\text { identified as having } \\
\text { a high incidence of } \\
\text { drug abuse, } \\
\text { prostitution, or } \\
\text { both }\end{array}$ & $\begin{array}{l}\text { 4,329 people } \\
58 \% \text { African } \\
\text { American (AA) } \\
21 \% \text { Hispanic } \\
21 \% \text { White } \\
50 \% \text { male }\end{array}$ & $\begin{array}{l}\text { Face-to-face } \\
\text { interviews }\end{array}$ & $\begin{array}{l}\text { Not } \\
\text { provided }\end{array}$ & $\begin{array}{l}\text { In the last } 3 \text { months, } \\
\text { have you seen or heard } \\
\text { anything around here } \\
\text { about how to protect } \\
\text { yourself from AIDS? } \\
\text { In the last } 3 \text { months, has } \\
\text { anyone talked to you } \\
\text { about AIDS, HIV, using } \\
\text { condoms, or cleaning } \\
\text { needles? }\end{array}$ \\
\hline $\begin{array}{l}\text { Essien et al. } \\
(2000)\end{array}$ & $\begin{array}{l}\text { Jan. } \\
1997- \\
\text { June } \\
1998\end{array}$ & 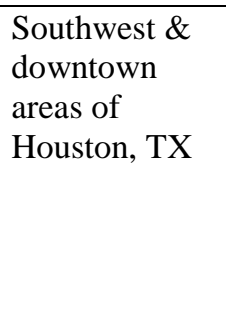 & $\begin{array}{l}\text { Recruited from } \\
\text { public parks, mass } \\
\text { transit locations, } \\
\text { malls \& shopping } \\
\text { centers from areas } \\
\text { with a large pop. of } \\
\text { AA \& Hispanics }\end{array}$ & $\begin{array}{l}\text { 456 Hispanic } \\
\text { American (HA) } \\
\text { 441 AA } \\
297 \text { White } \\
18 \text { \& over }\end{array}$ & $\begin{array}{l}\text { Self- } \\
\text { administered } \\
\text { questionnaire } \\
\text { (77 items) }\end{array}$ & $\begin{array}{l}56 \% \text { HA } \\
52 \% \text { AA } \\
58 \% \text { White }\end{array}$ & $\begin{array}{l}\text { "Where do you get most } \\
\text { of your HIV/AIDS } \\
\text { information?" } \\
\text { Which of the following } \\
\text { do you regard as the } \\
\text { most (least) reliable } \\
\text { source of HIV info.? }\end{array}$ \\
\hline
\end{tabular}


HIV prevention and testing. These differences are essential to know when designing culturally appropriate HIV prevention interventions or programs for specific audiences of message receivers.

When designing and implementing communication campaigns, it is important to determine which channels and sources are most suitable to deliver the messages created (Arya, Behforouz, \& Viswanath, 2009; Darrow et al., 2004; Stroman, 2005). If the target population is going to listen and react to HIV-prevention messages appropriately, they need to be strategic. Investigators should conduct formative research before designing and developing messages to ascertain the needs of the racial and ethnic minority communities they hope to influence. Needs assessment data should help program planners develop appealing, purposeful, and strategic messages that resonate in the community.

\section{Sources of HIV/AIDS information used by Black and Hispanic populations.} Various investigators have sought to identify from which sources Blacks and Hispanics obtain HIV/AIDS information (Essien et al., 2000) and use most frequently (Cline \& Engel, 1991; Cunningham et al., 1999; Hu et al., 1989). Respondents from different surveys reported television as a common source of HIV/AIDS information (Cunningham et al., 1999; Hu et al., 1989; Wolitski et al., 1996). Wolitski and colleagues (1996) examined HIV information sources among non-representative samples of low-risk and atrisk populations in five U.S. cities. The authors defined at-risk individuals as those who engaged in one or more of the following behaviors: (1) injection drug use, (2) had sex with someone who injected drugs, (3) prostitution, and (4) men who had anal sex with men. An individual who did not engage in any of those behaviors was classified as low- 
risk. The majority of participants were African American (58\%), followed by Hispanic (21\%) and White (21\%). Analyses showed that $78 \%$ of respondents reported receiving HIV information from mass or small media and $47 \%$ had discussed HIV with someone. At-risk African Americans and Hispanics mentioned receiving AIDS information more frequently from television, "other," and street-based sources in the past three months. Atrisk respondents cited friends and family as the most commonly used interpersonal source in the past three months. Women at increased risk were more likely to mention an interpersonal source as opposed to men. Researchers may need to utilize audience segmentation to provide relevant information on AIDS to Blacks and Hispanics at increased risk of acquiring HIV (Kreuter \& Wray, 2003; Marin \& Marin, 1990).

Similarly, 216 Hispanic respondents in the study by Hu and colleagues (1989) reported receiving AIDS information most frequently from television (42.6\%) and radio (19.9\%). Individuals who spoke mostly Spanish and whose primary language was Spanish were more likely to report reading the newspaper less than once a week (62.7\%) than those who spoke mostly English and whose primary language was English (34.6\%) (Hu et al., 1989). Similarly, African Americans and Hispanic Americans (37.6\% and $41.6 \%$, respectively) reported obtaining information about HIV/AIDS from the media, which included television, radio, newspaper, and public library, more frequently than from other sources (Essien et al., 2000). Essien and colleagues (2000) discovered Hispanic Americans with less than a high-school education were more likely to report they obtained information about HIV/AIDS from the media (45.0\%) than those with a high-school education or greater (34.6\%). Hispanic Americans and African Americans (29.3\% and 25.7\%, respectively) mentioned obtaining HIV/AIDS information from 
family and friends more frequently than Whites (17.6\%); however, Whites were more likely to cite obtaining information about HIV/AIDS from government agencies and professionals than their African American and Hispanic-American counterparts. When designing materials for campaigns, researchers need to consider their priority population's reading and writing level, as this could determine from which media the target population will obtain information on HIV/AIDS and other health topics.

Furthermore, Cunningham and colleagues (1999) identified television and newspapers as the HIV/AIDS sources most commonly used by 341 Black and 1,428 White adults, between the ages of 35-44 and 65-74, in Baltimore, Maryland. Black respondents mentioned the government, public health agencies, friends, family, and religious organizations more frequently than Whites as a source of AIDS information. Additionally, younger Blacks, 35 to 44 years old, with less than or equal to a high school education were more likely to have received AIDS information from their doctors compared to Whites, while younger Blacks with a high school education or greater were more likely to have received information from public health agencies and the government (Cunningham et al., 1999). Nevertheless, the most frequently reported source used is not often the most credible (Marin \& Marin, 1990) or reliable (Essien et al., 2000).

Credible sources of HIV/AIDS information. Approximately, 460 Hispanic residents in San Francisco identified an AIDS hotline, books, and pamphlets as the most credible sources of AIDS information (Marin \& Marin, 1990). They perceived physicians, clinic counselors, AIDS patients, and the Surgeon General as the most trustworthy sources to provide information on AIDS. Similarly, Essien and colleagues (2000) found that all three groups of respondents (African Americans, Hispanic 
Americans, and Whites) perceived government agencies and professionals as the most reliable source when it came to HIV/AIDS information, when compared to "family, friends, and school" and the media. In addition, over half of the individuals in each of the three ethnic groups, identified "family, friends, and school" as the least reliable source. Undergraduate students attending a university in the southeastern U.S. identified a national AIDS hotline, the American AIDS Foundation, surgeon general, and doctors as the most believable sources for information about AIDS (Cline \& Engel, 1991). Respondents rated friends the lowest in terms of interpersonal sources most believable for AIDS information.

Furthermore, Rich and colleagues (1996) conducted a survey at an inner-city community college in the Boston area to identify which sources of HIV/AIDS information students found the most trustworthy, believable, and helpful. The authors combined Black and Latino students into one group during data analysis. Twenty-five percent of participants were Black, eight percent were Latino, and 67\% were other (Rich et al., 1996). The majority of students preferred receiving HIV/AIDS information from health professionals, such as nurses and doctors, (59\%), while written materials and a hotline (7\%) were the least preferred sources. Likewise, participants selected the option "doctor and nurse" (84\%) the most frequently as the most believable source about AIDS information. Nevertheless, only $67 \%$ of Black and Latino students chose that option compared to other ethnicities (93\%). In terms of helpfulness, respondents selected books (59\%) the most often, followed by television (45\%) and doctor or nurse (43\%). Students identified friends or lover (eight to eleven percent) as the least helpful AIDS information source. 


\section{Summary}

The purpose of this literature review was to examine the existing body of literature on HIV/AIDS prevention and sources of health and HIV/AIDS information used and found credible by Black and Hispanic individuals. Various databases, journals, and search engines were used to identify pertinent articles that matched the inclusion criteria. Based on the literature review, the following five topics were discussed in this section: (1) racial and ethnic disparities in HIV/AIDS in the USA, southern USA, and Broward County, Florida, (2) HIV/AIDS information and education efforts in metropolitan areas, such as New York City and San Francisco, and elsewhere in the USA, (3) REACH 2010 projects addressing HIV/AIDS, (4) health information used and trusted by minority populations, and (5) HIV/AIDS information used and believed by racial and ethnic minorities.

A limited number of studies have examined sources of information Black and Hispanic young adults use, believe, and trust to obtain HIV/AIDS information (Cline \& Engel, 1991; Cunningham et al., 1999; Essien et al., 2000; Hu et al., 1989; Marin \& Marin, 1990; Rich et al., 1996; Wolitski et al., 1996). Very few have focused on at-risk minority populations and where they receive their information (Rich et al., 1996; Wolitski et al., 1996). There was a scarcity of studies exploring the differences in consumption of HIV/AIDS information (Arya et al., 2009) and health information (O’Malley et al., 1999) between different Black and Hispanic ethnic groups.

Additionally, no studies were found in the United States that investigated the relationship between primary sources of HIV/AIDS information, seeking HIV testing, and perceptions of getting HIV/AIDS among at-risk Black and Hispanic young adults 18 to 39 years of 
age. Much of the current literature focused on descriptive statistics of the sources of information individuals in the general population consumed. 


\section{CHAPTER III}

\section{METHODS}

This chapter presents the methodology used in this study and is divided into five sections. The first section describes sampling procedures and steps taken to protect human subjects. The next two sections describe instrumentation and data-collection procedures. In the fourth section, major independent, modifying, and dependent variables are defined. The chapter concludes with a review of the analysis plan and summary.

\section{Sampling Procedures}

A secondary analysis of all five available REACH 2010 Broward County crosssectional CATI data sets was conducted. Inclusion criteria for participation in the CATI surveys were (a) currently living in one of 12 ZIP-codes in Broward County with a high incidence of AIDS, (b) self-disclosed racial or ethnic minority (e.g., African American, Afro-Caribbean, Haitian, and Hispanic) status, and (c) 18 to 39 years of age at enrollment (Hlaing \& Darrow, 2006; Sanchez-Brana, 2011). Some participants were followed over multiple periods, but only first-time respondents $(\mathrm{N}=7,843)$ enrolled in 2001, 2002, 2003, 2005 , or 2007 were included in this study.

\section{Protection of Human Subjects}

FIU's institutional review board (IRB) reviewed the research study under the title, “Eliminating Disparities in HIV Disease in Broward County” and approved it in 2000. Participation in the CATI surveys was voluntary. Respondents were selected at random from lists of residential telephone numbers and agreed to participate in a telephone interview. Before beginning this secondary analysis, the researcher obtained IRB 
approval from FIU on October 28, 2015. The five data sets analyzed for this study contained no personal identifiers.

\section{Instrumentation}

The 2001 CATI survey contained 65 items that covered personal characteristics, involvement in local community affairs, HIV testing in the past year, condom use in the past year, perception of HIV/AIDS in Broward County, and media sources. Core questions were repeated on all five surveys, but some modifications were made as the REACH 2010 project evolved and research interests changed. IPOR added additional questions on topics such as country of origin and hearing about the work of ULBC in 2002. The 2003 survey contained 100 items with additional questions on stigma and seeing or hearing anything about HIV/AIDS on several specific radio and television stations. Two years later, the survey was reduced to 92 items and then expanded to 108 items in 2007 with additional questions on date of birth, religion, and spirituality.

IPOR staff developed the CATI survey in collaboration with community partners in Broward and the REACH 2010 implementation team. They took responsibility for pretesting each CATI survey and choosing the final wording of each question. Questions that inquired about mass and small media, such as (1) sources from which individuals obtained HIV/AIDS information in the past 12 months, (2) sources that were the most helpful, and (3) time spent listening to the radio in the past year, were the primary focus of this study. In the 2007 survey, coalition members and IPOR combined some options to reduce the burden on respondents. For example, they collapsed responses for questions inquiring about (1) and (2) from television news programs, television entertainment programs, and television commercials into a single response: television. 
Moreover, response choices for these two questions were shuffled, so each participant heard the options in a different order. In 2003, 2005, and 2007, the Broward Coalition included questions inquiring about hearing anything on AIDS on "HOT 105", "99 Jamz", "Mystik Radio", and "103.5 The Beat" because REACH 2010 staff worked most closely with these four stations. Moreover, the Broward Coalition suggested adding questions about seeing anything on AIDS on specific television channels (e.g., UPN Channel 33 and Island TV) and bus signs. These variables and the entire five-year CATI data set had not been analyzed previously.

\section{Instrument Validity}

IPOR staff conducted interviews in English, Spanish, or Haitian Creole.

Professional staff at FIU translated the questions on the CATI surveys into Spanish and Haitian Creole. Before enrolling community residents, staff members conducted inhouse mock interviews to become familiar with the survey (e.g., language, time needed to complete, and question placement). Most interviewers were FIU students and staff. The director of IPOR and his staff members reviewed each question with all of the interviewers in a training group session. Everyone then assembled into pairs to perform the mock interviews on each other. The director of IPOR and his staff members insisted that interviewers follow three cardinal rules: (1) ask questions as they were written, (2) interview everyone in the sample, and (3) keep accurate records. Interviewers read questions verbatim and did not explain or clarify questions to survey respondents. The director of IPOR and his staff members listened in occasionally on the telephone interviews to ensure interviewers were following appropriate protocol. 
The first 50 to 100 CATI surveys in 2001 served as a pilot test. After the completion of the pilot test, IPOR staff performed statistical analyses to check for errors and responses that did not make sense. Improvements were made and corrections were confirmed before full-scale implementation of data-collection procedures.

\section{Data Collection Processes}

Professional staff members at IPOR were responsible for conducting crosssectional CATI surveys in 2001, 2002, 2003, 2005, and 2007 with eligible respondents residing in Broward County households (Hlaing \& Darrow, 2006; Sanchez-Brana, 2011; Uribe et al., 2009). Table 2 shows when interviews were conducted for the five CATI surveys. IPOR conducted interviews Monday through Friday from 5:00-9:00 PM, Saturday from 11:00 AM to 5:00 PM, and Sunday from 12:00-6:00 PM. IPOR did not conduct CATI surveys in 2004 and 2006 due to budget limitations. When an interviewer reached a household with an eligible participant, $84.4 \%$ of respondents agreed to complete the REACH 2010 CATI survey in 2001. The cooperation rate decreased to 64.2\% in 2002 and it increased in 2003 and 2005 (80.3\% and 89.4\%, respectively) (Uribe et al., 2009).

IPOR had 24 stations from which telephone interviewers could place calls. They used a geographic information system procedure to assure that respondents met the inclusion criteria for the study (Gladwin, Goraczko, \& Darrow, 2002). From printed lists of randomly selected landline telephone numbers, trained interviewers called residents residing in the $12 \mathrm{ZIP}$-codes with high AIDS incidence. If no one answered, interviewers made nine more attempts before retiring the telephone number (Hlaing \& Darrow, 2006). When interviewers were successful in reaching someone, they asked to speak to a male 
living in the household who was Haitian, Caribbean, Hispanic, or African American, between 18 to 39 years of age, since it was well known that women were more likely to participate in telephone household surveys. If a male was not available who met the criteria, they asked to speak with a female meeting the eligibility criteria for ethnicity and age range. Some neighborhoods were oversampled. Oftentimes, IPOR had to purchase lists of additional telephone numbers to meet their quota of interviewing at least 2,000 respondents each of the five years. Obtaining phone lists can get very costly (Cottrell \& McKenzie, 2011); thus, IPOR sometimes exceeded their budget.

Table 2

Number of Days Each Month Interviews were Conducted for the Five CATI Surveys

\begin{tabular}{|l|c|c|c|c|c|c|c|c|c|c|c|c|}
\hline $\begin{array}{l}\text { Year/ } \\
\text { Month }\end{array}$ & Jan & Feb & Mar & Apr & May & Jun & Jul & Aug & Sep & Oct & Nov & Dec \\
\hline 2001 & & 3 & 31 & 29 & & & & & & & & \\
\hline 2002 & & & & & & 5 & 25 & & 24 & 1 & 19 & 12 \\
\hline 2003 & & & & & & & & 25 & 27 & 10 \\
\hline 2005 & & & & & 15 & 25 & 24 & & 11 & & \\
\hline 2007 & & & & & & 15 & 30 & 30 & 26 & 31 & 17 \\
\hline
\end{tabular}

\section{Variables}

Independent, modifying, and dependent variables used in this study and how they were measured are described in this section. Missing, "refused to answer," and "don't know and no response" answers from participants were excluded from analyses. 


\section{Independent Variables}

Table 3 identifies the major independent variables that were analyzed in this study. To determine the age of respondents, their country of origin, and length of their residence in Broward, interviewers asked respondents open-ended questions. To measure the rest of the personal attributes listed in Table 3, interviewers asked respondents closedended questions.

Table 3

Independent Variables

\begin{tabular}{ll}
\hline Personal Attributes & Question \\
\hline Age & What is your age? \\
Ethnicity & How would you describe yourself? Would you say \\
& you are... \\
Gender & What is your gender? \\
Marital status & What is your marital status? \\
Education & What is the highest grade in school you've completed? \\
Income & Approximately, what is your household income? \\
Country of origin & What is your country of origin? \\
Length of residence & How many years have you lived in Broward County? \\
Community orientation & What is community to you? \\
\hline
\end{tabular}

Age. Age was self-reported in years. Responses were collapsed into two dichotomous categories: 18-29 and 30-39 years old.

Ethnicity. Ethnicity was self-reported as African American, Hispanic or Hispanic American, Haitian or Haitian American, or Caribbean or Caribbean American. Gender. Gender was self-reported as male or female. 
Marital status. Marital status was self-reported as single, married, widowed, divorced, separated, never married, or other. Responses were recoded to unmarried (combining single, widowed, divorced, never married, and other) and married (combining married and separated).

Education. Education was self-reported as grade school, some high school, high school graduate, some college, college graduate, or graduate degree. Responses were recoded to high school ( $\leq 12$ years) and beyond high school (> 12 years).

Income. Income was self-reported as under $\$ 10,000, \$ 10,001-\$ 20,000, \$ 20,001-$ $\$ 30,000, \$ 30,001-\$ 50,000, \$ 50,001-\$ 80,000$, or over $\$ 80,001$. Responses were recoded to " $<\$ 10,000-\$ 30,000 "$ and " $\$ 30,001->\$ 80,001 "$.

Country of origin. Country of origin was self-reported. Respondents mentioned more than 73 countries and locations. For the purpose of this study, the countries are grouped into 18 categories. These categories are (1) The United States, (2) Haiti, (3) Jamaica, (4) Cuba, (5) Bahamas, (6) Puerto Rico, (7) Trinidad and Tobago, (8) Dominican Republic, (9) all other Caribbean countries, (10) Colombia, (11) Mexico, (12) Peru, (13) Honduras, (14) Argentina, (15) Nicaragua, (16) Venezuela, (17) all other South and Central American countries, and (18) Asia, Europe, and elsewhere.

Length of residence. Length of residence was self-reported in number of years. Responses were collapsed into two dichotomous categories: 0-8 years and 9-39 years.

Community orientation. Community orientation was self-reported as neighborhood, city, county, where you grew up, ethnic group, nationality, or something else. The last six choices were recoded to other. 


\section{Modifying Variables}

The modifying variables in the REACH 2010 conceptual framework were "exposure to HIV/AIDS information," "evaluation of helpfulness of HIV/AIDS information," and "perception of susceptibility." Table 4 identifies the modifying variables and the closed-ended questions associated with each of the three.

Table 4

Modifying Variables

\begin{tabular}{l} 
Question(s) \\
Exposure to HIV/AIDS info \\
(1) Did you get any news or information about HIV or AIDS \\
from this source, in the past 12 months? \\
(2) In the past year, please tell me if you heard anything about \\
AIDS in Broward County on HOT 105? \\
(3) In the past year, please tell me if you heard anything about \\
AIDS in Broward County on 99 Jamz? \\
(4) What about on Mystik Radio? \\
(5) What about on 103.5 The Beat? \\
(6) In the past year, please tell me if you saw anything about \\
AIDS in Broward County on UPN Channel 33? \\
(7) What about on Island TV? \\
(8) What about on the show "The Roof" at Mun2? \\
(9) In the past year, please tell me if you saw anything about \\
AIDS in Broward County on a bus? \\
(10) How much time did you spend listening to the radio \\
during the last year? \\
\cline { 2 - 3 } From which sources did you get the most helpful information?
\end{tabular}




\section{Exposure to HIV/AIDS Information}

Sources of information on HIV/AIDS. Sources of information on HIV/AIDS

were self-reported as one or more of the following responses presented in Table 5.

Responses were recoded as television (1-4), radio (5-8), newspapers and magazines (9-

11), poster or pamphlet (12-14), and choices (15-24) were left the same.

Table 5

Responses for Sources of Information on HIV/AIDS

Responses

(1) Television news programs

(2) Television entertainment programs

(3) Television commercials or public service announcements

(4) Television

(5) Radio talk shows or call-in shows

(6) Other radio programs

(7) Radio commercials or public service announcements

(8) Radio

(9) Newspapers

(10) Magazines

(11) Newspapers and magazines

(12) Poster or a pamphlet in a store

(13) Poster or pamphlet elsewhere

(14) Poster or pamphlet

(15) Billboard/bus ad

(16) Festivals/street fairs

(17) Family members, friends or acquaintances

(18) Materials distributed at work

(19) Church or other religious organization

(20) Doctor or another health care provider

(21) Local health dept. or local government agency

(22) Materials from AIDS organizations or advocacy groups

(23) Schools or universities

(24) Internet or a computer online service 
Heard anything about HIV on HOT 105. This variable was self-reported as yes, no, or never listen to HOT 105. Responses were recoded to yes and no (combining no and never listen to HOT 105).

Heard anything about HIV on 99 Jamz. This variable was self-reported as yes, no, or never listen to $99 \mathrm{Jamz}$. Responses were recoded to yes and no (combining no and never listen to $99 \mathrm{Jamz})$.

Heard anything about HIV on Mystik Radio. This variable was self-reported as yes, no, or never listen to Mystik Radio. Responses were recoded to yes and no (combining no and never listen to Mystik Radio).

Heard anything about HIV on 103.5 The Beat. This variable was self-reported as yes, no, or never listen to 103.5 The Beat. Responses were recoded to yes and no (combining no and never listen to 103.5 The Beat).

Saw anything about AIDS on UPN Channel 33. This variable was selfreported as yes, no, or never watch UPN Channel 33. Responses were recoded to yes and no (combining no and never watch UPN Channel 33).

Saw anything about AIDS on Island TV. This variable was self-reported as yes, no, or never watch Island TV. Responses were recoded to yes and no (combining no and never watch Island TV).

Saw anything about AIDS on "The Roof" at Mun2. This variable was selfreported as yes, no, or never watch The Roof. Responses were recoded to yes and no (combining no and never watch The Roof).

Saw anything about AIDS on bus. This variable was self-reported as yes or no. 
Time listened to radio. Time listened to radio in the past year was self-reported as every day, three to five days a week, once or twice a week, or not at all. The responses "three to five days a week" and "once or twice a week" were recoded to "one to five days a week."

\section{Evaluation of Helpfulness of HIV/AIDS Information}

Most helpful sources. Responses and recoding for this variable were the same as "sources of information on HIV/AIDS." Likewise, respondents could choose one or multiple responses.

\section{Perception of Susceptibility}

Level of HIV/AIDS in Broward. Level of HIV/AIDS in Broward was selfreported as much higher in Broward, somewhat higher in Broward, about the same, somewhat lower in Broward, or much lower in Broward. Responses were recoded to "higher in Broward" and "same or lower in Broward".

Chances of getting HIV. Chances of getting HIV was self-reported as high, medium, low, none, or already have AIDS or HIV. Responses were recoded to "some" and "none". Respondents who already had AIDS or HIV were removed from the analysis.

Meant to use condom but did not. Meant to use condom but did not was selfreported as yes or no.

\section{Dependent Variables}

Ever tested for HIV. Ever tested for HIV was measured by the question, "Have you ever been tested for HIV, the virus that causes AIDS?" Choices were yes or no. 
Ever received HIV results. Received HIV results was measured by the question, "Did you receive the results of this test?" Choices were "yes," "yes, respondent has HIV/AIDS," "yes, have comment," "no," or “no, have comment." Responses were recoded to yes and no.

Tested for HIV in past 12 months. Tested for HIV in past 12 months was measured by the question, "During the past 12 months, have you been tested for HIV, the virus that causes AIDS?" Choices were yes or no.

Results of HIV test in past 12 months. Results of HIV test in past 12 months was measured by the question, "Did you receive the results of this test?" Choices were "yes," “yes, respondent has HIV/AIDS," “yes, have comment," "no," or "no, have comment." Responses were recoded to yes and no.

Condom used in past 12 months. Condom used in the past 12 months was measured by the question, "In the last 12 months, have you used condoms with a partner?" Choices were for birth control, for disease protection, have not used a condom with a partner in last 12 months, or have not had sex in the last 12 months. Respondents could select both birth control and disease protection. Responses were recoded to yes (birth control and disease protection) and no (have not used a condom with a partner in last 12 months). Individuals who reported not having sex were removed from the analysis.

\section{Data Analysis}

IBM SPSS Statistics for Macintosh, Version 20.0, was used to manage and analyze the data (IBM Corporation, 2011). Various descriptive, inferential, and binary logistic regression tests were performed to answer the five research questions. 


\section{Descriptive and Inferential Analyses}

Cross tabulations were performed to obtain percentages, means, and standard deviations to describe the personal attributes, the modifying variables, condom use, and HIV-testing behaviors of respondents participating in the five CATI surveys. Frequency distributions helped in deciding whether or not to reduce and combine categories for each of the variables of interest. Pearson's chi-square test for independence was utilized to test for differences between various categories (Cronk, 2008). The chi-square test for independence was conducted to explore whether significant differences existed in stated country of origin between male and female respondents. Moreover, the chi-square test was used to answer the first three research questions. When performing this test, the $\mathrm{z}-$ test was also selected to compare column proportions (e.g., to determine if the four ethnic groups obtained HIV/AIDS information similarly to each other). The alpha level for each test was set at $p<.05$ and the Bonferroni method was selected to adjust the $\mathrm{p}$ values when the z-test was chosen.

\section{Regression Analyses}

To answer questions four and five in this study, binary logistic regression analyses were performed. Since the last two questions explored how the relationship between variables worked quantitatively, binary logistic regression was appropriate because "perception of susceptibility" and the five dependent variables were categorical with two levels (e.g., no or yes). Since the concept, "perception of susceptibility" encompassed three variables, binary logistic regression tests were conducted, one for each ethnic group, to explore each of those variables (level of HIV/AIDS in Broward, chances of getting HIV in Broward, and meant to use a condom but did not). Separate 
binary logistic regression analyses were also performed, one for each ethnic group, for the five dependent variables.

\section{Summary}

In this study, a five-year cross-sectional CATI data set was used. A total of 7,843 first-time respondents living in 12 ZIP-codes with a high incidence of AIDS in Broward County were included in the analysis. Participants were 18 to 39 years old and selfidentified as African American, Haitian, Caribbean, or Hispanic. To maintain survey validity, telephone interviewers asked respondents the CATI survey questions exactly as they were written. They did not offer clarifications.

This chapter presented and discussed the independent, modifying, and dependent variables of interest. "Exposure to HIV/AIDS information" was an important concept consisting of many variables. Chi-square test for independence, binary logistic regression analyses, and other descriptive statistics were conducted to answer the research questions. 


\section{CHAPTER IV}

\section{RESULTS}

The purpose of this study was to determine the channels through which racial and ethnic minorities were exposed to and obtained information about HIV/AIDS, the channels that provided the most helpful information about HIV/AIDS, and their perceptions of susceptibility. The current study also examined the relationship between obtaining HIV/AIDS information and being tested for HIV in the past twelve months among other behaviors and perceptions of contracting HIV/AIDS. This chapter presents the results of secondary analyses performed on the REACH 2010 CATI data sets for 2001-2007.

\section{Description of the Sample}

A total of 7,843 first-time respondents were enrolled in 2001, 2002, 2003, 2005, and 2007. Different sample sizes resulted from missing data for some items. The majority of participants were African American, female, unmarried, had beyond a highschool education, and reported making less than $\$ 30,001$ per annum (Table 6). The mean age of respondents was 28.4 years old (standard deviation $[\mathrm{SD}]=6.8$ ). The mean length of residence in Broward County was 11.5 years $(\mathrm{SD}=9.9)$. Respondents mentioned "other" most frequently when asked what community meant to them. "Other" included city, county, ethnic group, and nationality. Pearson's chi-square $\left(\chi^{2}\right)$ tests of independence revealed significant differences in ethnicity, educational level, income, and length of residence over time, $p<.001$. From 2001 to 2007, there was a decrease in Haitian and Caribbean Islander respondents and an increase in Hispanic respondents. 
The sample in 2007 reported higher educational levels, higher incomes, and more years of residence in Broward than earlier samples, $p<.001$.

Table 6

Sociodemographic Characteristics of Respondents, $2001-2007(N=7,843)$

\begin{tabular}{|c|c|}
\hline Variable & No. $(\%)$ \\
\hline \multicolumn{2}{|l|}{ Age (Years) } \\
\hline $18-29$ & $4,203(53.6)$ \\
\hline $30-39$ & $3,640(46.4)$ \\
\hline \multicolumn{2}{|l|}{ Ethnicity } \\
\hline African American & $2,613(33.3)$ \\
\hline Hispanic & $2,437(31.1)$ \\
\hline Caribbean & $1,478(18.8)$ \\
\hline Haitian & $1,315(16.8)$ \\
\hline \multicolumn{2}{|l|}{ Gender } \\
\hline Female & $5,122(65.3)$ \\
\hline Male & $2,721(34.7)$ \\
\hline \multicolumn{2}{|l|}{ Marital Status ${ }^{\mathrm{a}}$} \\
\hline Unmarried & $4,648(59.4)$ \\
\hline Married & $3,175(40.6)$ \\
\hline \multicolumn{2}{|l|}{ Educational Level $^{\mathrm{b}}$} \\
\hline$\leq 12$ years & $3,682(47.2)$ \\
\hline$>12$ years & $4,119(52.8)$ \\
\hline \multicolumn{2}{|l|}{ Income $^{c}$} \\
\hline$<\$ 10,000-\$ 30,000$ & $3,011(51.5)$ \\
\hline$\$ 30,001->\$ 80,000$ & $2,840(48.5)$ \\
\hline \multicolumn{2}{|l|}{ Length of Residence ${ }^{\mathrm{d}}$} \\
\hline $0-8$ Years & $3,984(51.0)$ \\
\hline 9-39 Years & $3,822(49.0)$ \\
\hline \multicolumn{2}{|l|}{ Community Orientation ${ }^{\mathrm{e}}$} \\
\hline Neighborhood & $3,683(47.5)$ \\
\hline Other & $4,063(52.5)$ \\
\hline $\begin{array}{l}\text { a20 missing data. } \\
\text { b42 missing data. } \\
{ }^{\mathrm{c}} 1,992 \text { missing data. } \\
\text { d } 37 \text { missing data. } \\
\text { e97 missing data. }\end{array}$ & \\
\hline
\end{tabular}


For the 2002, 2003, 2005, and 2007 CATI surveys, the majority of participants identified the United States $(\mathrm{n}=2,374)$ as their country of origin, followed by Haiti $(\mathrm{n}=$ 753), Jamaica $(n=697)$, and Colombia $(n=237)$ (Table 7). More than three-quarters (78.6\%) of the 5,816 CATI respondents preferred to be interviewed in English. Mexicans (88.2\%), Argentinians (75.0\%), Hondurans (74.5\%), and Peruvians (70.2\%) were more likely to request that they be interviewed in Spanish rather than English or Haitian Creole.

Table 7

Country of Origin of Survey Participants by Gender, 2002-2007 $(n=5,816)^{\mathrm{a}}$

\begin{tabular}{lrr}
\hline Country of Origin & $\begin{array}{c}\text { Males } \\
(\mathrm{n}=2,004)\end{array}$ & $\begin{array}{r}\text { Females } \\
(\mathrm{n}=3,812)\end{array}$ \\
\hline The United States & $791(39.5)$ & $1,583(41.5)$ \\
Caribbean & & \\
Haiti & $312(15.6)$ & $441(11.6)$ \\
Jamaica & $201(10.0)$ & $496(13.0)$ \\
Cuba & $49(2.4)$ & $84(2.2)$ \\
Bahamas & $46(2.3)$ & $76(2.0)$ \\
Puerto Rico & $40(2.0)$ & $80(2.1)$ \\
Trinidad and Tobago & $31(1.5)$ & $78(2.0)$ \\
Dominican Republic & $32(1.6)$ & $70(1.8)$ \\
All other Caribbean countries & $41(2.0)$ & $97(2.5)$ \\
& & \\
South and Central America & & \\
Colombia & $77(3.8)$ & $160(4.2)$ \\
Mexico & $98(4.9)$ & $123(3.2)$ \\
Peru & $47(2.3)$ & $84(2.2)$ \\
Honduras & $42(2.1)$ & $60(1.6)$ \\
Argentina & $19(0.9)$ & $37(1.0)$ \\
Nicaragua & $20(1.0)$ & $36(1.0)$ \\
Venezuela & $24(1.2)$ & $32(0.8)$ \\
All other South/Central American countries & $104(5.2)$ & $214(5.6)$ \\
Asia, Europe, and Elsewhere & & \\
\hline
\end{tabular}

${ }^{\mathrm{a}}$ All data are given as the number (percentage) of respondents. 


\section{Research Question 1}

What are the similarities and differences in obtaining information about HIV prevention from various channels (media) between Black (e.g., Haitians, Caribbean Islanders, African Americans) and Hispanic (e.g., Peruvians, Puerto Ricans, Colombians) young adults living in Broward County?

Television was the most frequently reported source by Haitians (76.7\%), Caribbean Islanders (87.3\%), African Americans (86.2\%), and Hispanics (83.5\%) for obtaining HIV/AIDS information in the past 12 months. The latter three groups mentioned newspapers or magazines the second most frequently as a source of information, whereas Haitians mentioned radio. Significant differences were detected by ethnicity for sources from which respondents reported obtaining HIV/AIDS information in the early $21^{\text {st }}$ century. African Americans and Caribbean Islanders mentioned television, newspapers or magazines, poster or pamphlet, work place, and Internet more frequently than Hispanics and Haitians. Hispanic and Haitian respondents were less likely to report obtaining information from a billboard or bus advertisement and a doctor or health provider than African Americans and Caribbean Islanders. Radio, church, family, friends, or acquaintances, work place, local health department, and Internet were mentioned more frequently by African Americans, Caribbean Islanders, and Haitians than by Hispanic respondents.

\section{Income and Educational Level}

Individuals who made more than $\$ 30,000$ were significantly more likely to report obtaining information about HIV/AIDS in the past year from newspapers or magazines, a billboard or bus ad, the work place, and the Internet than those who made less income. 
Festivals or street fairs, church, local health department, AIDS service organizations, and schools or universities were significantly more frequently mentioned by the latter group than the former group. Respondents with beyond a high-school education were significantly more likely to report television, radio, newspapers or magazines, poster or pamphlet, billboard or bus ad, work place, schools or universities, and Internet than those with a high-school education or less (Figure 2). Family or friends, church, and the local health department were significantly more frequently mentioned by participants with a high-school education or less than those who were more educated.

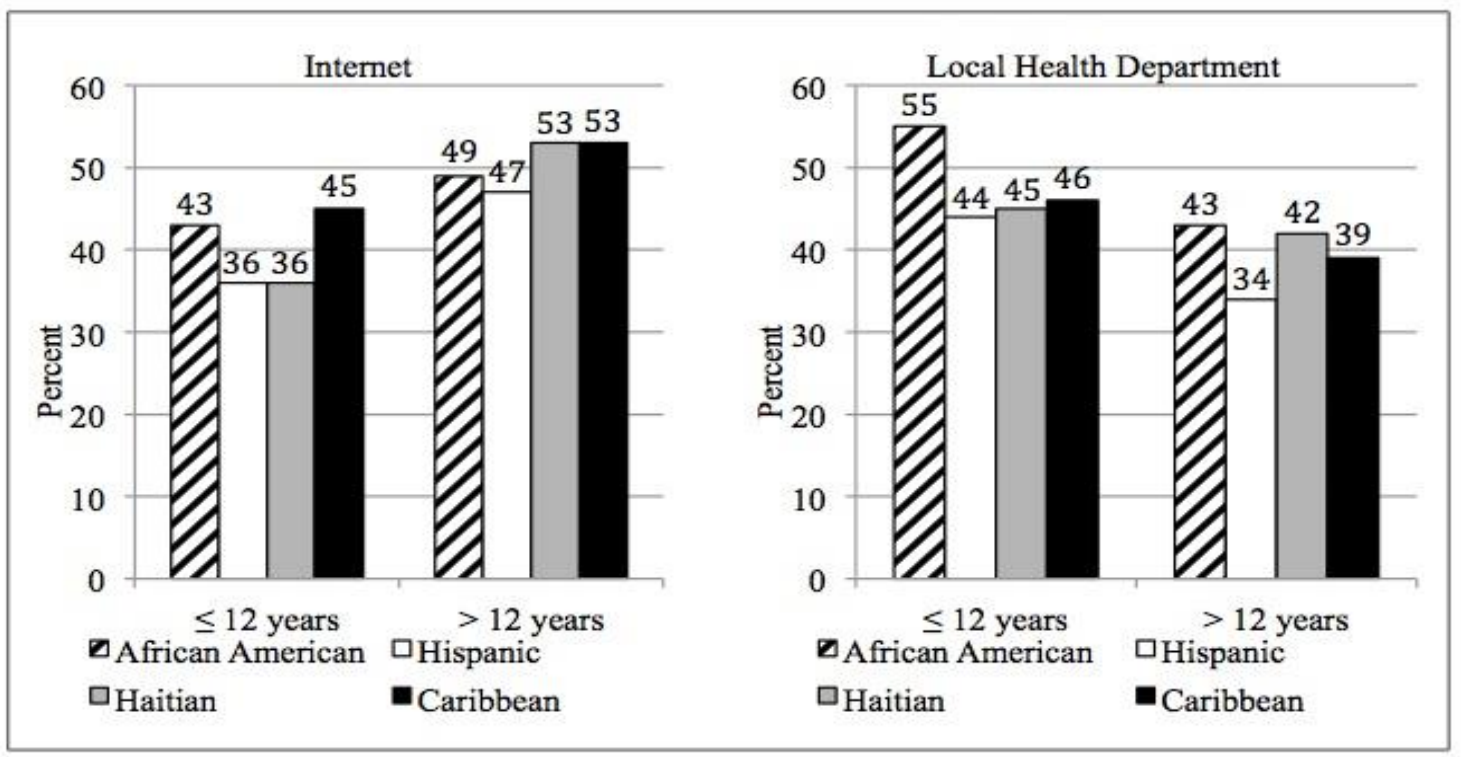

Figure 2. Percent of African American, Hispanic, Haitian, and Caribbean young adults who obtained HIV/AIDS information from selected sources, by Education, 2001-2007.

\section{Gender and Marital Status}

Similar proportions of men and women (45\%) reported obtaining HIV/AIDS information from the Internet in the past 12 months, $\chi^{2}=0.29, p<.59$. Men were significantly more likely to report obtaining information from radio, billboard or bus ad, family or friends, and AIDS service organizations than women. Poster or pamphlet, work 
place, doctor or health provider, and local health department were significantly more frequently mentioned by women $(66.8 \%, 30.0 \%, 70.5 \%$, and $45.2 \%$, respectively) than men $(64.2 \%, 26.4 \%, 59.2 \%$, and $39.5 \%$, respectively). Unmarried respondents were significantly more likely to report obtaining HIV/AIDS information from a poster or pamphlet, billboard or bus ad, festivals or street fairs, family or friends, AIDS organizations, schools or universities, and Internet than married participants.

\section{Ethnicity and Country of Origin}

From 2002 to 2007, the majority of Black non-Hispanic study participants $(\mathrm{n}=$ 3,903) were African American (41.5\%), followed by Jamaican (17.8\%), Haitian, who migrated from Haiti, (17.6\%), Haitian American (4.8\%), Caribbean American (3.3\%), Bahamian $(3.1 \%)$, Trinidadian $(2.8 \%)$, and other $(9.1 \%)$. Each of these categories had 100 or more respondents. Trinidadians and Jamaicans were more likely than other Black non-Hispanics to mention obtaining HIV/AIDS information from newspapers or magazines (Table 8). Citing a billboard or bus ad, church, and local health department was higher for African Americans and Bahamians than other Black non-Hispanics. Haitian Americans and Caribbean Americans were more likely than other Black nonHispanics to report obtaining HIV/AIDS information in the past year from television, schools or universities, and the Internet. Haitians, who migrated from Haiti, were least likely to cite billboard or bus ad, poster or pamphlet, and television than other respondents. Moreover, Haitian Americans and Caribbean Americans reported using the Internet as a source of information more often than Haitians, who migrated from Haiti. For Hispanics, the Internet was cited more frequently by Peruvians and Dominicans and less frequently by Mexicans living in Broward County. 
Table 8

Sources from which Black Non-Hispanics Reported Obtaining HIV/AIDS Information by Ethnicity and Country of Origin, 2002$2007(n=3,547)^{\mathrm{a}, \mathrm{b}}$

\begin{tabular}{lccccccc}
\hline & $\begin{array}{c}\text { African } \\
\text { American } \\
\mathrm{n}=1,619\end{array}$ & $\begin{array}{c}\text { Jamaican } \\
\mathrm{n}=694\end{array}$ & $\begin{array}{c}\text { Haitian } \\
\text { (from Haiti) } \\
\mathrm{n}=686\end{array}$ & $\begin{array}{c}\text { Haitian } \\
\text { American } \\
\mathrm{n}=187\end{array}$ & $\begin{array}{c}\text { Caribbean } \\
\text { American } \\
\mathrm{n}=130\end{array}$ & $\begin{array}{c}\text { Bahamian } \\
\mathrm{n}=122\end{array}$ & $\begin{array}{c}\text { Trinidadian } \\
\mathrm{n}=109\end{array}$ \\
\hline Television & 87.5 & 89.5 & 75.4 & 89.8 & 92.3 & 86.9 & 87.2 \\
Radio & 77.0 & 73.5 & 66.3 & 75.9 & 76.2 & 70.5 & 63.3 \\
Newspaper/Magazine & 75.4 & 77.2 & 62.7 & 75.9 & 70.0 & 75.4 & 78.9 \\
Poster or Pamphlet & 76.1 & 74.4 & 51.2 & 77.0 & 76.2 & 76.2 & 81.7 \\
Billboard or Bus Ad & 72.5 & 68.0 & 48.7 & 71.1 & 71.5 & 72.1 & 70.6 \\
Family or Friends & 62.0 & 55.6 & 48.8 & 55.1 & 57.7 & 54.1 & 52.3 \\
Doctor or Provider & 73.9 & 70.3 & 58.7 & 69.5 & 64.6 & 68.0 & 66.1 \\
Local Health Dept. & 49.3 & 43.1 & 39.5 & 46.5 & 35.4 & 49.2 & 39.4 \\
School or University & 53.7 & 57.5 & 55.1 & 78.1 & 65.4 & 59.0 & 57.8 \\
Internet & 48.6 & 54.5 & 44.8 & 62.0 & 60.8 & 47.5 & 50.5
\end{tabular}

${ }^{\mathrm{a}}$ All data are given as the number (percentage) of respondents.

${ }^{\mathrm{b}}$ Only countries that had 100 or more respondents were included in the analysis. 
The majority of Hispanic respondents $(n=1,913)$ were categorized as Hispanic American (22.9\%), followed by Colombian (12.4\%), Mexican (11.5\%), Peruvian (6.8\%), Cuban (6.8\%), Puerto Rican (5.8\%), Honduran (5.2\%), Dominican (5.0\%), and other (23.6\%). Peruvians and Colombians were more likely than other Hispanics to mention television and a poster or pamphlet as sources from which they obtained HIV/AIDS information (Table 9). Similarly, newspapers or magazines as a source of information were cited more frequently by Peruvians and less frequently by Mexicans. Radio was cited more frequently by Dominicans and Cubans than other Hispanic respondents living in Broward. Hondurans mentioned family or friends as a source of information less frequently than other Hispanic ethnic groups. The local health department was cited more frequently by Hondurans than other Hispanics.

\section{Exposure to Specific Radio Stations and Bus Signs}

From 2003 to $2007,99 \mathrm{Jamz}(43.7 \%)$ was the most frequently reported radio station for hearing anything about AIDS in Broward County, while Mystik Radio (3.7\%) was the least mentioned. Participants reporting hearing anything about AIDS in Broward on 103.5 The Beat continually increased during that period, $\chi^{2}=36.08, p<.001$, while reporting seeing anything on AIDS on bus signs decreased each year, $\chi^{2}=8.54, p<.01$. African Americans mentioned hearing something about AIDS in Broward on HOT 105 and 99 Jamz more often than other respondents (Figure 3). Individuals 18 to 29 years old (53.2\%) were significantly more likely to report hearing something about AIDS on 99 Jamz than those 30 to 39 years old $(32.1 \%), p<.001$. African Americans, Haitians, and Caribbean Islanders were significantly more likely to report hearing something about AIDS on 103.5 The Beat than Hispanics. Younger respondents $(40.8 \%)$ were 
Table 9

Sources from which Hispanics Reported Obtaining HIV/AIDS Information by Ethnicity and Country of Origin, 2002-2007 $(n=1,462)^{\mathrm{a}, \mathrm{b}}$

\begin{tabular}{lcccccccc}
\hline & $\begin{array}{c}\text { Hispanic } \\
\text { American } \\
\text { Source }\end{array}$ & $\begin{array}{c}\text { Colombian } \\
\mathrm{n}=438\end{array}$ & $\begin{array}{c}\text { Mexican } \\
\mathrm{n}=220\end{array}$ & $\begin{array}{c}\text { Peruvian } \\
\mathrm{n}=131\end{array}$ & $\begin{array}{c}\text { Cuban } \\
\mathrm{n}=130\end{array}$ & $\begin{array}{c}\text { Puerto } \\
\mathrm{n}=111\end{array}$ & $\begin{array}{c}\text { Honduran } \\
\mathrm{n}=99\end{array}$ & $\begin{array}{c}\text { Dominican } \\
\mathrm{n}=96\end{array}$ \\
\hline Television & 81.7 & 90.3 & 84.5 & 96.2 & 86.2 & 80.2 & 84.8 & 87.5 \\
Radio & 59.8 & 62.9 & 56.8 & 61.1 & 66.2 & 61.3 & 56.6 & 66.7 \\
Newspaper/Magazine & 69.4 & 73.0 & 53.6 & 80.9 & 67.7 & 76.6 & 68.7 & 66.7 \\
Poster or Pamphlet & 66.7 & 67.5 & 54.1 & 71.0 & 63.8 & 63.1 & 61.6 & 63.5 \\
Billboard or Bus Ad & 58.7 & 48.9 & 44.5 & 48.9 & 43.8 & 58.6 & 52.5 & 54.2 \\
Family or Friends & 44.3 & 45.6 & 40.5 & 50.4 & 44.6 & 46.8 & 33.3 & 40.6 \\
Doctor or Provider & 61.0 & 63.7 & 61.8 & 68.7 & 57.7 & 69.4 & 60.6 & 68.8 \\
Local Health Dept. & 36.5 & 40.9 & 41.8 & 40.5 & 36.2 & 43.2 & 52.5 & 36.5 \\
School or University & 52.7 & 54.9 & 37.3 & 58.8 & 43.1 & 54.1 & 53.5 & 57.3 \\
Internet & 49.8 & 44.3 & 20.5 & 53.4 & 37.7 & 49.5 & 45.5 & 52.1
\end{tabular}

${ }^{\mathrm{a}}$ All data are given as the number (percentage) of respondents.

bonly countries that had 96 or more respondents were included in the analysis. 
significantly more likely to report hearing something about AIDS on 103.5 The Beat than those 30 to 39 years old $(24.2 \%), p<.001$. Hispanics were least likely than other ethnic groups to report hearing something about AIDS on HOT 105, 99 Jamz, Mystik Radio, and 103.5 The Beat.

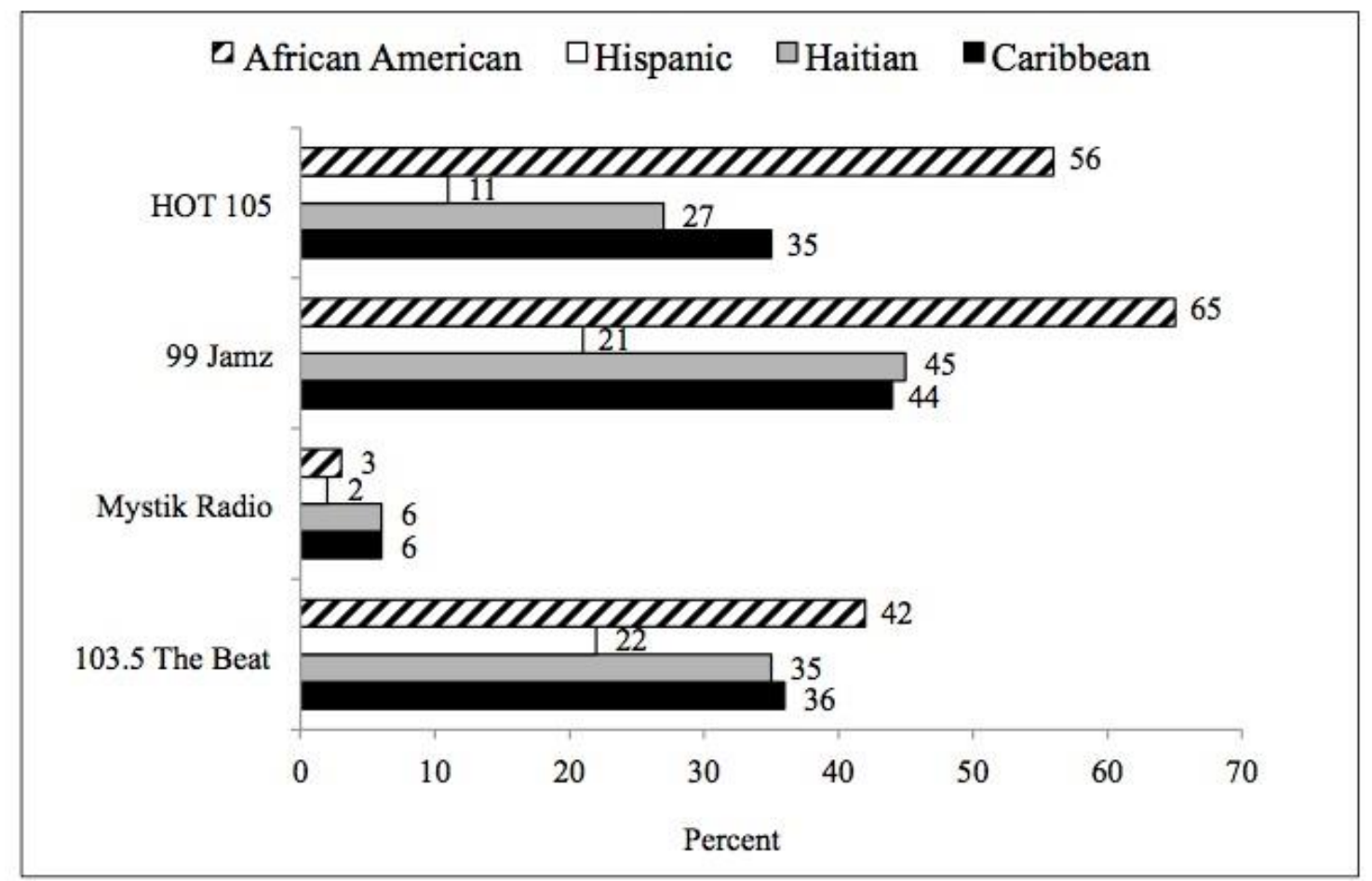

Figure 3. Percent of respondents who heard something about AIDS in Broward on specific radio stations, by Ethnicity, 2003-2007.

\section{Exposure to Specific Television Stations}

From 2003 to 2005, UPN Channel 33 was the most frequently reported television station for seeing anything about AIDS in Broward County, while Island TV was the least mentioned. African Americans, Haitians, and Caribbean Islanders were more likely to report seeing something about AIDS on UPN 33 than Hispanics (Figure 4).

Individuals 18 to 29 years old (55.9\%) were significantly more likely to report seeing something about AIDS on UPN 33 than older participants (40.0\%), $p<.001$. Hispanics 
were significantly more likely to report seeing something about AIDS in Broward on The Roof at Mun2 than Haitians, African Americans, and Caribbean Islanders, $p<.001$

(Figure 4).

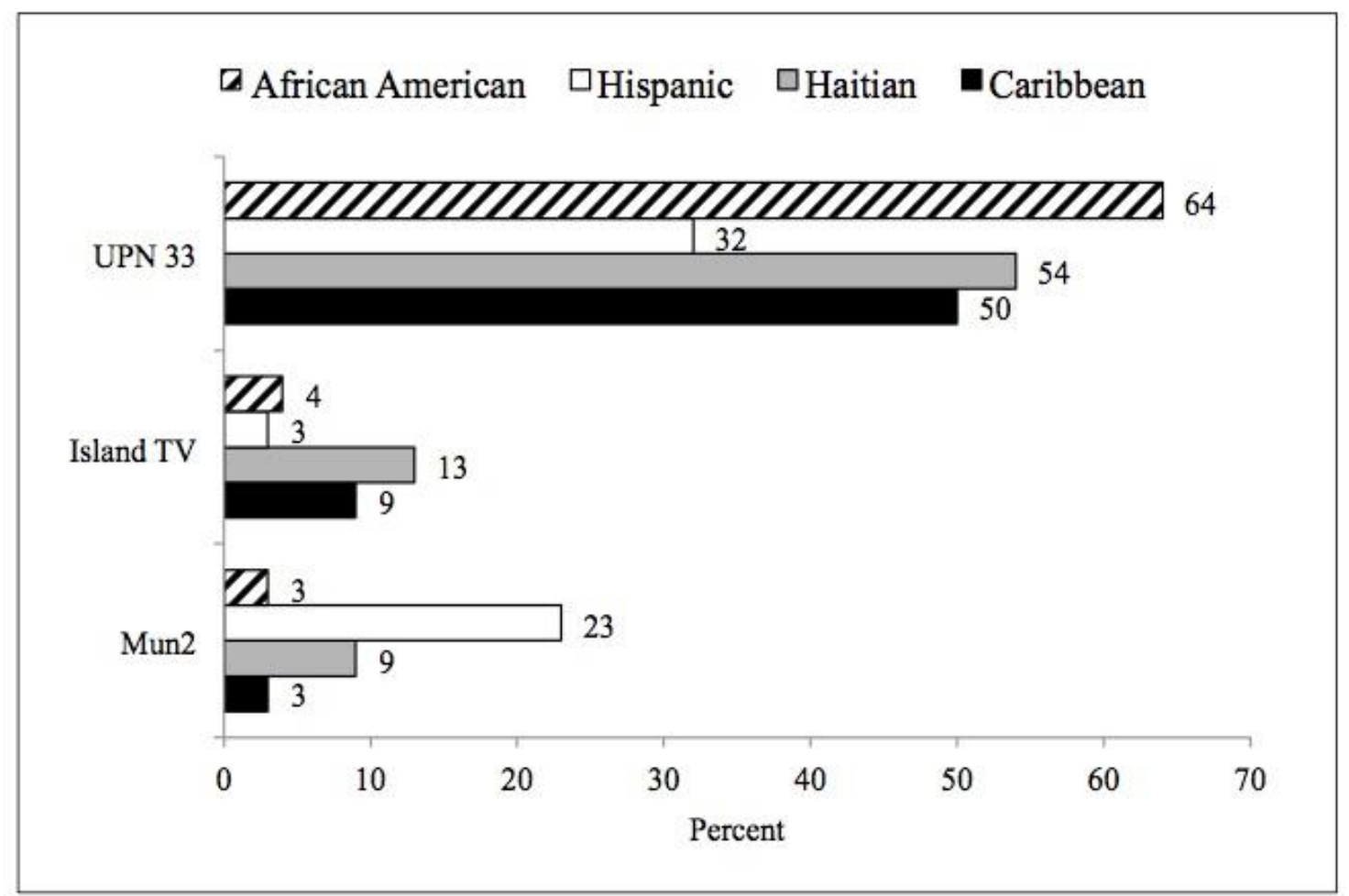

Figure 4. Percent of respondents who saw something about AIDS in Broward on specific television stations, by Ethnicity, 2003-2005.

\section{Research Question 2}

Which media sources provided the most helpful information about HIV prevention for Black and Hispanic young adults, 18 to 39 years old, living in Broward County?

Overall from 2001 to 2007, the most helpful sources for HIV/AIDS information cited were television $(35.6 \%)$, followed by doctor or health provider (18.6\%), schools or universities (14.2\%), newspapers or magazines (13.8\%), Internet (12\%), and radio $(11.3 \%)$. Internet was the only source that continually increased from $2001(9.2 \%)$ to 
$2007(20.6 \%), \chi^{2}=129.96, p<.001$, whereas the other sources fluctuated. For all ethnic groups the highest proportion of respondents (31.3\% to $40.3 \%$ ) mentioned television as the most helpful source from which they obtained HIV/AIDS information in the past year. African American, Hispanic, and Caribbean participants cited a doctor or health provider as the next most helpful source while Haitians cited schools or universities. All four ethnic groups reported obtaining the most helpful information about HIV/AIDS at a similar rate from newspapers or magazines, a billboard or bus ad, and AIDS organizations. African Americans and Haitians mentioned festivals and street fairs, family and friends, and church as being most helpful sources more frequently than Hispanics and Caribbean Islanders. Radio, schools or universities, and church were mentioned most frequently by Haitians as providing them the most helpful information about HIV/AIDS than the other ethnic groups. Caribbean Islanders were more likely to mention obtaining the most helpful information from the Internet than other respondents.

\section{Income}

Citing television, a doctor or health provider, and the local health department as sources that provided the most helpful HIV/AIDS information was higher for those who made less than $\$ 30,001$ than those who made higher annual incomes. Individuals who made more than $\$ 30,000$ were more likely to cite newspapers or magazines (15.5\%), Internet (14.0\%), and work place (4.9\%) than those who made less $(13.6 \%, 10.2 \%$, and $3.2 \%$, respectively).

\section{Educational Level and Gender}

More educated respondents (> 12 years) were significantly more likely to report obtaining the most helpful information on HIV/AIDS from schools or universities, 
newspapers or magazines, Internet, work place, and AIDS-service organizations than those with a high-school education or less. Television, doctor or health provider, local health department, family or friends, and church were significantly more frequently mentioned as being most helpful for HIV/AIDS information by participants with a highschool education or less than those who were more educated. Men were significantly more likely than women to report obtaining the most helpful information on HIV/AIDS from television, radio, family or friends, and billboard or bus ads. Women were significantly more likely than men to report obtaining the most helpful information from a doctor or health provider (22.3\% versus $11.6 \%)$, the local health department $(8.0 \%$ versus $4.4 \%)$, and a poster or pamphlet (7.2\% versus $5.2 \%)$.

\section{Age Groups}

Older respondents (30-39 years old) were more likely than younger participants (18-29 years old) to cite television, radio, newspapers or magazines, poster or pamphlet, work place, church, and local health department as sources that were most helpful for HIV/AIDS information. Citing family or friends, schools or universities, and Internet as sources that were most helpful was higher in the younger age group $(6.8 \%, 20.4 \%$, and $13.3 \%$, respectively) than the older age group $(4.3 \%, 7.0 \%$, and $10.5 \%$, respectively), $p<$ .001 .

\section{Ethnicity and Country of Origin}

For all Black non-Hispanic ethnic groups the highest proportion of CATI participants mentioned television $(29.6 \%$ to $40.6 \%)$ as a source from which they obtained the most helpful information on HIV/AIDS in the past year (Table 10). Doctor or health provider was the second most frequently cited source as providing the most helpful 
Table 10

Sources from which Black Non-Hispanics Reported Obtaining the Most Helpful Information about HIV/AIDS by Ethnicity and Country of Origin, 2002-2007 $(n=3,547)^{\mathrm{a}, \mathrm{b}}$

\begin{tabular}{lccccccc}
\hline & $\begin{array}{c}\text { African } \\
\text { American } \\
\mathrm{n}=1,619\end{array}$ & $\begin{array}{c}\mathrm{Jamaican} \\
\mathrm{n}=694\end{array}$ & $\begin{array}{c}\text { Haitian } \\
\text { (from Haiti) } \\
\mathrm{n}=686\end{array}$ & $\begin{array}{c}\text { Haitian } \\
\text { American } \\
\mathrm{n}=187\end{array}$ & $\begin{array}{c}\text { Caribbean } \\
\text { American } \\
\mathrm{n}=130\end{array}$ & $\begin{array}{c}\text { Bahamian } \\
\mathrm{n}=122\end{array}$ & $\begin{array}{c}\text { Trinidadian } \\
\mathrm{n}=109\end{array}$ \\
\hline Television & 31.1 & 40.6 & 29.6 & 38.5 & 39.2 & 31.1 & 33.9 \\
Radio & 11.8 & 13.0 & 17.9 & 10.2 & 13.1 & 7.4 & 9.2 \\
Newspaper/Magazine & 11.4 & 13.4 & 12.4 & 12.3 & 13.8 & 13.1 & 15.6 \\
Poster or Pamphlet & 7.2 & 7.1 & 3.6 & 7.5 & 5.4 & 10.7 & 11.9 \\
Family or Friends & 7.2 & 3.4 & 5.7 & 4.8 & 7.8 & 7.5 & 6.6 \\
Church & 5.8 & 3.2 & 7.0 & 3.7 & 4.7 & 6.7 & 3.8 \\
Doctor or Provider & 22.2 & 18.8 & 12.7 & 15.0 & 16.4 & 16.7 & 22.6 \\
Local Health Dept. & 7.8 & 5.4 & 6.3 & 6.4 & 3.1 & 8.3 & 5.7 \\
School or University & 12.0 & 13.9 & 19.0 & 25.1 & 18.8 & 22.5 & 17.0 \\
Internet & 11.1 & 14.7 & 13.9 & 11.8 & 18.8 & 15.0 & 17.0 \\
\hline
\end{tabular}

${ }^{\mathrm{a}}$ All data are given as the number (percentage) of respondents.

${ }^{\mathrm{b}}$ Only countries that had 100 or more respondents were included in the analysis. 
information by Trinidadians, African Americans, and Jamaicans, while Haitian Americans, Bahamians, Haitians, who migrated from Haiti, and Caribbean Americans identified schools or universities. Caribbean Americans and Trinidadians were more likely than other respondents to report Internet and newspapers or magazines as sources that were the most helpful to them. Citing radio as a HIV/AIDS information source that was most helpful was more common for Haitians, who migrated from Haiti, than other CATI respondents. Caribbean Americans, Bahamians, and African Americans were more likely to mention family, friends, or acquaintances as a source that provided them the most helpful information while Jamaicans found it the least helpful.

Likewise, for all Hispanic ethnic groups in Broward County, television was the source most frequently cited as being the most helpful for obtaining HIV/AIDS information (27.4\% to 55.7\%) (Table 11). Puerto Ricans and Hispanic Americans were more likely than other Hispanic respondents to mention the Internet, posters or pamphlets, and family members, friends, or acquaintances as being the most helpful sources. Mexicans were more likely than other respondents to report a doctor or health care provider as being a source that was most helpful for obtaining HIV/AIDS information in the past year. Doctor or health care provider was the second most common source cited by Mexicans after television. Moreover, citing radio as a HIV/AIDS information source that was most helpful was more common for Cubans than other Hispanic CATI participants living in Broward County, Florida. 
Table 11

Sources from which Hispanics Reported Obtaining the Most Helpful Information about HIV/AIDS by Ethnicity and Country of Origin, 2002-2007 $(n=1,462)^{\mathrm{a}, \mathrm{b}}$

\begin{tabular}{lcccccccc}
\hline & $\begin{array}{c}\text { Hispanic } \\
\text { American } \\
\mathrm{n}=438\end{array}$ & $\begin{array}{c}\text { Colombian } \\
\mathrm{n}=237\end{array}$ & $\begin{array}{c}\text { Mexican } \\
\mathrm{n}=220\end{array}$ & $\begin{array}{c}\text { Peruvian } \\
\mathrm{n}=131\end{array}$ & $\begin{array}{c}\text { Cuban } \\
\mathrm{n}=130\end{array}$ & $\begin{array}{c}\text { Puerto } \\
\mathrm{n}=111\end{array}$ & $\begin{array}{c}\text { Honduran } \\
\mathrm{n}=99\end{array}$ & $\begin{array}{c}\text { Dominican } \\
\mathrm{n}=96\end{array}$ \\
\hline Television & 27.4 & 47.3 & 50.0 & 55.7 & 46.9 & 32.4 & 45.5 & 47.9 \\
Radio & 7.5 & 7.6 & 8.6 & 6.9 & 11.5 & 4.5 & 5.1 & 7.3 \\
Newspaper/Magazine & 12.8 & 15.2 & 7.7 & 13.7 & 10.8 & 17.1 & 13.1 & 5.2 \\
Poster or Pamphlet & 8.7 & 6.3 & 8.2 & 3.8 & 6.2 & 9.0 & 8.1 & 7.3 \\
Family or Friends & 5.2 & 4.7 & 3.3 & 3.8 & 2.5 & 7.4 & 3.2 & 1.1 \\
Church & 2.1 & 4.3 & 1.9 & 0.8 & 6.6 & 2.8 & 7.4 & 2.2 \\
Doctor or Provider & 19.3 & 12.8 & 24.9 & 16.8 & 12.3 & 16.7 & 16.0 & 17.2 \\
Local Health Dept. & 6.4 & 8.5 & 8.1 & 3.8 & 4.1 & 6.5 & 4.3 & 6.5 \\
School or University & 16.5 & 16.2 & 7.2 & 13.0 & 9.0 & 14.8 & 10.6 & 15.1
\end{tabular}

${ }^{\mathrm{a}}$ All data are given as the number (percentage) of respondents.

bonly countries that had 96 or more respondents were included in the analysis. 


\section{Research Question 3}

How did obtaining information about HIV prevention from media sources change during 2001-2007 between Black and Hispanic young adults living in Broward County?

Most sources peaked in 2002 or 2003, for example, television, radio, and newspapers or magazines (Figure 5). Doctor or health care provider varied little ( $p<$ $.05)$, as did schools or universities $(p<.09)$. The greatest increase in source of information about HIV/AIDS was observed for Internet, which increased by $22.4 \%$ from baseline, 2001, to 2007, $\chi^{2}=190.30, p<.001$. African Americans, Hispanics, Haitians, and Caribbean Islanders mentioned Internet as a source of information the least in 2001 and the most in 2007, $p<.001$.

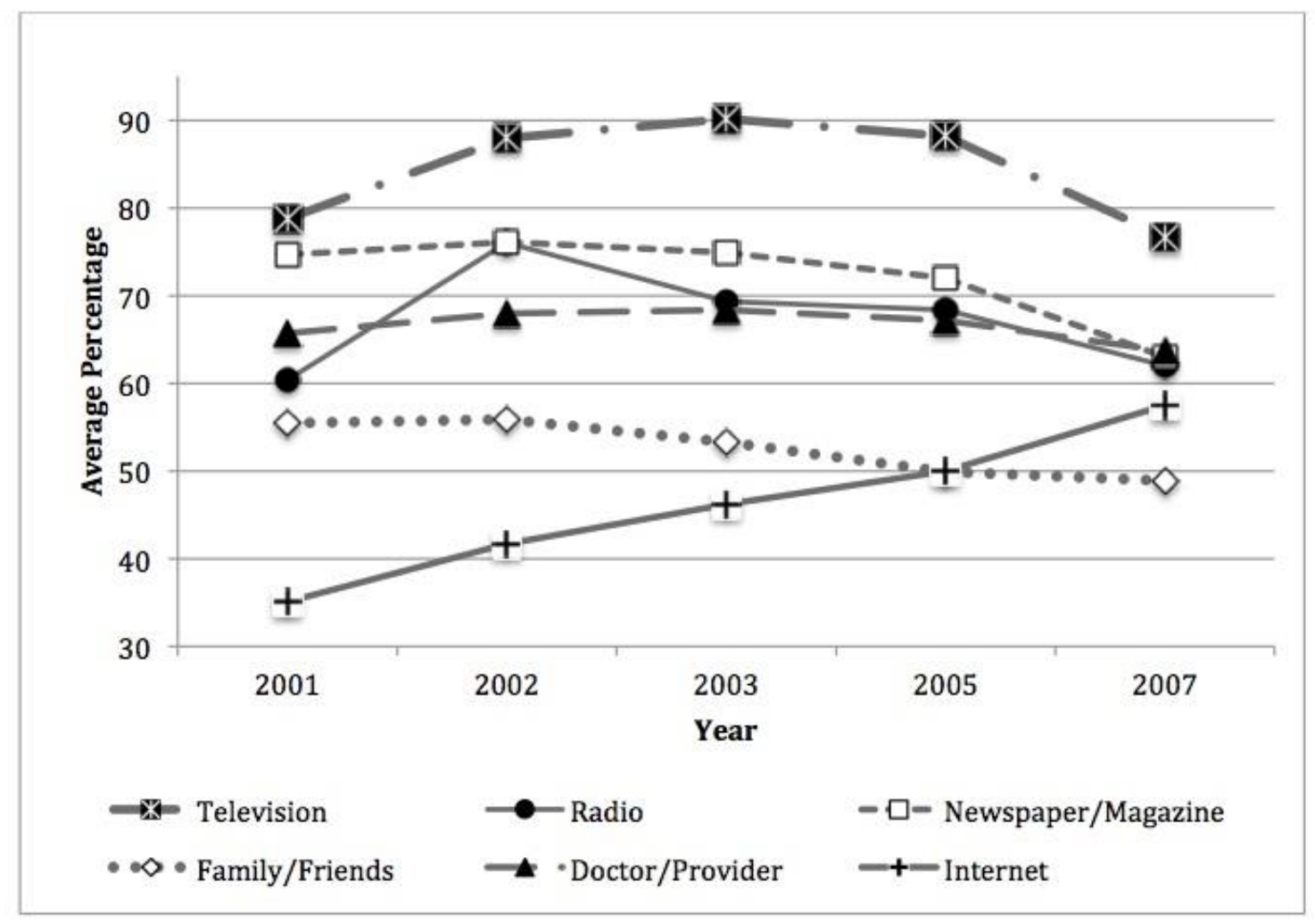

Figure 5. Trends in obtaining information about HIV/AIDS among racial and ethnic young people in Broward County, 2001-2007. 
Respondents from the four ethnic groups who reported obtaining HIV/AIDS information in the past year from family, friends, or acquaintances, work place, and/or schools or universities did not differ significantly each of the five years at the .05 level. During 2001 to 2005, African Americans and Caribbean Islanders obtained information similarly from newspapers or magazines and differently in $2007, p<.001$. All four racial and ethnic minority populations reported newspapers or magazines as a source of HIV/AIDS information the least frequently in 2007 than in the previous four years. Likewise, CATI respondents mentioned television the least frequently in 2007 than during 2001 through 2005.

Moreover, Haitian respondents reported listening to the radio more frequently every day during 2001 through 2003 (51.2\%, 52.6\%, and 49.0\%, respectively) and less frequently in $2005(44.6 \%)$ and $2007(36.3 \%), p<.001$. There was a slight decline in the number of African Americans, Hispanics, and Caribbean Islanders who accessed the radio every day. Similarly, Haitians reported obtaining HIV/AIDS most frequently from radio during $2002(77.8 \%)$ and then there was a steady decline from $2003(67.7 \%)$ to $2007(62.6 \%), p<.003$.

Black and Hispanic young adults living in Broward County mentioned hearing something about AIDS in Broward on HOT 105 and Mystik Radio similarly during 2003, 2005, and 2007 at the .05 level. The percentage of African American and Caribbean CATI respondents that mentioned hearing something about AIDS on 103.5 The Beat steadily increased during those three years, $p<.001$. Moreover, respondents from all four ethnic groups who reported seeing something about AIDS in Broward on UPN Channel 33 and Island TV were similar during 2003 and 2005 at the .05 level. 
Significantly fewer Hispanic respondents reported seeing anything about AIDS on "The Roof" at Mun2 (Telemundo's bilingual cable channel) in 2005 than 2003, $p<.01$, whereas the rate for the other three ethnic groups did not vary as much.

\section{Research Question 4}

What is the relationship between obtaining information about HIV/AIDS from media sources and perceived susceptibility of HIV during 2001-2007 among Black and Hispanic residents of Broward County?

The majority of Black and Hispanic residents of Broward County believed the number of people being infected with HIV was the same or lower in Broward compared

with the rest of the U.S. and they had some chance of becoming infected with HIV (Table 12). For the variable, meant to use condom but did not, most young adults replied no. From 2001 to 2007, there was an increase in the number of respondents who reported that they believed the level of HIV was higher in Broward than elsewhere (40.2\% to 57.4\%), $p<.001$. Binary logistic regression analyses were performed, one for each ethnic group, for each of the three variables (level of HIV/AIDS in Broward, chances of getting HIV, and meant to use condom but did not) encompassed by the concept "perception of susceptibility" in the REACH 2010 conceptual framework.

\section{Level of HIV/AIDS in Broward}

Duration of residence in Broward County, Florida, appeared to be the best predictor of knowledge about HIV prevalence in Broward, more so than source of HIV/AIDS information for African Americans ( $p \leq .01$ ), Hispanics, Haitians, and Caribbean Islanders $(p \leq .001)$. Internet (odds ratio $[\mathrm{OR}]=.79)$ and the local health department $(\mathrm{OR}=.81)$ as sources of information about HIV prevalence in Broward were 
negatively associated among Hispanic Americans. Positively associated with knowledge of increased risk of HIV infection among Hispanic Americans were higher levels of education $(\mathrm{OR}=1.30)$ and longer duration of residency $(\mathrm{OR}=1.40)$ in Broward County. Table 12

Perception of Susceptibility of Respondents, 2001-2007 (N = 7,843)

Variable

Level of HIV/AIDS in Broward ${ }^{\mathrm{a}}$

Same or Lower in Broward

Higher in Broward

Chances of Getting HIV

None

Some

Meant to Use Condom but Did $\operatorname{Not}^{\mathrm{c}}$

No

Yes

a2,214 missing data.

${ }^{\mathrm{b}} 333$ missing data.

${ }^{c} 2,321$ missing data.

Binary logistic regression tests showed that only one variable was significantly associated with knowledge of HIV prevalence among Haitian respondents. Source of information did not matter, but length of residency did. Haitian Americans who lived longer in Broward $(\mathrm{OR}=1.95)$ were more likely to know that Broward had a higher prevalence of HIV than most other cities. Among Caribbean respondents, those with higher incomes $(\mathrm{OR}=1.49)$ were more likely to know about the higher prevalence of HIV in Broward. They also lived in Broward for a longer duration $(\mathrm{OR}=1.85)$ and were less likely to obtain accurate information about HIV from a doctor or health care provider $(\mathrm{OR}=.58)$
$3,036(53.9)$

$2,593(46.1)$

$3,578(47.6)$

$3,932(52.4)$

$4,651(84.2)$

$871(15.8)$ 
For specific radio and television stations and bus signs, no one source seemed to be more important than another.

\section{Chances of Getting HIV}

African Americans, Hispanics, and Haitians who were men and unmarried were more likely than Caribbean respondents to believe they had some chance of getting HIV. Additionally, African Americans who had beyond a high school education $(\mathrm{OR}=1.23)$ and obtained HIV/AIDS information from radio $(\mathrm{OR}=1.47)$ and family, friends, or acquaintances $(\mathrm{OR}=1.35)$ were more likely to report they had some chance of getting HIV. Hispanic respondents who obtained HIV/AIDS information from newspapers or magazines $(\mathrm{OR}=1.31)$ and family, friends, or acquaintances $(\mathrm{OR}=1.33)$ were more likely to report they had some chance of getting HIV, than those who reported church $(\mathrm{OR}=.77)$ as a source of information in the past year.

Haitians who obtained HIV/AIDS information from television $(\mathrm{OR}=.70)$ were more likely to believe they had no chance of getting HIV, while those who obtained information from a doctor or health provider $(\mathrm{OR}=1.67)$ believed they might become infected with HIV. Furthermore, Caribbean Islanders who had beyond a high school education were 1.55 times more likely to believe they could be susceptible. Television $(\mathrm{OR}=1.43)$, family, friends, or acquaintances $(\mathrm{OR}=1.34)$, and festivals or street fairs $(\mathrm{OR}=1.30)$ as sources of information about HIV were positively associated among Caribbean Islanders for believing they had some chance of getting HIV, while church was negatively associated $(\mathrm{OR}=.65)$.

For specific radio and television stations and bus signs, African Americans who were men, unmarried, and reported seeing something about AIDS in Broward on a bus 
were more likely to believe they could be susceptible to HIV. Haitians who were men and those who mentioned hearing something about AIDS on 99 Jamz were more likely to believe they might become infected with HIV.

\section{Meant to Use Condom but Did Not}

Unmarried respondents from all four ethnic groups were more likely to report they meant to use a condom in the past year for disease protection and did not. Age, marital status, and educational level were negatively associated with intentions to use a condom among African Americans, while obtaining HIV/AIDS information from the radio was positively associated. African Americans who were younger and less educated meant to use a condom. Hispanics who obtained HIV/AIDS information from festivals or street fairs $(\mathrm{OR}=1.55)$, Haitians who obtained information from the work place $(\mathrm{OR}=$ 1.82), and Caribbean respondents who obtained information from schools or universities $(\mathrm{OR}=1.69)$ were more likely to report intentions to use a condom but did not for disease protection. For specific REACH 2010 media, no one source appeared to be more important than another to predict intentions to use a condom in the past year.

\section{Research Question 5}

What is the relationship between obtaining information about HIV/AIDS from media and engaging in different behaviors (e.g., being tested for HIV in the past 12 months) among Black and Hispanic residents of Broward County?

The majority of Black and Hispanic residents of Broward County replied yes to all five variables (ever tested for HIV, ever received HIV results, tested for HIV in the past 12 months, received results of HIV test in the past 12 months, and condom used in the past 12 months) (Table 13). Binary logistic regression analyses were performed, one 
for each ethnic group, for each of the five variables encompassed by the concept "behaviors" in the REACH 2010 conceptual framework.

Table 13

Behaviors of Respondents

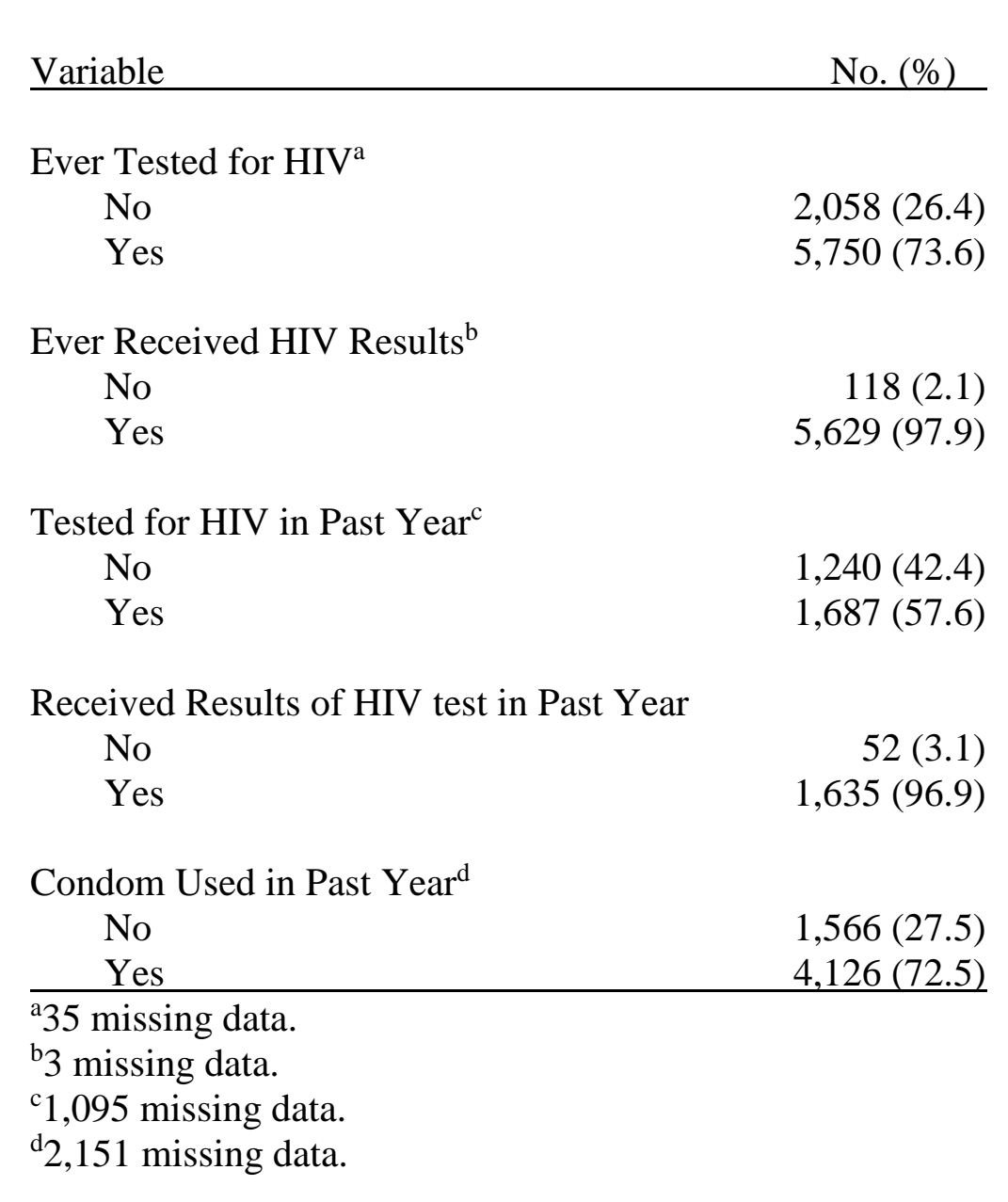

\section{Ever Tested for HIV}

Doctor or health provider as a source of HIV/AIDS information appeared to be the best predictor of reporting ever being tested for HIV for African Americans, Hispanics, and Caribbean Islanders (Table 14). For the African American regression model, the overall model containing the eight predictors listed in Table 14 was 
statistically significant, $\chi^{2}=192.09, p<.001$. The model correctly classified $81.3 \%$ of African American young adults. African Americans who obtained HIV information from a doctor or health provider were 2.48 times more likely to report ever being tested for HIV, while those who obtained information from the Internet were .74 times less likely to ever be tested.

For the Hispanic regression model, the overall model containing the six predictors listed in Table 14 was statistically significant, $\chi^{2}=202.25, p<.001$. The model correctly classified $73.6 \%$ of Hispanic young adults. Hispanics who were older, women, married, and more educated were more likely to report ever being tested for HIV. Respondents who obtained information from a doctor or health provider were 2.14 times more likely to report ever being tested, while those who obtained information from schools or universities were .62 times less likely to report ever being tested.

For the Haitian regression model, the overall model containing the five predictors listed in Table 14 was statistically significant, $\chi^{2}=134.93, p<.001$. The model correctly classified $65.9 \%$ of Haitian young adults. Haitians who were older, 30 to 39 years old, were 2.13 times more likely to ever be tested for HIV and participants who obtained HIV information from a doctor or health provider were 1.92 times more likely to report ever being tested.

For the Caribbean Islanders regression model, the overall model containing the six predictors listed in Table 14 was statistically significant, $\chi^{2}=135.55, p<.001$. The model correctly classified $77.3 \%$ of Caribbean young adults. Caribbean respondents who were older were 1.85 times more likely to ever be tested for HIV and participants who obtained HIV information from a doctor or health provider were 2.48 times more likely 
Table 14

Binary Logistic Regression Analyses Predicting Ever Tested for HIV by Ethnicity

\begin{tabular}{|c|c|c|c|c|c|c|c|c|c|c|c|c|}
\hline \multirow[b]{2}{*}{ Variable } & \multicolumn{3}{|c|}{ African American } & \multicolumn{3}{|c|}{ Hispanic } & \multicolumn{3}{|c|}{ Haitian } & \multicolumn{3}{|c|}{ Caribbean Islander } \\
\hline & $\beta$ & Wald & OR & $\beta$ & Wald & OR & $\beta$ & Wald & OR & $\beta$ & Wald & OR \\
\hline Age & .40 & 11.07 & $1.49^{* *}$ & .51 & 24.55 & $1.67^{* *}$ & .76 & 27.93 & $2.13^{* *}$ & .61 & 20.81 & $1.85^{* *}$ \\
\hline Gender & .27 & 6.14 & $1.32^{*}$ & .37 & 14.61 & $1.45^{* *}$ & .56 & 20.59 & $1.75^{* *}$ & & & \\
\hline Marital Status & .52 & 14.27 & $1.68^{* *}$ & .32 & 9.37 & $1.37^{*}$ & .50 & 12.12 & $1.64^{* *}$ & & & \\
\hline Education & .45 & 16.94 & $1.56^{* *}$ & .50 & 28.15 & $1.66^{* *}$ & .39 & 10.51 & $1.48^{* *}$ & .57 & 19.71 & $1.78^{* *}$ \\
\hline Doctor & .91 & 55.35 & $2.48^{* *}$ & .76 & 57.64 & $2.14^{* *}$ & .65 & 27.18 & $1.92^{* *}$ & .91 & 39.65 & $2.48^{* *}$ \\
\hline Health Dept. & .41 & 12.29 & $1.51^{* *}$ & & & & & & & .41 & 8.12 & $1.51^{*}$ \\
\hline School & -.51 & 18.22 & $.60^{* *}$ & -.48 & 22.96 & $.62^{* *}$ & & & & -.51 & 12.30 & $.60^{* *}$ \\
\hline Internet & -.30 & 7.02 & $.74^{*}$ & & & & & & & -.36 & 7.09 & $.70^{*}$ \\
\hline
\end{tabular}


to report ever being tested. Those who obtained information from the Internet were .70 times less likely to ever be tested for HIV.

For specific radio and television stations and bus signs, African Americans who were older $(\mathrm{OR}=2.93)$ and heard something about HIV in Broward on HOT $105(\mathrm{OR}=$ 1.60) and $99 \mathrm{Jamz}(\mathrm{OR}=1.71)$ in the past year were more likely to report ever being tested for HIV. Among Haitian respondents, those who were older ( $\mathrm{OR}=2.73)$, married $(\mathrm{OR}=1.99)$, more educated $(\mathrm{OR}=1.65)$, and reported seeing something about AIDS in Broward on a bus $(\mathrm{OR}=1.50)$ were more likely to ever be tested for HIV. When looking at specific radio and television stations and bus signs for Hispanic and Caribbean young

adults, no one source seemed to be more important than another for reporting ever being tested.

\section{Ever Received HIV Results}

African American women $(\mathrm{OR}=2.11)$ and those who obtained HIV information from a doctor or health provider $(\mathrm{OR}=2.34)$ in the past year were more likely to report ever receiving their HIV test results. Similarly, Haitians who obtained information from a doctor or health provider were 4.15 times more likely to receive their results, while those who reported the Internet as a source of HIV information were .35 times less likely to receive their results. Moreover, Hispanics who obtained information from a church were 2.72 times more likely to receive their results. For Caribbean respondents, no one source seemed to be more important than another.

For specific radio stations, African American and Haitian women were more likely to report ever receiving HIV results. African American women were 4.09 times 
more likely to ever receive their HIV results and those who heard something about AIDS in Broward on 99 Jamz were 3.67 times more likely to ever receive their results.

\section{Tested for HIV in Past 12 Months}

For all four ethnic groups, younger individuals, 18 to 29 years old, were significantly more likely to report they were tested for HIV in the past 12 months. Additionally, African Americans $(\mathrm{OR}=2.08)$, Hispanics $(\mathrm{OR}=1.80)$, and Caribbean Islanders $(\mathrm{OR}=1.56)$ who obtained HIV/AIDS information from a doctor or health provider in the past year were significantly more likely to report being tested in the past year. African Americans who obtained information from AIDS organizations were 1.38 times more likely to report receiving a HIV test in the past year. Moreover, Caribbean young adults who obtained information from the local health department in the past year were 1.78 times more likely to be tested in the past year.

Among Hispanic respondents, binary logistic regression showed that only two variables were significantly associated with receiving a HIV test in the past 12 months. Source of information did not matter but age and gender did. Hispanic Americans who were younger $(\mathrm{OR}=.56)$ and women $(\mathrm{OR}=1.91)$ were more likely to report they were tested for HIV in the past year.

For specific radio and television stations, African Americans and Hispanics who were younger and reported hearing something about AIDS in Broward on 103.5 The Beat were more likely to receive a HIV test in the past year. Additionally, African Americans who reported seeing something about AIDS on Island TV were 4.05 times more likely to report getting tested in the past year, while those who were married were less likely. 


\section{Results of HIV Test in Past 12 Months}

African American women $(\mathrm{OR}=2.95)$ and Caribbean respondents who identified obtaining HIV/AIDS information from a doctor or health provider $(\mathrm{OR}=4.72)$ were more likely to report receiving their HIV test results in the past 12 months. Source of HIV information did not matter for the former ethnic group. The local health department was negatively associated with receiving HIV test results among Hispanic Americans. Furthermore, the Haitian regression model was not significant.

When looking at specific REACH 2010 media, only the African American regression model was significant. African American women were 3.58 times more likely to receive their HIV results in the past year, while those who reported hearing something about AIDS on Mystik Radio were .19 times less likely.

\section{Condom Used in Past 12 Months}

For all four ethnic groups, unmarried individuals were significantly more likely to report they used a condom in the past 12 months (Table 15). African Americans who obtained HIV/AIDS information from the Internet in the past year were 1.27 times more likely to report using a condom in the past year. School as a source of HIV information for Hispanic and Caribbean young adults was positively associated with condom usage in the past year. Haitian respondents who obtained information from the work place were 1.55 times more likely to use a condom, while those who obtained information from the radio were .59 times less likely to use a condom in the past year. For specific radio and television stations, no one source seemed to be more important than another. 
Table 15

Binary Logistic Regression Analyses Predicting Condom Usage in the Past Year by Ethnicity

\begin{tabular}{|c|c|c|c|c|c|c|c|c|c|c|c|c|}
\hline \multirow[b]{2}{*}{ Variable } & \multicolumn{3}{|c|}{ African American } & \multicolumn{3}{|c|}{ Hispanic } & \multicolumn{3}{|c|}{ Haitian } & \multicolumn{3}{|c|}{ Caribbean Islander } \\
\hline & $\beta$ & Wald & OR & $\beta$ & Wald & OR & $\beta$ & Wald & OR & $\beta$ & Wald & OR \\
\hline Age & -.82 & 51.16 & $.44^{* * *}$ & -.30 & 6.77 & $.74^{* *}$ & & & & -.42 & 7.33 & $.66^{* *}$ \\
\hline Gender & -.57 & 20.55 & $.57^{* * *}$ & -.39 & 11.72 & $.68^{* * *}$ & -.62 & 10.49 & $.54^{* * *}$ & & & \\
\hline Marital Status & -1.41 & 154.39 & $.24^{* * *}$ & -1.07 & 80.08 & $.34^{* * *}$ & -1.11 & 36.07 & $.33^{* * *}$ & -1.35 & 77.29 & $.26^{* * *}$ \\
\hline Internet & .24 & 4.59 & $1.27^{*}$ & & & & & & & & & \\
\hline School & & & & .25 & 5.27 & $1.28^{*}$ & & & & .32 & 4.69 & $1.37^{*}$ \\
\hline Radio & & & & & & & -.53 & 5.87 & $.59^{*}$ & & & \\
\hline Work Place & & & & & & & .44 & 4.55 & $1.55^{*}$ & & & \\
\hline
\end{tabular}

Two-tailed tests of significance: ${ }^{*} \mathrm{p}<.05 .{ }^{* *} \mathrm{p} \leq .01 .{ }^{* * *} \mathrm{p} \leq .001$. 


\section{Summary}

This chapter presented the results of secondary analyses performed on the REACH 2010 CATI data sets for 2001, 2002, 2003, 2005, and 2007. Findings were presented and summarized for each of the five research questions guiding this study. Data collected from 2001-2007 showed that the percentage of respondents who reported obtaining HIV information from the Internet increased from baseline, 2001, to 2007 for all four ethnic groups. Nevertheless, not many CATI participants cited Internet as being "most helpful," especially Mexicans. In addition, although the health department should be regarded as a reliable source of information, very few people obtained HIV/AIDS information from there and found the information received there to be "helpful." Furthermore, the longer people lived in Broward, the more they knew about the HIV problem in their community and what was going on to address it. Strategic communications cannot make up for length of residency, but it can provide avenues for residents to be informed and make more informed decisions about their health. The last chapter concludes with a summary and discussion of major findings, recommendations for interventions and future research, and conclusions. 


\section{CHAPTER V}

\section{DISCUSSION}

This last chapter provides a brief summary of the preceding four chapters and reviews the problem and purpose of this study. Major findings are discussed and compared with other similar studies in the literature, when available. Limitations are presented as well as recommendations for future research. Lastly, the conclusion summarizes the study and provides implications for public health and HIV/AIDS prevention.

\section{Summary of Study}

This study examined the channels through which African American, Hispanic, Haitian, and Caribbean young adults obtained HIV/AIDS information and how access to information was related to perceived susceptibility of HIV and engaging in different health-related behaviors (e.g., receiving an HIV test in the past year). The REACH 2010 conceptual framework guided this study and major theoretical concepts were derived from McGuire's classic Communication-Persuasion Matrix and HBM. The five concepts included in the framework were: (1) exposure to HIV/AIDS information, (2) evaluation of helpfulness of HIV/AIDS information, (3) perception of susceptibility, (4) selfreported behaviors, and (5) personal attributes. A secondary analysis of all five REACH 2010 Broward County cross-sectional CATI data sets (2001, 2002, 2003, 2005, and 2007) examined operationally defined concepts in the conceptual framework to answer the research questions of interest. 


\section{Statement of the Problem}

In 2010, Fort Lauderdale, Florida, had the second highest incidence of HIV in the U.S. (Florida Department of Health in Broward County, n.d.b). One in 43 Blacks, one in 127 Whites, and one in 168 Hispanics were living with HIV in Broward County. In 2014, there were 418 Blacks and 175 Hispanics diagnosed with HIV in Broward (Florida Department of Health in Broward County, n.d.a). Over half of the new cases for each of those two ethnic groups were between 13 to 39 years old.

Little is known about HIV/AIDS sources of information accessed and used by racial and ethnic minority young adults in the U.S. (Cline \& Engel, 1991; Cunningham et al., 1999; Hu et al., 1989). Few studies have examined the HIV/AIDS sources Black and Hispanic populations obtain HIV/AIDS information from (Essien et al., 2000), find helpful (Rich et al., 1996), and depend on to make informed decisions. Additionally, there is even less known about the relationship between HIV/AIDS information obtained, HIV testing behaviors, and perceptions of contracting HIV/AIDS among Black and Hispanic young adults. Diverse people of color are frequently lumped into a single category, such as "Black” or “African American” (Agyemang et al., 2005; Brodie et al., 1999; Cunningham et al., 1999; Essien et al., 2000; Wolitski et al., 1996) and then compared with the predominantly White population. However, the culture of African Americans is different from that of Caribbean Islanders, Haitian Americans, and other groups that live in Broward County.

REACH 2010 in Broward was conducted from October 2000 through September 2008 to reduce disparities in HIV disease. A total of 7,843 African American, Haitian, Jamaican and other Caribbean and Hispanic young adults, 18 to 39 years old, from one of 
twelve high AIDS-prevalence ZIP-code areas participated in five cross-sectional CATI surveys (Darrow et al., 2004; Obiaja et al., 2010). Identifying how diverse Black and Hispanic young adult populations obtained HIV-related information is vital in guiding the decisions of public health administrators and health educators on how to communicate effectively, promote testing, and deliver high-impact educational, and other riskreduction interventions to populations in need.

\section{Purpose of Study}

The purpose of this study was to identify the media through which Black and Hispanic young adults in Broward County, Florida, obtained and were exposed to information about HIV/AIDS and determine the sources that provided the most helpful information. Additionally, this study explored the relationship between obtaining HIV/AIDS information and receiving an HIV test in the past twelve months as well as other behaviors (response to risk) and perceptions of contracting HIV/AIDS.

\section{Discussion of Major Findings}

\section{Exposure to HIV/AIDS Information}

REACH 2010 in Broward used strategic communications as one of four interventions to prevent HIV and help eliminate disparities in Broward County, Florida. Materials developed by the Broward Coalition were available in English, Spanish, and Haitian Creole. CATI surveys of 7,843 Black and Hispanic 18 to 39 year old residents conducted in English, Spanish, and Haitian Creole revealed television (news, PSAs, and entertainment programs) was the most frequently mentioned source for obtaining HIV/AIDS information by African Americans, Hispanics, Haitians, and Caribbean Islanders. This finding was consistent with other studies of Black (Cunningham et al., 
1999; Essien et al., 2000) and Hispanic populations in the U.S. (Essien et al., 2000; Hu et al., 1989). African Americans and Hispanic Americans cited media (i.e., television, radio, newspaper, and public library) more often than doctors and health providers and family, friends, and schools (Essien et al., 2000). Haitians in Broward County mentioned radio as the second most frequently cited source, while African Americans, Hispanics, and Caribbean respondents cited newspapers or magazines. The latter finding was comparable with prior research where Black respondents in Baltimore, Maryland, cited newspapers the second most frequently as a source of AIDS information (Cunningham et al., 1999).

When looking at respondents by ethnicity and country of origin, results showed that Haitian Americans and Caribbean Americans were more likely to identify Internet as a source of HIV/AIDS information (62.0\% and 60.8\%, respectively) than other nonHispanic Black respondents (44.8\% to 54.5\%). Different messages transmitted through different media will have differential impact in different ethnic groups. Stroman (2005) wrote "multiple communication sources and channels are needed to reach the diverse segments of African American communities most effectively" (p. 28). Moreover, findings from this study revealed that Peruvians and Dominicans obtained information about HIV from the Internet ( $53.4 \%$ and $52.1 \%$, respectively) more frequently than Mexicans (20.5\%) and other Hispanic respondents. A prior study showed that Hispanics had less access to the Internet than Whites in 2000 and 2002 and fewer Hispanic than White respondents had searched for health information on the Internet (Lorence, Park, \& Fox, 2006). 
To generate knowledge about eliminating health disparities in HIV disease, the Broward Coalition placed REACH 2010 60-second and 30-second PSAs on various television and radio stations in Broward to reach Black and Hispanic young adults. Results showed that $99 \mathrm{Jamz}$ was the radio station respondents most frequently mentioned for hearing something about AIDS in Broward while Mystik Radio was the least mentioned by each of the four ethnic groups. Funding was limited for strategic communications efforts and the Broward Coalition often had their television and radio PSAs run at midnight or later when many people were likely to be sleeping.

Since this was a community mobilization project, the Broward Coalition insisted that the majority of funding received for the REACH 2010 project in Broward County, Florida, be used to benefit the community. During their best years, which were 2001 through 2004 and 2006, the coalition received from over $\$ 900,000$ to one million dollars a year to support program activities (Darrow et al., 2010). The three CBOs received $\$ 100,000$ each year to conduct their outreach work and other duties. Overhead and staff salaries at FIU cost about $\$ 300,000$ per annum. The coalition spent approximately $\$ 100,000$ per year on communications development, implementation, and evaluation. Expenditures supported television and radio PSAs, spoken-word poetry events, prize money and other gifts for winning poetry slams and other contests, gift cards for completing CATI survey, palm cards, mugs, fountain pens, videotapes, and other REACH 2010 educational and prevention items (e.g., latex condoms for men, female condoms, instructions for proper use and disposal). 


\section{Evaluation of Helpfulness of HIV/AIDS Information}

Results from the study revealed that overall, CATI respondents believed they obtained the most helpful HIV/AIDS information from television, followed by a doctor or health-care provider, schools or universities, newspapers or magazines, and the Internet. When looking at respondents by ethnicity and country of origin, study findings indicated that television was rated "most helpful" by every one of the 15 ethnic groups studied in Broward County. Haitians cited schools or universities as the second most helpful source while African Americans, Hispanics, and Caribbean Islanders mentioned doctor or health provider. Prior research of African Americans and Hispanic Americans in Houston, Texas, found that both racial and ethnic minority populations mentioned "government agencies and professionals" (e.g., doctor's office) the most frequently for being a reliable source of HIV information (Essien et al., 2000). Furthermore, Englishspeaking non-Hispanic Black respondents in Broward were more likely to report the Internet as a most helpful source of HIV/AIDS information than most Hispanic respondents.

\section{Changes in Media during 2001-2007}

CATI surveys of Black and Hispanic young adults showed some changes in sources of information used in 2001, 2002, 2003, 2005, and 2007. There was little variation in respondents reporting schools or universities and a doctor or health provider as sources of HIV information. Results from the study revealed that Internet use increased dramatically, and more so among some ethnic groups than others. Although the Internet was shown to become an ever-increasing source of information about HIV/AIDS, it was regarded by many Black and Hispanic young adults in Broward 
County to be less reliable than the more traditional mass media and interpersonal sources of HIV/AIDS information.

\section{Perception of Susceptibility}

Level of HIV/AIDS in Broward. Results showed that length of residence in Broward County, Florida, was the best predictor of knowledge about HIV prevalence in Broward for African Americans, Hispanics, Haitians, and Caribbean Islanders. This finding makes sense because respondents who live longer in an area are more likely to be familiar with health concerns in their community than people who recently moved there. Moreover, results from binary regression analyses revealed that no one source appeared to be more significant than another for predicting correctly that the level of HIV was higher in Broward than the rest of the U.S. This was also the case for REACH 2010 media. The latter finding is logical since many respondents might not have been exposed to some of the radio and television PSAs because either they did not listen or watch the specific station(s) that were selected or they were working, sleeping, or elsewhere when the PSAs aired. Consistent with health communication theories, if public health practitioners want to reach African Americans and the other three ethnic groups, they might have to use more than one channel (NCI, 2004). Furthermore, findings indicated that Hispanics who obtained HIV information from the local health department and Internet were less likely to report that the number of people getting infected with HIV was higher in Broward than elsewhere in the U.S. This could be due to Hispanic young adults searching for general HIV/AIDS information in the U.S. and not for HIV statistics on the extent of the problem in Broward County, Florida. 
Chances of getting HIV. The present study showed that African Americans, Haitians, and Hispanics who were unmarried and men were more likely than Caribbean participants to believe they had some chance of getting HIV. Married respondents are likely to be monogamous and believe their partner is faithful, hence it is rational for them to assume they have no chance of becoming infected with HIV especially if they were previously tested for HIV and the test was negative. Additionally, results revealed that obtaining HIV information from family, friends, or acquaintances was positively associated with reporting there was a some chance of getting HIV for African Americans, Hispanics, and Caribbean Islanders, while obtaining information from a church was negatively associated among Hispanic and Caribbean young adults. Hispanics tend to be family oriented and are influenced by communications that target the group (Elder, Ayala, Parra-Medina, \& Talavera, 2009). Moreover, the Black church and faith organizations are central in many African-American communities and play a major role in shaping the attitudes, beliefs, and perceptions of community members. Often times, pastors and other church leaders present HIV as a disease that affects those who are promiscuous and or homosexual (Woodyard, Peterson, \& Stokes, 2000).

Meant to use condom but did not. Results revealed that unmarried participants from all four racial and ethnic minority populations were more likely to report they meant to use a condom for disease protection in the past year but did not.

\section{Behaviors}

Ever tested for HIV and received results. This present study showed that for Hispanic, African American, and Caribbean young adults, obtaining information from a doctor was the best predictor for reporting ever being tested for HIV. This finding is 
logical because patients go to the doctor to get blood work done, often yearly, and the physician might test their blood for HIV without asking them, or he or she might recommend the test if the patient is sexually active. Similarly, some patients might go to the local health department to receive information about HIV/AIDS and/or receive an HIV test, so it follows that obtaining HIV information from the health department was positively associated with ever being tested by African American and Caribbean young adults. Internet was negatively associated with ever being tested for the two latter ethnic groups. This finding might suggest that the importance of HIV testing was not emphasized in Internet messages about HIV/AIDS during the early years of the $21^{\text {st }}$ century.

For specific REACH 2010 media, two radio stations, HOT 105 and 99 Jamz, were positively associated with ever being tested for African Americans, while seeing something about AIDS in Broward on a bus was positively associated for Haitians or Haitian Americans. The Broward Coalition focused its messages about HIV prevention on bus routes that went through the 12 ZIP-codes with a high incidence of AIDS. The assumption was that some young people residing in those neighborhoods could not afford to drive a car and if they were going to travel, they might go by bus. Hence, while they were waiting at bus stops, there would be REACH 2010 signs on the bench and on the side of a bus emphasizing choices, including taking a HIV test.

Results revealed that reporting ever receiving HIV test results was positively associated with obtaining HIV information from a doctor or health provider for African Americans and Haitian or Haitian Americans and church for Hispanics. The Internet was negatively associated with obtaining HIV test results for Haitian or Haitian Americans. 
Tested for HIV in past 12 months. This study showed that younger individuals, 18-29 years old, were more likely to be tested for HIV in the past year. Additionally, obtaining HIV/AIDS information from a doctor or health provider was positively associated with being tested in the past 12 months among African American, Hispanics, and Caribbean Islanders.

Condom used in past 12 months. Findings indicated that using a condom in the past year was positively associated with obtaining HIV information from the Internet for African Americans, schools or universities for Hispanic and Caribbean young adults, and the work place for Haitian or Haitian Americans. Young adults for all four ethnic groups who were married were least likely to use a condom in the past year.

\section{Limitations}

This cross-sectional study has several limitations. First, since an available data set was used, analyses were limited because the existing data set was created to answer specific research questions of interest to the Broward Coalition. The questions asked regarding strategic communications could have been more specific and detailed and built on one another. For example, questions about seeing or hearing a PSA by REACH 2010 about AIDS in Broward on specific television and radio stations were not included in any of the five CATI surveys. Moreover, questions about the relationship between specific behaviors (e.g., receiving an HIV test in the past year) and recalling a REACH 2010 PSA or other message were not included in the CATI questionnaires. Nevertheless, REACH 2010 in Broward County, Florida, was able to include several questions about its strategic communications campaign as part of the community mobilization program. The emphasis was on strategic communications plus outreach, education, and other 
interventions to stimulate the community to take action and cope with a problem of AIDS.

Additionally, response burden is something to keep in mind when conducting telephone and other types of surveys. The director of IPOR emphasized the importance of keeping the surveys concise and relevant so that they could complete data collection within 10 to 15 minutes because after 15 minutes respondents' might lose interest and their answers would not be reliable. Therefore, the Broward Coalition reviewed and edited the CATI questionnaire before each period of administration. Since, they were dealing with inner-city neighborhoods and individuals who may have been in the U.S. illegally, they could not ask too many sensitive questions. To minimize the burden on respondents, the coalition decided to limit the number of items covered during the IPORadministered telephone interview.

Second, noncoverage bias may be an issue since coalition staff did not foresee the adoption of cell phones when the CATI survey was first created in 2000. The sample of respondents included each year in the study had a landline telephone. So, it is possible there was a difference between those individuals who only had cell phones and those who had landline telephones (Lee, Brick, Brown, \& Grant, 2010). Also, nonresponse bias may exist because respondents had to be home when IPOR interviewers called to conduct the survey. Young adults who met the inclusion criteria and were working or elsewhere when IPOR staff called Monday through Friday from 5:00-9:00 PM, Saturday from 11:00 AM to 5:00 PM, and/or Sunday from 12:00-6:00 PM might be at higher risk for acquiring HIV. 
Third, participant responses may reveal the presence of social desirability bias due to data being self-reported and not verified by IPOR staff. Additionally, this study was conducted only in Broward County, Florida, and there was no comparison community. Findings may not be generalizable to Black and Hispanic populations elsewhere in the U.S. Finally, since this study was cross-sectional, causality cannot be inferred about the various behaviors.

Despite these limitations, the present study adds to the limited HIV literature investigating the association between obtaining HIV/AIDS information from media (large and small), HIV testing behavior, and perceptions of susceptibility among African American, Hispanic, Haitian, and Caribbean young adults. Recall bias should not have been an issue since questions inquired if a participant ever engaged in the behavior(s) and if he or she engaged in the behavior(s) in the past year. Respondents were not asked to quantify any behaviors. Furthermore, in contrast to previous studies that lumped all Black individuals together and combined all Hispanic people, this is the first study to explore from which sources Black and Hispanic ethnic groups (e.g., Jamaicans, Trinidadians, Haitians, Colombians, Mexicans, and Peruvians) obtained HIV/AIDS information from in the past year and which channels provided them with the most helpful HIV information.

\section{Recommendations for Future Research}

When conducting communications campaigns for HIV and other infectious diseases, investigators should examine how different Black and Hispanic ethnic groups access and obtain information as well as which sources they find the most helpful and credible. As this study revealed, not every Black and Hispanic ethnic group obtained 
information similarly. It is crucial for public health educators to know the population they are attempting to reach. This will allow interventionists to pick suitable channels, messages, and spokespeople to communicate effectively with their intended audience (Kreuter \& Wray, 2003). Additionally, although the Internet has gained in popularity along with social media (i.e., Facebook, Instagram, Twitter, and Snapchat), traditional media like television, radio, newspapers, and magazines should not be overlooked when designing and developing comprehensive communications programs in the digital age. Moreover, community mobilization projects that include a communications component should continue to be supported. FDOH initiatives (i.e., Man Up and SOS) to reduce HIV infections primarily emphasize testing to identify HIV-infected men and women not under medical care. Current interventions incorporate biomedical strategies and stress taking medications and distributing condoms without providing individuals with adequate information, motivation, and skills training for HIV prevention.

Furthermore, ongoing HIV communications campaigns should be evaluated and those evaluations should be published and disseminated in a timely manner for those who are interested to review. Knowing what is working and not working allows researchers to design more effective campaigns and programs and avoid repeating past mistakes.

Hence, if a campaign is not effective, the component(s) not working should be identified and modified or discontinued.

\section{Conclusion}

Findings from this study have important implications for HIV/AIDS strategic communications campaigns. Since racial and ethnic disparities continue to exist in HIV disease among Black and Hispanic populations, it is imperative that public health 
practitioners identify the channels through which diverse Black and Hispanic ethnic groups obtain HIV information and determine which sources they find most helpful and credible. Programs should be culturally relevant. Current HIV/AIDS programs and communications campaigns may not be effective if ethnic origin is not considered.

\section{Strategic Communications in the Black Community of Young Adults in Broward}

During 2001 through 2007, all seven non-Hispanic Black ethnic groups in Broward County, Florida, obtained HIV/AIDS information most frequently from television news, entertainment programs, and PSAs. Radio was ranked second most frequently by African Americans, Haitians who migrated from Haiti, and Caribbean Islanders. Afro-Caribbean young adults also obtained information from a poster or pamphlet. Similarly, several other Black ethnic groups mentioned printed information. Newspapers and magazines were cited as a source of HIV information second most frequently by Jamaicans, while Bahamians and Trinidadians preferred a poster or pamphlet and Haitian Americans listed schools or universities. Clearly, diverse nonHispanic Black young people in Broward obtained HIV/AIDS information in different ways. If public health officials and interventionists wish to communicate effectively with Black communities about HIV prevention, they should consider the countries of origin, cultural values, and health-related beliefs of the audiences they are trying to reach.

Regarding risk perception, church as a source of HIV information was negatively associated with Caribbean Islanders believing they could become infected with HIV. Since the church is an important institution in many Black communities, health educators should consider collaborating with Black faith organizations to provide parishioners with HIV-prevention education (Agate et al., 2005) and reduce stigmatization of HIV 
(Woodyard et al., 2000). For HIV testing, obtaining information from a doctor or health provider was the best predictor for reporting ever being tested among African American and Afro-Caribbean young adults residing in Broward. Doctor or health provider was the second most frequently named HIV/AIDS information source for being "most helpful" by African Americans. Continuing education courses and other trainings for doctors and other health professionals might be offered on how to communicate with patients about HIV-prevention options to reduce HIV disparities in racial and ethnic minority populations (Cunningham et al., 1999).

\section{Strategic Communications in the Hispanic Community of Young Adults in Broward}

As was true for the Black populations in Broward, all eight Hispanic ethnic groups reported television most frequently as a source of HIV/AIDS information. The diverse Hispanic ethnic groups obtained HIV/AIDS information from media at different rates. Mexicans were least likely of all Hispanic groups to obtain HIV information from the Internet, newspapers, and magazines. Cubans were least likely to obtain information from the local health department. Knowing which media diverse Hispanic ethnic groups (e.g., Peruvians, Colombians, and Mexicans) access and find helpful allows public health practitioners to design and implement appropriate HIV-prevention programs for each audience. Country of origin, acculturation, and other sociocultural variables are relevant when reaching out to and working with Hispanic populations (Elder et al., 2009).

\section{Traditional Media, Internet, and Social Media in the $21^{\text {st }}$ Century}

When designing HIV strategic communications campaigns, public health officials cannot overlook television. Television as a commonly cited source of HIV/AIDS information by Black and Hispanic populations is consistent with previously reported 
research (Cunningham et al., 1999; Dawson \& Hardy, 1989a, 1989b; Essien et al., 2000; Hardy \& Biddlecom, 1991; Hu et al., 1989). The impact of strategic communications for specific REACH 2010 television stations in Broward County was limited by the sources of information accessed and used by residents of high-incidence areas. REACH 2010 staff had little influence on local TV news reports and limited funds to pay for advertisements. Print media should also be included in comprehensive HIV-prevention programs. Often times, broadcast or print media might be the source where individuals first learn about a disease and then they might follow-up with another source to find out more information about the disease of interest.

Although Internet use increased significantly from 2001 to 2007, most young adults in Broward, particularly those from Mexico, did not find it "most helpful." Furthermore, African-American and Caribbean respondents who obtained HIV information from the Internet were less likely to have ever been tested for HIV. Broward residents did not often use the local health department as a source of HIV/AIDS information and it was not viewed as very helpful. Further studies are needed to examine the credibility of HIV information obtained via the Internet and local health departments. Social media platforms, such as Facebook and Twitter, have the potential to reach millions of people worldwide. Since social media is commonly used by younger adults (Chou, Hunt, Beckjord, Moser, \& Hesse, 2009), it should be considered when developing HIV strategic communications campaigns to inform sexually active Black and Hispanic Americans about HIV/AIDS prevention. Studies have begun to explore Internet-based interventions to reduce HIV infections, but, so far, have met with very limited success 
among young people in the United States (Bull, Pratte, Whitesell, Rietmeijer, \& McFarlane, 2009).

\section{Strategic Communications in the $21^{\text {st }}$ Century}

This study was the first to assess how various groups of Black and Hispanic young adults residing in high AIDS-incidence areas obtained HIV/AIDS information from different media sources in the past 12 months and whether they considered the sources to be helpful. Moreover, this study provided insights into how HIV information was related to perceptions of risk and self-reported histories of HIV testing. Culturally competent communications should be incorporated into comprehensive HIV-prevention programs to inform Black and Hispanic young adults of their risks of HIV infection, prevention alternatives, and scientific advances in prevention, treatment, and care. Research should continue to focus on finding the right balance of broadcast, print, and social media to deliver the most impact for vulnerable populations at increased risk. 


\section{REFERENCES}

Agate, L. L., Cato-Watson, D., Mullins, J. M., Scott, G. S., Rolle, V., Markland, D., \& Roach, D. L. (2005). Churches united to stop HIV (CUSH): A faith-based HIV prevention initiative. Journal of the National Medical Association, 97(7), 60S$63 \mathrm{~S}$.

Agyemang, C., Bhopal, R., \& Bruijnzeels, M. (2005). Negro, Black, Black African, African Caribbean, African American or what? Labelling African origin populations in the health arena in the 21st century. Journal of Epidemiology and Community Health, 59(12), 1014-1018. doi:10.1136/jech.2005.035964

Arya, M., Behforouz, H. L., \& Viswanath, K. (2009). African American women and HIV/AIDS: A national call for targeted health communication strategies to address a disparity. AIDS Read, 19(2), 79-C3.

Brodie, M., Kjellson, N., Hoff, T., \& Parker, M. (1999). Perceptions of Latinos, African Americans, and Whites on media as a health information source. Howard Journal of Communications, 10(3), 147-167. doi:10.1080/106461799246799

Brooks, J. (1998). Clinton announces racial and ethnic health disparities initiative. Office of Minority Health Resource Center, U.S. Department of Health and Human Services.

Bull, S., Pratte, K., Whitesell, N., Rietmeijer, C., McFarlane, M. (2009). Effects of an Internet-based intervention for HIV prevention: The Youthnet trials. AIDS and Behavior, 13(3), 474-487. doi:10.1007/s10461-008-9487-9

Centers for Disease Control and Prevention. (n.d.). Investments in community health:

Racial and ethnic approaches to community health (REACH). Atlanta, GA:

National Center for Chronic Disease Prevention and Health Promotion, Division of Community Health. Retrieved from

http://www.cdc.gov/nccdphp/dch/programs/reach/pdf/FINAL_REACH_factsheet-092012_TAG508.pdf

Centers for Disease Control and Prevention. (2011). Health communication basics. Atlanta, GA: Division of Public Affairs, Office of the Associate Director for Communication. Retrieved from http://www.cdc.gov/healthcommunication/healthbasics/whatishc.html

Centers for Disease Control and Prevention. (2014). HIV among African American youth. Atlanta, GA: U.S. Department of Health and Human Services, Centers for Disease Control and Prevention. 
Centers for Disease Control and Prevention. (2015a). HIV among Hispanics/Latinos. Atlanta, GA: Division of HIV/AIDS Prevention, Centers for Disease Control and Prevention.

Centers for Disease Control and Prevention. (2015b). HIV surveillance report: Diagnoses of HIV infection in the United States and dependent areas, 2014 (Vol. 26). Atlanta, GA: National Center for HIV/AIDS, Viral Hepatitis, STD, and TB Prevention, Division of HIV/AIDS Prevention.

Centers for Disease Control and Prevention. (2015c). HIV in the United States: At a glance. Atlanta, GA: National Center for HIV/AIDS, Viral Hepatitis, STD, and TB Prevention, Division of HIV/AIDS Prevention.

Centers for Disease Control and Prevention. (2016a). HIV among African Americans. Atlanta, GA: Division of HIV/AIDS Prevention, Centers for Disease Control and Prevention.

Centers for Disease Control and Prevention. (2016b). HIV among youth. Atlanta, GA: Division of HIV/AIDS Prevention, Centers for Disease Control and Prevention.

Centers for Disease Control and Prevention. (2016c). HIV surveillance report: Diagnosed HIV infection among adults and adolescents in metropolitan statistical areasUnited States and Puerto Rico, 2014 (Vol.21, No.1). Retrieved from http://www.cdc.gov/hiv/library/reports/surveillance/

Centers for Disease Control and Prevention. (2016d). Today's HIV/AIDS epidemic. Retrieved from http://www.cdc.gov/nchhstp/newsroom/docs/factsheets/todaysepidemic-508.pdf

Centers for Disease Control and Prevention National Prevention Information Network. (2013). Social marketing and education campaigns - Health communication strategies. Retrieved from http://www.cdcnpin.org/scripts/campaign/strategy.asp

Chou, W. Y. S., Hunt, Y. M., Beckjord, E. B., Moser, R. P., \& Hesse, B. W. (2009). Social media use in the United States: Implications for health communication. Journal of Medical Internet Research, 11(4), e48. doi:10.2196/jmir.1249

Citizen's Commission to Protect the Truth. (2007). The Truth campaign. Retrieved from http://www.protectthetruth.org/truthcampaign.htm

Clayman, M. L., Manganello, J. A., Viswanath, K., Hesse, B. W., \& Arora, N. K. (2010). Providing health messages to Hispanics/Latinos: Understanding the importance of language, trust in health information sources, and media use. Journal of Health Communication, 15(Suppl 3), 252-263. doi:10.1080/10810730.2010.522697 
Cline, R. J. W., \& Engel, J. L. (1991). College students' perceptions of sources of information about AIDS. Journal of American College Health, 40(2), 55-63.

Cottrell, R. R., \& McKenzie, J. F. (2011). Health promotion \& education research methods: Using the five-chapter thesis/dissertation model ( $2^{\text {nd }}$ ed.). Sudbury, MA: Jones and Bartlett.

Cristancho, S., Peters, K., \& Garces, M. (2014). Health information preferences among Hispanic/Latino immigrants in the U.S. rural Midwest. Global Health Promotion, 21(1), 40-49. doi:10.1177/1757975913510727

Cronk, B. C. (2008). How to use SPSS: A step-by-step guide to analysis and interpretation $\left(5^{\text {th }}\right.$ ed.). Glendale, CA: Pyrczak Publishing.

Cunningham, W. E., Davidson, P. L., Nakazono, T. T., \& Anderson, R. M. (1999). Do black and white adults use the same sources of information about AIDS prevention? Health Education \& Behavior, 26(5), 703-713.

Darrow, W. W. (2013). Community mobilization, community planning, and communitybased research for HIV prevention in the United States. In R. A. Smith (Ed.), Activism and Community Mobilization: Vol. 3. Global HIV/AIDS politics, policy, and activism: Persistent challenges and emerging issues (pp. 375-399). Santa Barbara, CA: Praeger.

Darrow, W. W., Kim, S., Montanea, J., Uribe, C., Sanchez-Brana, E., \& Gladwin, H. (2010). Summative evaluation of a community mobilization program to eliminate racial and ethnic disparities in HIV disease. International Public Health Journal, 2(3), 301-312.

Darrow, W. W., Montanea, J., Fernandez, P., Zucker, U., Stephens, D., \& Gladwin, H. (2004). Eliminating disparities in HIV disease: Community mobilization to prevent HIV transmission among Black and Hispanic young adults in Broward County, Florida. Journal of Ethnicity and Disease, 14(3 Suppl 1), S108-S116.

Davis, R. E., Alexander, G., Calvi, J., Wiese, C., Greene, S., Nowak, M., ... Resnicow, K. (2010). A new audience segmentation tool for African Americans: The black identity classification scale. Journal of Health Communication, 15(5), 532-554. doi: $10.1080 / 10810730.2010 .492563$

Dawson, D. A., \& Hardy, A. M. (1989a). AIDS knowledge and attitudes of Black Americans: Provisional data from the 1988 National Health Interview Survey. Advance Data From Vital and Health Statistics (No. 165). Hyattsville, MA: U.S. Department of Health and Human Services, Public Health Service, Centers for Disease Control, National Center for Health Statistics. 
Dawson, D. A., \& Hardy, A. M. (1989b). AIDS knowledge and attitudes of Hispanic Americans: Provisional data from the 1988 National Health Interview Survey. Advance Data From Vital and Health Statistics (No. 166). Hyattsville, MA: U.S. Department of Health and Human Services, Public Health Service, Centers for Disease Control, National Center for Health Statistics.

DeJong, W., Wolf, R. C., \& Austin, S. B. (2001). U.S. federally funded television public service announcements (PSAs) to prevent HIV/AIDS: A content analysis. Journal of Health Communication, 6(3), 249-263. doi:10.1080/108107301752384433

Department of Health and Human Services. (1999). Racial and Ethnic Approaches to Community Health 2010 (REACH 2010): Application kit. Atlanta, GA: Procurement and Grants Office.

Dobransky, K., \& Hargittai, E. (2012). Inquiring minds acquiring wellness: Uses of online and offline sources for health information. Health Communication, 27(4), 331-343. doi:10.1080/10410236.2011.585451

Dutta-Bergman, M. J. (2004). Primary sources of health information: Comparisons in the domain of health attitudes, health cognitions, and health behaviors. Health Communication, 16(3), 273-288.

Elder, J. P., Ayala, G. X., Parra-Medina, D., \& Talavera, G. A. (2009). Health communication in the Latino community: Issues and approaches. Annual Review of Public Health, 30, 227-251. doi:10.1146/annurev.publhealth.031308.100300

Essien, E. J., Ross, M. W., Linares, A. C., \& Osemene, N. I. (2000). Perception of reliability of human immunodeficiency virus/AIDS information sources. Journal of the National Medical Association, 92(6), 269-274.

Farrelly, M. C., Davis, K. C., Haviland, M. L., Messeri, P., \& Healton, C. G. (2005). Evidence of a dose-response relationship between "truth" antismoking ads and youth smoking prevalence. American Journal of Public Health, 95(3), 425-431. doi:10.2105/AJPH.2004.049692

Feldman, D. A., \& Miller, J. W. (1998). The AIDS crisis: A documentary history. Westport, CT: Greenwood Press.

Florida Department of Health. (2012). We Make the Change. Retrieved from http://www.wemakethechange.com/wp-content/uploads/WMTC-Facts1.pdf

Florida Department of Health. (2016). Stop the Spread. Retrieved from http://www.stopthespread.com 
Florida Department of Health in Broward County. (n.d.a). January-December, 2014 Broward HIV/AIDS surveillance. Fort Lauderdale, FL: Florida Department of Health in Broward County.

Florida Department of Health in Broward County. (n.d.b). Jurisdictional prevention plan 2012-2016: Defining HIV planning through our eyes - HIV stakeholders engaged for AIDS-free Broward County. Retrieved from http://browardchd.org/jurisdictional.html\#/0

Geana, M. V., Kimminau, K. S., \& Greiner, K. A. (2011). Sources of health information in a multiethnic, underserved, urban community: Does ethnicity matter? Journal of Health Communication, 16(6), 583-594. doi:10.1080/10810730.2011.551992

Giles, W. H., Tucker, P., Brown, L., Crocker, C., Jack, N., Latimer, A., .. Harris, V. B. (2004). Racial and Ethnic Approaches to Community Health (REACH 2010): An overview. Journal of Ethnicity and Disease, 14(3 Suppl 1), S5-S8.

Gladwin, H., Goraczko, A. R., \& Darrow, W. W. (2002). GIS technique for reaching a hard-to-find high HIV risk sample. Poster presented at XVI International AIDS Conference (July 7-12), Barcelona, Spain.

Green, L. W., \& Kreuter, M. W. (1992). CDC's planned approach to community health as an application of PRECEED and an inspiration for PROCEED. Journal of Health Education, 23(3), 140-147.

Hardy, A. M., \& Biddlecom, A. E. (1991). AIDS knowledge and attitudes of Black Americans: United States, 1990 (No. 206). Hyattsville, MA: National Center for Health Statistics.

The Henry J. Kaiser Family Foundation. (2014a). Black Americans and HIV/AIDS. Retrieved from http://kff.org/hivaids/fact-sheet/black-americans-and-hiv-aids/

The Henry J. Kaiser Family Foundation. (2014b). Latinos and HIV/AIDS. Retrieved from http://kff.org/hivaids/fact-sheet/latinos-and-hivaids/

Hicks, J. J. (2001). The strategy behind Florida's "truth" campaign. Tobacco Control, 10(1), 3-5. doi:10.1136/tc.10.1.3

Hlaing, W. M., \& Darrow, W. W. (2006). HIV risk reduction among young minority adults in Broward County. Journal of Health Care for the Poor and Underserved, 17(2 Suppl), 159-173.

Hu, D., Keller, R., \& Fleming, D. (1989). Communicating AIDS information to Hispanics: The importance of language and media preference. American Journal of Preventive Medicine, 5(4), 196-200. 
IBM Corporation. (2011). IBM SPSS Statistics for Macintosh, Version 20.0. Armonk, NY: IBM Corporation.

Institute for Dynamic Educational Advancement. (2011). What is strategic communications? Retrieved from http://www.idea.org/blog/2011/03/16/what-isstrategic-communications/

Joint United Nations Programme on HIV/AIDS (UNAIDS). (2016). AIDS by the numbers - 2016. Retrieved from http://www.unaids.org/en/resources/documents/2016

Keiser, N. H. (1991). Strategies of mass marketing for "America Responds to AIDS" and applying lessons learned. Public Health Reports, 106(6), 623-627.

Kreuter, M. W., \& Wray, R. J. (2003). Tailored and targeted health communication: Strategies for enhancing information relevance. American Journal of Health Behavior, 27(Suppl 3), S227-S232.

LaCroix, J. M., Snyder, L. B., Huedo-Medina, T. B., \& Johnson, B. T. (2014). Effectiveness of mass media interventions for HIV prevention, 1986-2013: A meta-analysis. Journal of Acquired Immune Deficiency Syndromes, 66(Suppl 3), S329-S340. doi:10.1097/QAI.0000000000000230

Lee, S., Brick, J. M., Brown, E. R., \& Grant, D. (2010). Growing cell-phone population and noncoverage bias in traditional random digit dial telephone health surveys. Health Services Research, 45(4), 1121-1139. doi:10.1111/j.14756773.2010.01120.x

Livingston, G., Minushkin, S., \& Cohn, D. (2008). Hispanics and health care in the United States: Access, information, and knowledge. Washington, DC \& Princeton, NJ: Pew Hispanic Center and Robert Wood Johnson Foundation.

Lorence, D. P., Park, H., \& Fox, S. (2006). Racial disparities in health information access: Resilience of the digital divide. Journal of Medical Systems, 30(4), 241249. doi:10.1007/s10916-005-9003-y

Marin, G., \& Marin, B. V. (1990). Perceived credibility of channels and sources of AIDS information among Hispanics. AIDS Education and Prevention, 2(2), 154-161.

Metayer, N., Jean-Louis, E., \& Madison, A. (2004). Overcoming historical and institutional distrust: Key elements in developing and sustaining the community mobilization against HIV in the Boston Haitian community. Journal of Ethnicity and Disease, 14(3 Suppl 1), S46-S52. 
National Cancer Institute. (2004). Making health communication programs work. U.S. Department of Health and Human Services and National Institutes of Health.

National Cancer Institute. (2005). Theory at a glance: A guide for health promotion practice (2nd ed.). U.S. Department of Health and Human Services and National Institutes of Health.

Niederdeppe, J., Farrelly, M. C., \& Haviland, M. L. (2004). Confirming “truth": More evidence of a successful tobacco countermarketing campaign in Florida. American Journal of Public Health, 94(2), 255-257.

Obiaja, K. C., Darrow, W. W., Sanchez-Brana, E., \& Uribe, C. L. (2008). Self-assessed spirituality, worship attendance, and HIV-related preventive behaviors among unmarried ethnic minority adults living in a high AIDS prevalence area. Journal of HIV/AIDS \& Social Services, 7(4), 399-415. doi:10.1080/15381500802529665

O’Malley, A. S., Kerner, J. F., \& Johnson, L. (1999). Are we getting the message out to all? Health information sources and ethnicity. American Journal of Preventive Medicine, 17(3), 198-202. doi:10.1016/S0749-3797(99)00067-7

O’Sullivan, G. A., Yonkler, J. A., Morgan, W., \& Merritt, A. P. (2003). A field guide to designing a health communication strategy. Baltimore, MD: Johns Hopkins Bloomberg School of Public Health/Center for Communication Programs.

Puckett, S. B., \& Bye, L. L. (1987). The Stop AIDS Project: An interpersonal AIDSprevention program. San Francisco, CA: Stop AIDS Project.

Ratzan, S. C., Payne, J. G., \& Massett, H. A. (1994). Effective health message design: The America Responds to AIDS campaign. American Behavioral Scientist, 38(2), 294-309. doi:10.1177/0002764294038002010

REACH 2010 at Florida International University. (2007). HIV/AIDS primary prevention: Lessons learned manual for Broward County, Florida. Florida: Hope Herman Marketing and External Relations.

Rice, R. E., \& Atkin, C. K. (Eds.). (2013). Public communication campaigns (4th ed.). Thousand Oaks, CA: SAGE.

Rich, J. A., Holmes, M. D., \& Hodges, D. M. (1996). Preferred sources of AIDS information, risk perceptions, and risk behaviors among inner-city community college students. Journal of the National Medical Association, 88(2), 87-93.

Richardson, A., Allen, J. A., Xiao, H., \& Vallone, D. (2012). Effects of race/ethnicity and socioeconomic status on health information-seeking, confidence, and trust. 
Journal of Health Care for the Poor and Underserved, 23(4), 1477-1493. doi:10.1353/hpu.2012.0181

Ruffin, J. (2010). The science of eliminating health disparities: Embracing a new paradigm. American Journal of Public Health, 100(Suppl 1), S8-S9. doi:10.2105/AJPH.2010.191957

Sanchez-Brana, E. (2011). Sources of information and HIV/AIDS in minority communities of Broward County (Doctoral dissertation, University of Miami). Available from Open Access Dissertations. (UMI No. 3491121)

Simons-Morton, B., McLeroy, K. R., \& Wendel, M. (2012). Behavior theory in health promotion practice and research. Burlington, MA: Jones \& Bartlett.

Siska, M., Jason, J., Murdoch, P., Yang, W. S., \& Donovan, R. J. (1992). Recall of AIDS public service announcements and their impact on the ranking of AIDS as a national problem. American Journal of Public Health, 82(7), 1029-1032.

Stanford University Libraries. (2012). STOP AIDS Project records, 1985-2011 (M1463). Stanford, CA: Department of Special Collections and University Archives, Stanford University Libraries. Retrieved from http://pdf.oac.cdlib.org/pdf/stanford/mss/m1463.pdf

Steele, C. B., Meléndez-Morales, L., Campoluci, R., DeLuca, N., \& Dean, H. D. (2007). Health disparities in HIV/AIDS, viral hepatitis, sexually transmitted diseases, and tuberculosis: Issues, burden, and response, a retrospective review, 2000-2004. Atlanta, GA: Department of Health and Human Services, Centers for Disease Control and Prevention. Retrieved from http://www.cdc.gov/nchhstp/healthdisparities/

Stewart, E., \& Rappaport, J. (2009). Narrative insurrections: HIV, circulating knowledges, and local resistances. In E. J. Trickett \& W. Pequegnat (Eds.), Community interventions and AIDS (pp. 56-87). New York, NY: Oxford University Press.

Stroman, C. A. (2005). Disseminating HIV/AIDS information to African Americans. Journal of Health Care for the Poor and Underserved, 16(4 Suppl B), 24-37. doi:10.1353/hpu.2005.0118

Swanson, D. J. (1993, April). "Repellent and Shameful:" The portrayal of AIDS in "America Responds to AIDS" broadcast public service announcements, 1987. 1992. Paper presented at the $4^{\text {th }}$ Annual Sooner Communications Conference, Norman, OK. 
Thornton, R. L., Glover, C. M., Cené, C. W., Glik, D. C., Henderson, J. A., \& Williams, D. R. (2016). Evaluating strategies for reducing health disparities by addressing the social determinants of health. Health Affairs, 35(8), 1416-1423. doi:10.1377/hlthaff.2015.1357

Uribe, C. L., Darrow, W. W., Villanueva, L. P., Obiaja, K. C., Sanchez-Brana, E., \& Gladwin, H. (2009). Identifying HIV risk-reduction strategies for Hispanic populations in Broward County. Annals of Epidemiology, 19(8), 567-574. doi:10.1016/j.annepidem.2009.04.006

U.S. Department of Health and Human Services. (2010). Healthy People: What are its goals? Retrieved from http://www.healthypeople.gov/2010/About/goals.htm

Villanueva, L. P., Darrow, W. W., Uribe, C., Sanchez-Brana, E., Obiaja, K., \& Gladwin, H. (2010). Ethnic differences in HIV risk perceptions and behaviors among Black 18-39 year-old residents of Broward County, Florida. AIDS Education and Prevention, 22(2), 160-171. doi:10.1521/aeap.2010.22.2.160

Wendel, M. L., Burdine, J. N., McLeroy, K. R., Alaniz, A., Norton, B., \& Felix, M. R. J. (2009). Community capacity: Theory and application. In R. J. DiClemente, R. A. Crosby, \& M. C. Kegler (Eds.), Emerging theories in health promotion practice and research (pp. 278-302). San Francisco: Jossey-Bass.

White House. (n.d.). One America: About the initiative. Retrieved from http://clinton4.nara.gov/Initiatives/OneAmerica/about.html

Wohlfieler, D. (1997). Community organizing and community building among gay and bisexual men: The STOP AIDS Project. In M. Minkler (Ed.), Community organizing and community building for health (pp. 230-243). New Brunswick, NJ: Rutgers University Press.

Wolitski, R. J., Bensley, L., Corby, N. H., Fishbein, M., Galavotti, C., \& the AIDS Community Demonstration Projects. (1996). Sources of AIDS information among low-risk and at-risk populations in five U.S. cities. Journal of Community Health, 21(4), 293-310.

Woods, D. R., Davis, D., \& Westover, B. J. (1991). “America Responds to AIDS": Its content, development process, and outcome. Public Health Reports, 106(6), 616622.

Woodyard, J. L., Peterson, J. L., \& Stokes, J. P. (2000). "Let us go into the house of the Lord": Participation in African American churches among young African American men who have sex with men. Journal of Pastoral Care, 54(4), 451460. 
World Health Organization. (2016). Global Health Observatory (GHO) data: HIV/AIDS. Retrieved from http://www.who.int/gho/hiv/en/

Zimmerman, R. S., Palmgreen, P. M., Noar, S. M., Lustria, M. L. A., Lu, H. Y., \& Horosewski, M. L. (2007). Effects of a televised two-city safer sex mass media campaign targeting high-sensation-seeking and impulsive-decision-making young adults. Health Education \& Behavior, 34(5), 810-826. doi:10.1177/1090198107299700 
VITA

\section{ELENA SEBEKOS}

2016

Dissertation Year Fellowship

Florida International University

Miami, FL

2013

George Kastrenakes Scholastic Award

AHEPA Kendall Chapter No. 476

Miami, FL

2012-2016

Doctoral Candidate, Public Health

Florida International University

Miami, FL

2012-2015

Graduate Assistant, Mentor: William W. Darrow

Florida International University

2012

AHEPA Scholarship Award

AHEPA Kendall Chapter No. 476

Miami, FL

2010-2012

Student Assistant, Mentor: William W. Darrow

Florida International University

2009-2011

MPH, Public Health

Florida International University

Miami, FL

2008

BS, Biological Sciences; Minor, Chemistry

Florida International University

Miami, FL

\section{PUBLICATIONS AND PRESENTATIONS}

Weissman, J., Preston, S., Sebekos, E., Latorre, W., Alsaif, B., Krupp, K., \& Darrow, W. W. (2016). Associations between health and academic success at a Florida university: An exploratory cross-sectional study. Florida Public Health Review, 13, 91-98.

Weissman, J., Preston, S., Sebekos, E., Latorre, W., Alsaif, B., Krupp, K., \& Darrow, W. W. (2016). Can an on-campus medical home improve academic performance in college students?: An exploratory cross-sectional study. Poster presented at the 
American College Health Association Annual Meeting (May 31-June 4), San Francisco, CA.

Sebekos, E., Darrow, W. W., \& Gladwin, H. (2016). Effective media communications to reduce HIV infections among Black and Hispanic young adults. Poster presented at the Florida Public Health Association South Florida Regional Conference (April 27), North Miami, FL.

Weissman, J., Preston, S., Sebekos, E., Latorre, W., Alsaif, B., Krupp, K., \& Darrow, W. W. (2015). Psychological health and academic success in college students: An exploratory cross-sectional study. Poster presented at 143rd American Public Health Association Meeting \& Exposition (October 31-November 4), Chicago, IL.

Weissman, J., Latorre, W., Preston, S., Alsaif, B., Krupp, K., Sebekos, E., \& Darrow, W. W. (2015). Significant associations between health and academic success in college students: An exploratory cross-sectional study. Poster presented at the Educational Conference of the Florida Public Health Association (August 19-21), Orlando, FL.

Sebekos, E., \& Darrow W. W. (2014). Strategic communications to prevent HIV infections and reduce health disparities among Black and Hispanic young adults. Oral presentation presented at 142nd American Public Health Association Meeting \& Exposition (November 15-19), New Orleans, LA.

Rubens, M., Darrow W. W., Sebekos, E., Gabbidon, K., Batra, A., \& Tanaka, H. (2014). Exploring the determinants of risky sexual behavior among ethnically diverse university students: The student behavioral health survey. Poster presented at 142nd American Public Health Association Meeting \& Exposition (November 15-19), New Orleans, LA.

Sebekos, E., \& Darrow, W. W. (2013). Reasons why university students fail to respond to online health and wellness surveys: Looking at qualitative data. Poster presented at 141st American Public Health Association Meeting \& Exposition (November 2-6), Boston, MA.

Darrow, W.W., Silva-Suarez, G., \& Sebekos, E. (2011). Proceedings from the $20^{\text {th }}$ World Congress of Sexual Health Glasgow, United Kingdom, June 12-16 2011: Ethics, principles, practices, and issues in public and sexual health: The development, implementation, and evaluation of a masters-level university course. The Journal of Sexual Medicine, 8, 283. 